\author{
Universidade de São Paulo \\ Instituto de Física
}

\title{
Investigação teórica de nanoestruturas do tipo grafeno para aplicação em baterias de íons de lítio
}

\author{
Bruno Bueno Ipaves Nascimento
}

Orientadora: Profa. Dra. Lucy Vitória Credidio Assali

Dissertação apresentada ao Instituto de Física da Universidade de São Paulo para a obtenção do título de Mestre em Ciências

Banca Examinadora:

Profa. Dra. Lucy Vitória Credidio Assali (IFUSP)

Prof. Dr. Luiz Tadeu Fernandes Eleno (EEL-USP)

Prof. Dr. Marcelo Marques (ITA)

São Paulo

2018 


\section{FICHA CATALOGRÁFICA \\ Preparada pelo Serviço de Biblioteca e Informação do Instituto de Física da Universidade de São Paulo}

Nascimento, Bruno Bueno Ipaves

Investigação teórica de nanoestruturas do tipo grafeno para aplicação em baterias de íons de lítio. São Paulo, 2018.

Dissertação (Mestrado) - Universidade de São Paulo. Instituto de Física. Depto. de Física de Materiais e Mecânica.

Orientador: Profa. Dra. Lucy Vitória Credidio Assali Área de Concentração: Física

Unitermos: 1. Física da matéria condensada; 2. Física do estado sólido; 3. Propriedades dos sólidos; 4. Estrutura dos sólidos; 5. Física computacional. 


\author{
University of São Paulo \\ Physics Institute
}

\title{
Theoretical investigation of graphene-like nanostructures for application in lithium ion batteries
}

\author{
Bruno Bueno Ipaves Nascimento
}

Supervisor: Profa. Dra. Lucy Vitória Credidio Assali

Dissertation submitted to the Physics Institute of the University of São Paulo in partial fulfillment of the requirements for the degree of Master of Science.

Examining Committee:

Profa. Dra. Lucy Vitória Credidio Assali (IFUSP)

Prof. Dr. Luiz Tadeu Fernandes Eleno (EEL-USP)

Prof. Dr. Marcelo Marques (ITA)

São Paulo

2018 



\section{Agradecimentos}

Agradeço muito à minha orientadora Profa. Dra. Lucy Vitória Credidio Assali, pela dedicação, paciência, pelos esclarecimentos de dúvidas e discussões sobre o trabalho, pela amizade e apoio em certos momentos durante o Mestrado.

À Profa. Wanda V. M. Machado, pela colaboração e dedicação que sempre teve, pelas sugestões e discussões valiosas que ajudaram a melhorar e complementar o trabalho, e pela amizade.

Ao Prof. João Francisco Justo Filho, pela colaboração e motivação em divulgar nossos resultados.

Aos colegas do Departamento de Física dos Materiais e Mecânica, que contribuíram diretamente ou indiretamente em algum momento do Mestrado. Também agradeço ao Samuel Silva dos Santos, Michel Lacerda Marcondes dos Santos e Luiz Henrique de Melo dos Santos que sempre se mostraram disponíveis em ajudar nos momentos em que mais precisava.

Aos amigos que sempre me apoiaram nos momentos difíceis durante este período da minha vida.

À toda minha família pelo suporte emocional, pelo apoio em todas as decisões e pela dedicação e carinho. Também agradeço à minha mãe Gislene Bueno Ipaves Nascimento e à meu pai Celso Nascimento, pela dedicação e ajuda em todos os momentos difíceis da minha vida.

À Sandra e Rosana, secretárias do departamento e ao pessoal da CPG pelo suporte na área administrativa.

Ao auxilio dos recursos de HPC disponibilizados pela Superintendência de Tecnologia da Informação da Universidade de São Paulo e ao Centro Nacional de Processamento de Alto Desempenho em São Paulo (CENAPAD-SP), pelas facilidades computacionais.

À $\mathrm{CNPq}$ pelo apoio financeiro. 



\section{Resumo}

A maior parte da energia consumida no mundo provém da queima de combustíveis fósseis, responsáveis pelo desenvolvimento da sociedade moderna, mas, também, por diversos danos ao meio ambiente. Desse modo, a exploração de fontes limpas e alternativas de energia renovável, tais como a solar e a eólica, tem ganhado grande importância e atenção dos pesquisadores nos últimos anos. Entretanto, o armazenamento destas formas de energia precisa ser eficiente, para que possam ser utilizadas nos períodos de indisponibilidade da fonte. Neste sentido, as baterias são uma das mais eficazes formas de geração e armazenamento de energias renováveis. No entanto, seu uso ainda é limitado, principalmente para aplicação em veículos automotores, que são um dos responsáveis pela emissão de gases poluentes.

O principal fator limitante está relacionado às baixas densidades energéticas nos materiais utilizados para compor os elementos das baterias modernas. O desenvolvimento experimental de novos materiais, para este fim, é um trabalho demorado e caro, de tal forma que métodos teóricos têm sido usados com sucesso para prever o comportamento de novos materiais, apropriados para utilização como componentes básicos das baterias. Neste projeto serão investigados, teoricamente, materiais nanoestruturados para aplicação como eletrodos de baterias de íons de lítio, uma das formas mais populares de baterias atualmente.

Neste trabalho apresentamos as propriedades estruturais, eletrônicas e vibracionais da grafite e dos sistemas bidimensionais grafeno, SiC e CN utilizando cálculos ab initio baseados na teoria do funcional da densidade, onde se utilizou o método de pseudopotencial PAW (Projector Augmented Wave) e aproximação van der Waals (optB88-vdW) para o termo de troca-correlação. A grafite e o grafeno foram estu- 
dados para validar o método aplicado, o qual foi usado para estudar as estruturas de $\mathrm{SiC}$ (bicamadas) e CN (monocamada e bicamada) como possíveis nanomateriais para compor ânodos de baterias de íons de lítio.

Estudamos a adsorção de Li nas bicamadas de $\mathrm{SiC}$ em diferentes sítios encontrando a posição estável e as possíveis vantagens e desvantagens de utilizá-las como ânodos de baterias de íons de lítio. As estruturas CN não se mostraram ser sistemas viáveis, uma vez que são dinamicamente instáveis. No entanto, estudamos as propriedades de camadas de CN hidrogenadas, que são dinamicamente estáveis e possíveis candidatas para aplicação em baterias de lítio.

Palavras-chave: DFT, materiais bidimensionais, grafeno, baterias, lítio. 


\section{Abstract}

Most of the energy consumed in the world comes from the burning of fossil fuels, responsible for the development of modern society, but also for various damages to the environment. Thus, the exploration of clean and alternative sources of renewable energy, such as solar and wind, has gained great importance and attention from researchers in recent years. However, the storage of these forms of energy must be efficient, so that they can be used during periods of unavailability of the source. In this sense, batteries are one of the most effective forms of generation and storage of renewable energies. However, its use is still limited, mainly for application in automotive vehicles, which are one of the responsible for the emission of polluting gases.

The main limiting factor is related to the low energy densities in the materials used to compose the elements of modern batteries. The experimental development of new materials for this purpose is a time consuming and expensive work, so that theoretical methods have been used successfully to predict the behavior of new materials suitable for use as basic components of the batteries. In this project it will be investigated, theoretically, nanostructured materials for application as electrodes of lithium-ion batteries, currently, one of the most popular forms of batteries.

In this work we present the structural, electronic and vibrational properties of graphite and two-dimensional graphene, $\mathrm{SiC}$ and $\mathrm{CN}$ systems using ab initio calculations based on the density functional theory, where the pseudopotential PAW (Projector Augmented Wave) method and van der Waals approximation (optB88vdW) for the exchange-correlation were used. Graphite and graphene were studied 
to validate the applied method, which was used to study the $\mathrm{SiC}$ (bilayer) and $\mathrm{CN}$ (monolayer and bilayer) structures as possible nanomaterials to compose anodes of lithium-ion batteries.

We studied the adsorption of $\mathrm{Li}$ in the $\mathrm{SiC}$ bilayers at different sites, finding the stable position and the possible advantages and disadvantages of using them as anodes of lithium-ion batteries. The CN structures have not been shown to be viable systems, since they are dynamically unstable. However, we have studied the properties of hydrogenated CN layers, which are dynamically stable and possible candidates for application in lithium batteries.

Key-words: DFT, bidimensional materials, graphene, battery, lithium. 


\section{Índice}

1 Introdução 1

$\begin{array}{llll}2 & \text { Fundamentos Teóricos e Metodologia } & 7\end{array}$

2.1 Aproximação de Born-Oppenheimer . . . . . . . . . . . . . . . . 7

2.2 Equação de Schrödinger eletrônica . . . . . . . . . . . . . . . . 8

2.3 Teoria do Funcional da Densidade . . . . . . . . . . . . . . . . . . . 9

2.3.1 Aproximação da Densidade Local - LDA . . . . . . . . . . . 12

2.3.2 Aproximação do Gradiente Generalizado - GGA . . . . . . . 14

2.3.3 Aproximação van der Waals - vdW . . . . . . . . . . 15

2.4 Método PAW . . . . . . . . . . . . . . . . . . . . 16

2.4 .1 Função de Onda . . . . . . . . . . . . . . . . . . . . . . . 19

2.5 Cálculo de fônons por primeiros princípios . . . . . . . . . . . 24

2.6 Detalhes computacionais . . . . . . . . . . . . . . . . . 28

2.6.1 Parâmetros de convergência . . . . . . . . . . . . . . . 28

2.6.2 Simulação de sistemas bidimensionais . . . . . . . . . . . . . 31

3 Grafeno e Grafite: Estudos de Casos 33

3.1 Grafite . . . . . . . . . . . . . . . . . 34

3.1.1 Propriedades estruturais e eletrônicas . . . . . . . . . . . . . 34

3.1 .2 Estabilidade dinâmica . . . . . . . . . . . . . . . 37

3.2 Grafeno . . . . . . . . . . . . . . . . . . . . 39

3.2.1 Propriedades estruturais e eletrônicas . . . . . . . . . . . . 39

3.2.2 Estabilidade dinâmica . . . . . . . . . . . . . . . . 40

3.3 Conclusão . . . . . . . . . . . . . . . . . . . . . . . . . . . . . . 42 
4 Sistemas bidimensionais $\mathrm{SiC} \quad 43$

4.1 Bicamada de $\mathrm{SiC}$ tipo grafite $\mathrm{AB}^{\prime} \ldots \ldots$. . . . . . . . . . . 44

4.1.1 Propriedades estruturais e eletrônicas . . . . . . . . . . . 44

4.1 .2 Estabilidade dinâmica . . . . . . . . . . . . . . 48

4.1.3 Adsorção de um átomo de Li na estrutura AB'-SiC . . . . . 49

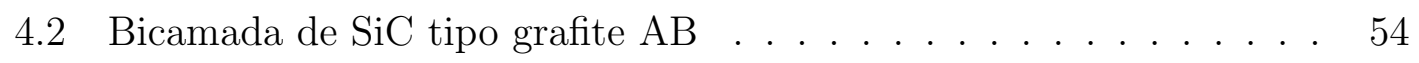

4.2.1 Propriedades estruturais e eletrônicas . . . . . . . . . . . 54

4.2 .2 Estabilidade dinâmica . . . . . . . . . . . . . 57

4.2.3 Adsorção de um átomo de Li na estrutura AB-SiC . . . . . 58

4.3 Conclusão . . . . . . . . . . . . . . . . . . . 60

5 Sistemas bidimensionais CN $\quad 63$

5.1 Folha de $\mathrm{CN}$ tipo grafeno $(\mathrm{g}-\mathrm{CN}) \ldots \ldots . \ldots . . \ldots 65$

5.1 .1 Propriedades estruturais e eletrônicas . . . . . . . . . . 65

5.1 .2 Estabilidade dinâmica . . . . . . . . . . . 66

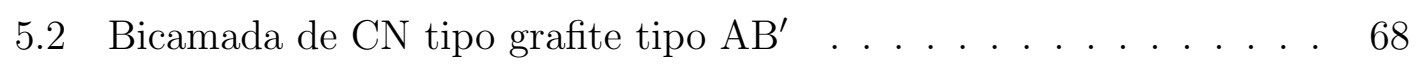

5.2.1 Propriedades estruturais e eletrônicas . . . . . . . . . . 68

5.2 .2 Estabilidade dinâmica . . . . . . . . . . . . . 69

5.3 Folha de $\mathrm{CNH} \ldots \ldots . \ldots . \ldots . \ldots 70$

5.3.1 Propriedades estruturais e eletrônicas . . . . . . . . . 70

5.3.2 Estabilidade dinâmica . . . . . . . . . . . . . . 72

6 Conclusões $\quad 75$

A Energia de Formação $\quad 79$

A.1 Energia de Formação . . . . . . . . . . . . . . . . . . . . . . . . . 79

A.1.1 Potencial Químico . . . . . . . . . . . . . 79

A.1.2 Entalpia de Formação . . . . . . . . . . . . . . . . 82

Referências Bibliográficas $\quad 85$ 


\section{Capítulo 1}

\section{Introdução}

A substituição de combustível fóssil (não renovável) por fontes de energia renováveis (solar, eólica, hidrelétrica) é uma das preocupações que tem sido, frequentemente, discutida no século 21. Um dos obstáculos nesta substituição está na dificuldade de armazenamento de energia gerada por estes tipos de fontes. Uma maneira de solucionar estes problemas está no aperfeiçoamento das baterias (dispositivos de armazenamento de energia). Os principais parâmetros que caracterizam um dispositivo de armazenamento de energia são: densidade de energia em Wh $/ \mathrm{kg}$, e densidade de potência em $\mathrm{W} / \mathrm{kg}$. A densidade de energia descreve basicamente a quantidade de energia que está disponível para o uso, e a densidade de potência mostra a rapidez com que esta energia pode ser liberada. Estes dois fatores são determinantes para qualificar um dispositivo.

O desenvolvimento de baterias recarregáveis e portáteis teve início na década de 50. As baterias de NiCd alavancaram o desenvolvimento da telefonia móvel, sendo substituídas, na década de 90, pelas baterias de hidreto metálico de Ni (NiMH), as quais não têm Cd na sua composição, material bastante tóxico, apresentam maior capacidade, durabilidade e foram utilizadas em telefones celulares, câmeras digitais e notebooks. Com o passar dos anos, as baterias de íons de lítio (Li) (LIB "lithium-ion battery") passaram a ser preferidas, em relação às de NiMH, pois são mais leves e mais seguras, além de apresentarem baixa taxa de autodescarga, maior densidade energética e ciclos de vida longos. Estas baterias, as quais tem sido am- 
plamente usadas há 20 anos, possuem tecnologia avançada na área de dispositivos eletrônicos portáteis [1]. No entanto, para que possam ser empregadas em sistemas de grande escala e potência, como em veículo elétrico hibrido (PHEV) ou veículo elétrico (PEV), é necessário o desenvolvimento de baterias visando a melhoria do rendimento, segurança, custo benefício dentre outros fatores [1]. Por exemplo, a densidade de energia fornecida por uma bateria de íons de Li é de $387 \mathrm{Wh} / \mathrm{kg}$, enquanto que sistemas que utilizam gasolina ou diesel, este valor é de $12.200 \mathrm{Wh} / \mathrm{kg}$ e $13.762 \mathrm{Wh} / \mathrm{kg}$, respectivamente [2]. Estes objetivos têm incentivado o desenvolvimento de novos materiais de baixo custo, especialmente aquelas destinadas para aplicação na área de transporte. Além disso, com o crescimento das preocupações ambientais com o descarte das baterias em fim de vida útil, as baterias de íons de lítio apresentam menor impacto ao meio ambiente quando comparadas com as tradicionais baterias com $\mathrm{Cd}$ e chumbo.

Os principais componentes de uma LIB são o cátodo (eletrodo positivo), o ânodo (eletrodo negativo) e o eletrólito (condutor elétrico de natureza líquida ou sólida, no qual cargas são transportadas por meio de íons). Uma maneira de se aumentar a densidade de energia das baterias de íons de Li é através do desenvolvimento de materiais com alta capacidade tanto para compor o cátodo como o ânodo. Materiais adequados para serem utilizados em LIB's tem que apresentar capacidade reversível, boas condutividades iônica e elétrica, tempo de vida cíclica longa, alta taxa de difusão de Li, baixo custo e ser ecologicamente compatíveis.

Atualmente, os materiais utilizados tanto para o cátodo quanto para o ânodo são materiais do tipo laminares em camadas, ou seja, compostos com propriedades de intercalação possibilitando a inserção e extração de íons de lítio de modo reversível. Em geral, o cátodo é composto por óxidos de metais de transição $\left(\mathrm{LiCoO}_{2}\right.$ e seus derivados [3]) e o ânodo por grafite. Durante o processo de carregamento, onde é necessário fornercer energia elétrica ao sistema [4], os íons de Li se movem através do eletrólito saindo do cátodo e intercalando-se no ânodo. Assim como os íons de Li, os elétrons se movem do cátodo para o ânodo, por um circuito externo, criando um circuito elétrico. Uma ilustração esquemática do funcionamento de uma bateria 
de íons de lítio está mostrada na Fig. 1.1 [1]. O inverso do processo supracitado representa o descarregamento, onde ocorre uma reação de oxidação/redução dos eletrodos, ou seja, energia química é transformada em elétrica [4]. O eletrólito, o qual fica entre o cátodo e o ânodo é responsável pelo transporte dos íons de lítio, precisa ser um condutor iônico, isolante elétrico e combinar as propriedades de condução de um líquido, a estabilidade mecânica de um sólido e alta estabilidade química [5].

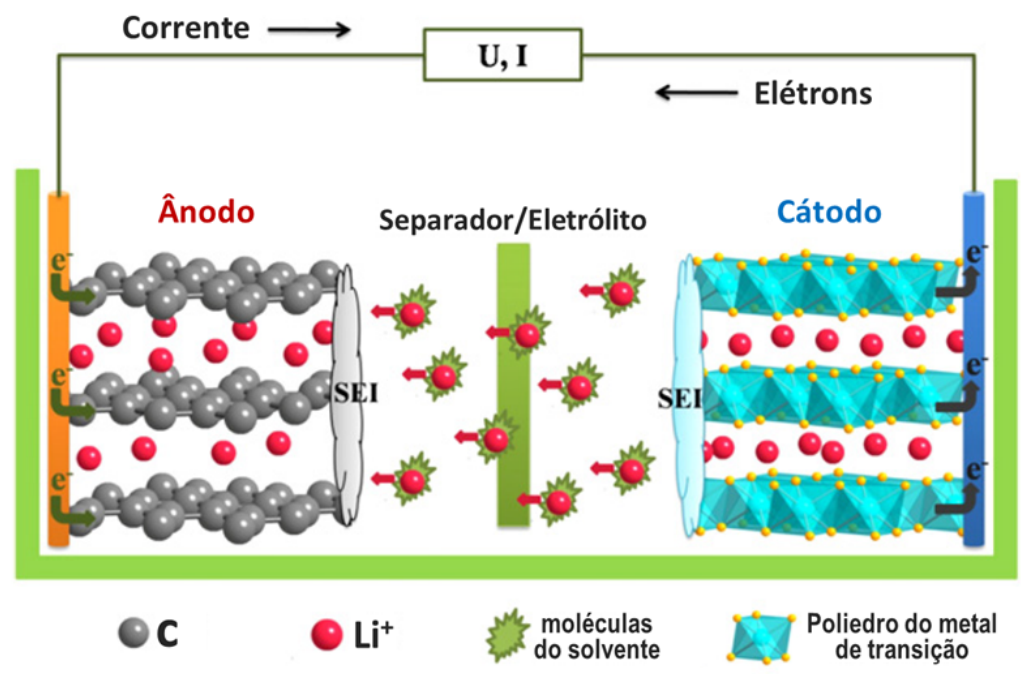

Figura 1.1: Ilustração do carregamento de uma bateria de íons de lítio (LIB) [1].

Pode-se combinar diferentes materiais para compor o cátodo, na tentativa de aperfeiçoar as baterias, resultando em vantagens em relação a sua vida cíclica, seu custo e estabilidade térmica. Como exemplo de cátodo, composto por diferentes materiais, cita-se $\mathrm{LiMn}_{2} \mathrm{O}_{4}$ e $\mathrm{LiNi}_{x} \mathrm{Co}_{1-x-y} \mathrm{Al}_{y} \mathrm{O}_{2}$ que possuem maior tempo de vida útil, mas menor estabilidade térmica [6]. Assim como no caso do cátodo, pesquisas sobre materiais para compor o ânodo têm se intensificado, apesar de a grafite apresentar excelentes características para compor este elemento, como baixa função trabalho (potencial) vs. lítio, baixo custo e bom tempo de vida útil cíclico. Entretanto, a baixa capacidade equivalente reversível (somento um $\mathrm{Li}^{+}$para seis átomos de carbono) e baixa razão de difusão do lítio em grafite 
resulta em baterias com baixa densidade de energia, levando à necessidade de substituição da grafite como ânodo nas LIB's. Nesse sentido, esforços têm sido feitos para se obter materiais, baseados em carbono ou não, com o objetivo de aumentar a capacidade anódica das baterias. Uma das vertentes de investigação tem desenvolvido combinação de outros materiais a grafite ou ao silício (dopagem) a fim de melhorar as características do eletrodo negativo (ânodo). Os cátodos, devido ao número reduzido de famílias estruturais, são mais limitados em relação a inserção ou intercalação de compostos em comparação ao ânodo, o qual possui uma grande variedade de reações químicas possíveis, podendo incluir metais de transição e elementos não metais em sólidos com diferentes estequiometrias [7].

As baterias de íons de lítio usam carbono no ânodo, pois este é de baixo custo, abundante na natureza e com possibilidades de modificações [7]. No entanto, uma outra abordagem para a melhoria das baterias está no chamado " carbono livre" (sem a presença de átomos de carbono). As preocupações com o ambiente e as mudanças climáticas cresceram muito nos últimos anos, levando à busca de novas tecnologias para o desenvolvimento, por exemplo, de materiais sem a presença de átomos de carbono. A lista dos materiais que têm sido investigados como potenciais candidatos à compor o ânodo inclui nanotubos de carbono, grafeno, $\mathrm{SiO}_{2}$, silício, germânio, óxidos de metais de transição, nitretos, fosfetos, etc. A Fig. 1.2 apresenta uma ilustração do gráfico do potencial vs $\mathrm{Li} / \mathrm{Li}^{+}$e as correspondentes densidades de capacidade para os materiais mais adequados para ser utilizados como ânodos na nova geração de LIB's [8].

Os materiais bidimensionais (2D) tem recebido grande atenção desde a esfoliação do grafeno em 2004 [9]. A lista de materiais 2D estudados tem crescido nos últimos anos, incluindo isolantes (nitreto de boro hexagonal (h-BN) e óxidos de metais de transição), isolantes topológicos $\left(\mathrm{Bi}_{2} \mathrm{Te}_{3}\right)$, semicondutores $\left(\mathrm{MoS}_{2}\right.$ e $\left.\mathrm{WSe}_{2}\right)$, metais $\left(\mathrm{TiS}_{2}\right)$ e supercondutores $\left(\mathrm{NbSe}_{2}\right)$ [10]. O grafeno, por exemplo, tem sido amplamente estudado devido as suas propriedades físicas, químicas e mecânicas, tais como flexibilidade estrutural e a ótima condutividade elétrica e térmica [11]. Além disso, o grafeno tem uma boa capacidade de armazenar Li e, 


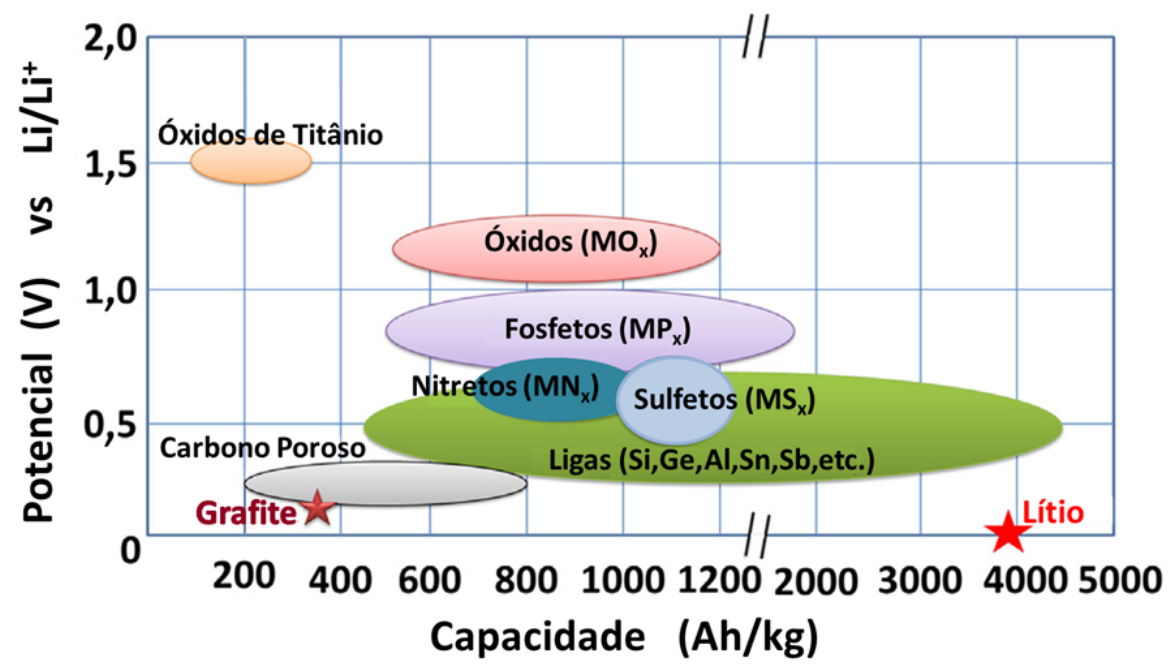

Figura 1.2: Ilustração esquemática dos materiais mais adequados para ser utilizados como ânodos na nova geração de bateriais de íons de lítio, mostrando o potencial vs $\mathrm{Li} / \mathrm{Li}^{+}$e as correspondentes densidades de capacidade [8].

portanto, acredita-se que nanomateriais baseados em grafeno e/ou do tipo grafeno possam substituir a grafite nas LIBs [11]. Recentemente, uma nova forma de silício cristalino, o siliceno, foi obtida experimentalmente [12]. O siliceno, devido a sua estrutura favo de mel em duas dimensões, apresenta algumas propriedades importantes para compor o ânodo de LIB 's como, por exemplo, ser um semicondutor de gap nulo e ter alta condutividade térmica e elétrica [2]. Portanto, o siliceno seria, a princípio, um ótimo substituto do carbono no ânodo. Além disso, a capacidade do ânodo das baterias atuais podem ser, teoricamente, melhorada com a substituição de carbono por outros materiais [13]. Dentre as diversas dificuldades encontradas em se propor novos materiais para o ânodo, citam-se a grande expansão em volume, capacidade baixa de transporte de elétrons e diminuição da capacidade com o uso, mostrando deterioração durante os ciclos. Uma das soluções possíveis para tentar sanar estes problemas consiste em produzir nanoestruturas dos materiais supracitados, onde é esperado que o uso de nanotecnologia contribua para, por exemplo, aperfeiçoar a capacidade específica, pois quanto maior a relação superfície/volume 
maior o contato com o eletrólito, facilitando o fluxo de íons de lítio entre os eletrodos. Espera-se, também, uma maior transferência de elétrons [8]. O problema de aumento de volume citado anteriormente, o qual pode levar a deformação do material, pode ser, do mesmo modo, solucionado com a utilização de materiais nanoestruturados [14].

Dentro do contexto apresentado, o objetivo do projeto é desenvolver teoricamente, através de cálculos de estrutura eletrônica, inovadores materiais com morfologias adaptadas para serem potenciais candidatos a eletrodo negativo (ânodo) na bateria de íons de Li, com o propósito de aperfeiçoá-las. Neste trabalho foram estudadas as propriedades estruturais, eletrônicas e de vibração dos sistemas bidimensionais de $\mathrm{SiC}$ e $\mathrm{CN}$.

Este trabalho está estruturado da seguinte forma: No Capítulo 2 são apresentados os fundamentos teóricos e a metodologia utilizada; no Capítulo 3 são apresentados os resultados das propriedades estruturais, eletrônicas e vibracionais da grafite e do grafeno; no Capítulo 4 são estudados sistemas bidimensionais $\mathrm{SiC}$, onde são mostrados os resultados das propriedades estruturais, eletrônicas e vibracionais dos sistemas na forma pura e na adsorção de um átomo de lítio; no Capítulo 5 são estudados sistemas bidimensionais CN, onde são mostrados os resultados das propriedades estruturais, eletrônicas e vibracionais dos sistemas. As considerações finais e conclusões estão no Capítulo 6. No Apêndice A apresentamos uma descrição sobre entalpias e energias de formação, aplicando os formalismos nos sistemas estudados neste trabalho. 


\section{Capítulo 2}

\section{Fundamentos Teóricos e Metodologia}

\subsection{Aproximação de Born-Oppenheimer}

Num sistema físico composto por íons e elétrons, a descrição de tais elementos é feita via equação de Schrödinger

$$
\hat{H} \Psi=E \Psi
$$

onde a hamiltoniana $H$ é dada por

$$
\hat{H}=\hat{T}_{e}+\hat{T}_{N}+\hat{V}_{e N}+\hat{V}_{e e}+\hat{V}_{N N}
$$

onde os operadores energia cinética dos elétrons e dos núcleos atômicos são, respectivamente, $\hat{T}_{e}$ e $\hat{T}_{N}$. $\hat{V}_{e N}$ é a interação entre os elétrons e os núcleos atômicos, $\hat{V}_{e e}$ é a interação elétron-elétron (potencial coulombiano) e $\hat{V}_{N N}$ é o potencial entre núcleos. A função de onda $\Psi(\vec{r}, \vec{R})$ é a solução completa da equação $(2.1)$, onde $\vec{r}$ são as posições dos elétrons e $\vec{R}$ dos núcleos. A solução completa não é conhecida mesmo para os sólidos mais simples, portanto, é feita uma primeira aproximação: os núcleos são muito mais pesados em comparação aos elétrons e se movem mais lentamente. Deste modo, as funções de onda dos elétrons e dos núcleos podem ser desacopladas 


$$
\Psi(\vec{r}, \vec{R})=R(\vec{R}) \psi(\vec{r}, \vec{R})
$$

onde a função de onda $R(\vec{R})$ descreve o movimento dos íons e $\psi(\vec{r}, \vec{R})$ dos elétrons, que tem uma dependência paramétrica com as posições atômicas $\vec{R}$. Assim, a equação de Schrödinger eletrônica é

$$
\left[\hat{T}_{e}+\hat{V}_{e N}+\hat{V}_{e e}\right] \psi_{n}(\vec{r}, \vec{R})=E_{n}(\vec{R}) \psi_{n}(\vec{r}, \vec{R})
$$

e a equação de Schrödinger iônica é

$$
\left[\hat{T}_{N}+\hat{V}_{N N}+E_{n}(\vec{R})\right] R(\vec{R})=\epsilon R(\vec{R}) .
$$

Essa aproximação desconsidera a excitação eletrônica induzida pelo movimento iônico e desacopla os graus de liberdade dos elétrons dos graus de liberdade dos íons e é chamada de Born-Oppenheimer.

\subsection{Equação de Schrödinger eletrônica}

Na seção anterior foi apresentada a aproximação de Born-Oppenheimer. Nesta aproximação se considera que o movimento dos íons é muito mais lento em comparação ao dos elétrons. Uma outra aproximação é considerar que os íons são estáticos e, sendo assim, contribuem através da geração de um potencial externo aos elétrons.

Pode-se escrever a equação (2.4) na forma

$$
\hat{H}_{e l} \psi(\vec{r})=E \psi(\vec{r})
$$

onde a hamiltoniana eletrônica $\hat{H}_{e l}$ é dada por

$$
\hat{H}_{e l}=-\frac{\hbar^{2}}{2} \sum_{i} \frac{\nabla_{r_{i}}^{2}}{m_{e}}-\frac{1}{4 \pi \epsilon_{0}} \sum_{i \neq j} \frac{Z_{i} e^{2}}{\left|\vec{R}_{i}-\vec{r}_{j}\right|}+\frac{1}{8 \pi \epsilon_{0}} \sum_{i \neq j} \frac{e^{2}}{\left|\vec{r}_{i}-\vec{r}_{j}\right|},
$$


em que $\vec{R}_{i}$ denotam as posições dos núcleos com número atômico $Z_{i}$ e $\vec{r}_{i}\left(i=1, \ldots N_{e}\right)$ as posições dos elétrons de massa $m_{e}$. Esta hamiltomiana não contém o termo de energia cinética dos núcleos atômicos, pois a rede esta sendo considerada estática.

Esta é uma equação que, apesar de simplificada com a aproximação de BornOppenheimer, ainda é de muitas partículas interagentes, o que impossibilita, na prática, sua resolução. Uma das alternativas para se resolver problemas de muitos corpos é utilizar a teoria do funcional da densidade (Density Functional Theory DFT) [15] que será apresentada nas próximas seções.

\subsection{Teoria do Funcional da Densidade}

A DFT foi estabelecida formalmente em 1964 através de dois teoremas formulados por Hohenberg e Kohn [15]. Eles mostraram que a densidade eletrônica $n(\vec{r})$ define univocamente a energia total do estado fundamental do sistema $(E)$, que é um funcional dessa densidade $(E[n(\vec{r})])$. Os dois teoremas fundamentais da DFT mostram que as propriedades do estado fundamental de um sistema de elétrons interagentes podem ser expressas como funcionais da densidade eletrônica $n(\vec{r})$ :

1) Existe uma correspondência unívoca entre a densidade $n(\vec{r})$ do estado fundamental de um sistema de muitos elétrons e o potencial externo $v(\vec{r})$. Como consequência, o valor esperado, no estado fundamental, para um observável $\hat{O}$, é um funcional único da densidade eletrônica do estado fundamental do sistema, que depende de $v(\vec{r})$, tal que

$$
\langle\Psi|\hat{O}| \Psi\rangle=O_{v}[n(\vec{r})]
$$

2) Se o operador $\hat{O}$ for o hamiltoniano, existe um funcional energia total do estado fundamental de elétrons interagentes que é um funcional da densidade de carga eletrônica

$$
E=E[n(\vec{r})]=T_{e}[n(\vec{r})]+E_{n e}[n(\vec{r})]+E_{e e}[n(\vec{r})]
$$

e seu valor será mínimo se $n(\vec{r})$ for a densidade eletrônica exata para o estado fundamental. $T_{e}[n]$ é o funcional energia cinética, $E_{n e}[n]$ é o funcional de interação 
elétron-núcleo e $E_{e e}[n]$ é o funcional de interação elétron-elétron. A minimização do funcional energia (equação (2.9)), com relação às variações da densidade, deve ser realizada mantendo-se o vínculo de conservação do número total de elétrons do sistema

$$
N=\int n(\vec{r}) d^{3} r
$$

Kohn e Sham, em seu trabalho de 1965 [16], propuseram reescrever a equação (2.9), do funcional energia total, da seguinte maneira:

$$
E[n(\vec{r})]=T_{s}[n(\vec{r})]+E_{n e}[n(\vec{r})]+E_{H}[n(\vec{r})]+E_{x c}[n(\vec{r})],
$$

onde $T_{s}[n(\vec{r})]$ é o funcional energia cinética de um sistema de elétrons não interagentes com densidade $n(\vec{r}) . E_{n e}[n(\vec{r})]$ é o funcional energia associado ao potencial nuclear externo, $E_{H}[n(\vec{r})]$ define as interações elétron-elétron puramente coulombianas, conhecido como termo de Hartree, e a parcela $E_{x c}[n(\vec{r})]$ corresponde à energia de troca e correlação, que engloba, primeiro, a diferença entre os funcionais que definem as interações elétron-eletron e o termo de Hartree $\left(E_{e e}[n(\vec{r})]-E_{H}[n(\vec{r})]\right)$ e, segundo, a diferença entre a energia cinética de um sistema de partículas interagentes e a de um de partículas não interagentes $\left(T_{e}[n(\vec{r})]-T_{s}[n(\vec{r})]\right)[16]$.

Utilizando o segundo teorema de HK, temos que a correta densidade para o estado fundamental é a que minimiza o funcional energia total do sistema, dado pela equação (2.11), com a restrição de que o número total de elétrons $N$ seja constante, ou seja, a condição de mínimo é obtida por meio de

$$
\delta\{E[n]-\varepsilon N\}=0,
$$

onde $\varepsilon$ é um multiplicador de Lagrange.

Para encontrarmos as equações de KS devemos, neste ponto, expressar a densidade eletrônica do sistema em termos de um conjunto de $N$ funções ortonormais $\varphi_{i}$ 


$$
n(\vec{r})=\sum_{i=1}^{N}\left|\varphi_{i}(\vec{r})\right|^{2} .
$$

Com isso, podemos, no processo variacional, substituir a variação em $n(\vec{r})$ por variações nas funções $\varphi_{i}^{*}(\vec{r})$ e $\varphi_{i}(\vec{r})$ e obter o hamiltoniano de Kohn-Sham

$$
H_{K S}=-\frac{\hbar^{2}}{2 m} \nabla^{2}+\frac{e^{2}}{4 \pi \varepsilon_{0}} \int \frac{n\left(\vec{r}^{\prime}\right)}{\left|\vec{r}-\vec{r}^{\prime}\right|} d \vec{r}+v_{x c}+v_{e x t},
$$

onde o potencial de troca e correlação $v_{x c}$ é obtido através da derivada funcional de $E_{x c}[n]$

$$
v_{x c}=\frac{\delta E_{x c}[n]}{\delta n} .
$$

As funções $\varphi_{i}$, introduzidas na equação (2.13), satisfazem às equações de KhonSham $(\mathrm{KS})$

$$
H_{K S} \varphi_{i}(\vec{r})=\varepsilon_{i} \varphi_{i}(\vec{r})
$$

as quais são exatas, mas o termo $v_{x c}$, que provém do funcional energia de troca e correlação $E_{x c}[n]$, não tem uma forma analítica conhecida. Os orbitais $\varphi_{i}$ obedecem às equações de KS de uma partícula em termos do potencial de $\mathrm{KS}$, de modo que

$$
\left(-\frac{\hbar^{2}}{2 m} \nabla_{j}^{2}+v_{K S}(\vec{r})\right) \varphi_{j}(\vec{r})=\varepsilon_{j} \varphi_{j}(\vec{r})
$$

onde

$$
v_{K S}(\vec{r})=v_{e x t}(\vec{r})+\frac{e^{2}}{4 \pi \varepsilon_{0}} \int \frac{n\left(\vec{r}^{\prime}\right)}{|\vec{r}-\vec{r}|} d \vec{r}+v_{x c}(\vec{r})
$$

e a densidade eletrônica é dada pela equação (2.13). As equações (2.17) devem ser resolvidas de maneira autoconsistente.

O processo autoconsistente tem início partindo-se de uma densidade inicial $n_{0}$ (densidade "tentativa") com a qual se obtém o potencial, através da equação de Poisson, construindo-se, assim, o hamiltoniano de Kohn-Sham $\hat{H}_{K S 1}$. Então, 
resolvemos o problema de auto-valores gerando um conjunto de auto-funções $\varphi_{i}(\vec{r})$, das quais a nova densidade $n_{1}$ é obtida. Provavelmente, esta densidade será diferente da densidade inicial $n_{0}$. Uma mistura adequada desta nova densidade $n_{1}$ com a antiga $n_{0}$ é usada para construir o próximo hamiltoniano $\hat{H}_{K S 2}$, que resultará na próxima densidade $n_{2}$, e assim por diante. Este procedimento é repetido até que as densidades obtidas em dois ciclos consecutivos sejam iguais, dentro de um critério pré-estabelecido. Esta densidade final $n_{f}$ é então assumida ser a densidade correta, a qual permite obter as propriedades do sistema.

Para se obter os estados eletrônicos de um sistema, utilizando-se as equações de KS, devemos tomar uma forma aproximada para o funcional energia de troca e correlação pois, na prática, para a maior parte das densidades, ele não é conhecido exatamente. Atualmente, existem várias aproximações para este termo de troca e correlação. A aproximação mais comum é a chamada aproximação da densidade local (LDA-Local Density Approximation) [16]. Nesta aproximação supõe-se que a contribuição de troca-correlação de um volume infinitesimal dependa apenas da densidade local daquele volume. Esta aproximação, apesar de simples, fornece resultados muito satisfatórios, para uma grande variedade de sistemas, e tem sido amplamente utilizada na física da matéria condensada. No entanto, em alguns casos, a aproximação LDA não funciona muito bem e o passo seguinte foi fazer com que a contribuição de troca-correlação de todo o volume infinitesimal não dependesse apenas da densidade local daquele volume, mas também da densidade nos volumes vizinhos, ou seja, incluindo a dependência do gradiente da densidade. Esta aproximação é chamada de aproximação do gradiente generalizado (GGA Generalized Gradient Approximation) [17].

\subsubsection{Aproximação da Densidade Local - LDA}

A LDA, proposta por Kohn e Sham em 1964 [16], foi a primeira ideia de aproximação para o potencial de troca e correlação. Nesta aproximação, considera-se um volume infinitesimal do sistema e se aproxima $E_{x c}$ para um sistema de gás de elétrons homogêneo de mesma densidade local do sistema original, então, soma-se 
cada elemento de volume

$$
E_{x c}^{L D A}[n(\vec{r})]=\int n(\vec{r}) \epsilon_{x c}^{h o m}(n) d \vec{r},
$$

onde $\epsilon_{x c}^{\text {hom }}(n)$ é a energia de troca e correlação, por elétron, de um gás homogêneo de elétrons de densidade $n$. Esta função pode ser decomposta em uma densidade de energia de troca e densidade de energia de correlação:

$$
\epsilon_{x c}^{h o m}(n)=\epsilon_{x}^{h o m}(n)+\epsilon_{c}^{h o m}(n),
$$

onde a densidade de energia de troca é dada por:

$$
\epsilon_{x}^{h o m}(n)=-\frac{3 e^{2}}{2}\left[\frac{3 n}{8 \pi}\right]^{\frac{1}{3}}
$$

e o termo de correlação é obtido via métodos quânticos computacionais de Monte Carlo $[18,19]$.

A densidade de carga $n(\vec{r})$, quando se considera polarização de spin, possui duas parcelas, uma representando os elétrons com spin up $n_{\uparrow}(\vec{r})$ e outra para os elétrons com spin down $n_{\downarrow}(\vec{r})$. Assim, a densidade total do sistema é $n(\vec{r})=n_{\uparrow}(\vec{r})+n_{\downarrow}(\vec{r})$ e a densidade de spin do sistema é $n_{\text {spin }}(\vec{r})=n_{\uparrow}(\vec{r})-n_{\downarrow}(\vec{r})$. A energia total do sistema, neste caso, passa a ser um funcional das duas densidades de spin,

$$
E[n(\vec{r})]=E\left[n_{\uparrow}(\vec{r}), n_{\downarrow}(\vec{r})\right],
$$

levando em consideração a polarização de spin (LSDA), a energia de troca e correlação será

$$
E_{x c}^{L S D A}\left[n_{\uparrow}(\vec{r}), n_{\downarrow}(\vec{r})\right]=\int n(\vec{r}) \epsilon_{x c}^{h o m}\left(n_{\uparrow}, n_{\downarrow}\right) d \vec{r},
$$

A LDA ou LSDA é válida, a priori, para sistemas onde a densidade eletrônica varia muito lentamente, pois o sistema, neste caso, é aproximado localmente por um gás de elétrons homogêneo. Embora para sistemas atômicos esta condição seja raramente satisfeita, ela prevê e explica propriedades dos estados fundamentais 
Fundamentos Teóricos e Metodologia

para muitos sistemas cristalinos e moleculares. A densidade de carga eletrônica varia pouco na região de cauda das funções de onda atômica. Nesta região ocorrem as ligações entre átomos, nas moléculas e nos sólidos o que explica o sucesso da teoria.

\subsubsection{Aproximação do Gradiente Generalizado - GGA}

Assim como na LDA, a GGA [17] considera que a contribuição de troca-correlação de um volume infinitesimal depende da densidade local daquele volume. Além disso, na GGA, considera-se a densidade nos volumes vizinhos, onde se inclui a dependência no gradiente da densidade $\nabla n(\vec{r})$ [20-22]. O funcional energia de troca-correlação, levando em consideração uma função local dependente da densidade e da intensidade de seu gradiente, fica

$$
E_{x c}^{G G A}\left[n_{\uparrow}, n_{\downarrow}\right]=\int n(\vec{r}) f\left(n_{\uparrow}(\vec{r}), n_{\downarrow}(\vec{r}), \nabla n_{\uparrow}(\vec{r}), \nabla n_{\downarrow}(\vec{r})\right) d \vec{r},
$$

onde $f$ é uma função universal das densidades de spin-up e spin-down e seus gradientes. Aqui neste trabalho a versão GGA utilizada foi a proposta por Perdew, Burke e Ernzerhof (PBE) [17]. Para sistemas que apresentam densidades de carga não homogêneas, a GGA, em geral, fornece melhores resultados para cálculos de energia total e das diferenças nas energias estruturais quando comparados com a aproximação LSDA. O funcional de troca-correlação na aproximação GGA-PBE é

$$
E_{x c}^{G G A}\left[n_{\uparrow}, n_{\downarrow}\right]=E_{x}^{G G A}\left[n_{\uparrow}, n_{\downarrow}\right]+E_{c}^{G G A}\left[n_{\uparrow}, n_{\downarrow}\right] .
$$

Para se construir o funcional energia de correlação $\left(E_{c}^{G G A}\right)$, leva-se em consideração três condições:

1. No limite de variações lentas da densidade, a energia de correlação deve tender para sua expansão do gradiente: $E_{c}^{G G A} \rightarrow E_{c}^{G E A}$ (GEA - Gradient expansion approximation).

2. No limite de variações rápidas da densidade, a energia de correlação deve tender para sua expressão LDA: $E_{c}^{G G A} \rightarrow E_{c}^{L D A}$. 
3. Sob uma transformação de semelhança uniforme $\left(\left[n(\vec{r}) \rightarrow \lambda^{3} n(\lambda \vec{r})\right]\right)$ para o limite de altas densidades, a energia de correlação deve escalonar para uma constante negativa: $E_{c}^{G G A} \rightarrow-$ const..

O funcional energia de troca $\left(E_{x}^{G G A}\right)$ é construído com base em quatro condições:

1. Dentro de um dimensionamento uniforme da densidade, de acordo com o item 3 supracitado, a energia de troca deve escalonar com $\lambda: E_{x}^{G G A}\left[n_{\lambda}\right]=$ $\lambda E_{x}^{G G A}[n]$.

2. A energia de troca exata deve obedecer à relação de dimensionamento de spin [23]:

$$
E_{x}^{G G A}\left[n_{\uparrow}, n_{\downarrow}\right]=\frac{E_{x}^{G G A}\left[2 n_{\uparrow}\right]+E_{x}^{G G A}\left[2 n_{\downarrow}\right]}{2} .
$$

3. No limite de pequenas variações da densidade em torno da densidade uniforme, a resposta linear deve ser a mesma que a da LDA.

4. O limite de Lieb-Oxford [24] deve ser satisfeito: $E_{x c}^{G G A}=2,273 E_{x}^{L D A}$.

A partir destas quatro condições, chega-se ao fator de intensificação (enhancement):

$$
F_{x}(s)=1+\kappa-\frac{\kappa}{1+\mu s^{2} / \kappa}, \operatorname{com} \mu \simeq 0,21952 \text { e } \kappa \leqslant 0,804,
$$

onde $s=\left|\nabla_{n}\right| /\left(2 n k_{F}\right)$ é um gradiente adimensional da densidade, com $k_{F}^{3}=3 \pi^{2} n$

A aproximação GGA-PBE retém as características corretas da LSDA e as combina com as características energéticas mais importantes da não localidade, corrigida pelo gradiente.

\subsubsection{Aproximação van der Waals - vdW}

Na teoria do funcional da densidade (DFT), os funcionais locais ou semilocais não conseguem descrever com boa precisão os efeitos não locais [25]. As forças de van der Waals (vdW) que foram identificadas em 1873 e, hoje, estão bem estabelecidas 
Fundamentos Teóricos e Metodologia

[26], são consideradas um efeito não local que contribui para a estabilidade de uma grande variedade de sistemas.

Nos últimos anos, vários artigos de revisão sobre métodos baseados na DFT que incluem a interação de van der Waals (vdW) têm sido publicados [26,27]. Os métodos DFT-D e DFT-D2 adicionam um termo de dispersão atrativo da forma $-C^{6} / r^{6}$ à energia total. A partir deste método, foi desenvolvido o método DFT-D3, que leva em consideração a dependência do parâmetro $C^{6}$ com o ambiente [28-30]. A energia de vdW é um efeito de correlação e, portanto, é incluída no termo exato de troca-correlação da DFT. A família de funcionais da densidade com adição da interação de van der Waals (vdW-DF), conhecida como família de funcionais Rutgers-Chalmers, reconstrói a energia de correlação para incorporar as interações de longo e médio alcance [26]. Para se incluir as forças de vdW, a energia de troca e correlação do sistema é reescrita na forma [31]:

$$
E_{x c}=E_{x}^{G G A}+E_{c}^{L D A}+E_{c}^{n l}
$$

em que $E_{c}^{n l}$ é o termo de energia não-local que leva em consideração, de modo aproximado, os efeitos de correlação de elétrons não-locais. A energia de troca $E_{x}^{G G A}$ usa o funcional revPBE GGA [32], e a energia de correlação $E_{c}^{L D A}$ usa a LDA [25]. Para este trabalho a aproximação escolhida foi optB88-vdW [33], uma vez que, de modo geral, é o que melhor descreve sólidos a base de carbono e/ou silício [25].

\subsection{Método PAW}

Existem vários métodos de solução das equações de KS e são classificados de acordo com as representações usadas para a densidade, para o potencial e, principalmente, para os orbitais de KS. Os métodos diferem entre si quanto ao conjunto de funções de base em que são expandidos os orbitais de KS, devendo-se levar em conta os custos computacionais dos cálculos. De qualquer modo, escolhe-se um conjunto de 
funções de base $\left\{\varphi_{j}(\vec{r})\right\}$ e expressa-se o orbital de KS em termos desta base

$$
\Psi_{i}(\vec{r})=\sum_{j} c_{i j} \varphi_{j}(\vec{r})
$$

As funções de base mais comuns para se determinar a função de onda periódica de um elétron num sólido são as ondas planas. Entretanto, essa base não é conveniente para descrever as variações rápidas que as funções de onda, que descrevem os elétrons, possuem em regiões próximas aos núcleos atômicos. A fim de superar esta dificuldade pode-se eliminar a presença destas oscilações através do método de pseudopotenciais ou tomando um conjunto misto de funções de base.

O método LAPW (Linear Augmented Plane Waves) é um exemplo de método que utiliza uma base mista e foi construído a partir do método APW (Augmented Plane Waves), originalmente proposto por Slater [34], em 1937, o qual leva em conta o fato das funções, que descrevem o potencial, serem do tipo atômicas, e praticamente esféricas, nas regiões próximas aos núcleos atômicos e suaves, praticamente constantes, na região intersticial entre os átomos. Assim, a expansão em ondas planas foi aumentada com a solução das funções de onda atômicas nas regiões esféricas próximas aos núcleos, assumindo que o potencial é esfericamente simétrico dentro das esferas atômicas e nulo na região intersticial.

O método de pseudopotenciais começou como uma extensão do método OPW (Orthogonalized Plane Wave), proposto por Herring em 1940 [35]. Nesta aproximação, as funções de onda dos elétrons de valência são construídas como uma combinação linear de ondas planas com funções atômicas. Através de uma escolha apropriada dos coeficientes dessa expansão, estas funções de onda são então, por construção, ortogonais aos estados de caroço. Como os estados de caroço não são essenciais para a correta descrição das ligações químicas, a função de onda total é separada em uma parte oscilante e uma parte suave, sem nós, chamada pseudofunção de onda. Não possuindo nenhum nó, esta função corresponde ao estado fundamental de um problema atômico efetivo, onde o potencial verdadeiro é substituído por um potencial efetivo, válido para os elétrons de valência, ou simplesmente, por um pseudopotencial. 
Fundamentos Teóricos e Metodologia

Peter E. Blöchl [36], em 1994, desenvolveu o método PAW (Projector Augmented Wave), o qual utiliza ideias provenientes dos métodos de pseudopotencial [37] e LAPW (Linear Augmented Plane Wave method) [38]. Esta abordagem mantém características do LAPW, onde todos os elétrons são considerados, mas, por outro lado, a função de onda total é decomposta em termos de uma pseudofunção de onda suave e em uma contribuição localizada que varia rapidamente na região iônica. No método de pseudopotencial a função de onda é modificada próxima ao núcleo, dentro de uma região de raio $\mathrm{r}_{c}$ (raio de corte), eliminando suas singularidades na região. No método PAW, em comparação ao de pseudopotenciais, os raios de corte são menores e a energia de corte, na expansão em ondas planas da função de onda, deverá ser maior. Mostraremos, nesta seção, a metodologia PAW da maneira como proposta no trabalho de Kresse e Joubert [39].

Mostraremos, nesta seção, a metodologia PAW da maneira como proposta no trabalho de Kresse e Joubert [39]. Neste método é possível reconstruir, aplicandose um operador $\tau$, a função de onda verdadeira $\Psi$ que modifica a suavidade de uma função de onda auxiliar $\widetilde{\Psi}$ na região atômica, levando a uma função com a estrutura nodal correta. A região em que existem interações entre átomos, ou seja, a região que contém a cauda das funções de onda atômicas é bem descrita pelo conjunto de ondas planas do método PAW. Próximo ao núcleo atômico é necessário um grande número de ondas planas, pois as funções de onda podem oscilar muito. Embora nas expansões em orbitais atômicos é possível descrever a estrutura nodal da função de onda perto do núcleo, faltarão graus de liberdade variacionais para descrever as regiões de ligação e de "cauda".

O método PAW, com um conjunto bem definido de funções de base, combina as virtudes das representações numéricas nas duas regiões, evitando o esforço duplo no cálculo de estrutura eletrônica (ondas planas e orbitais atômicos) tratando os coeficientes dos orbitais atômicos como funções dos coeficientes das ondas planas. A energia total da DFT é recuperada no método PAW e, assim, as expansões em orbitais atômicos e em ondas planas formam uma base completa. Isso faz diminuir os erros que poderiam ocorrer na escolha do conjunto de bases. Para superar 
Fundamentos Teóricos e Metodologia

as limitações provenientes do conjunto de base em ondas planas para sistemas aperiódicos, escolhe-se uma supercélula suficientemente grande e se desacopla as interações de longo alcance. O método PAW pode, então, ser usado para estudar sólidos, moléculas e superfícies dentro de uma mesma aproximação.

\subsubsection{Função de Onda}

A função de onda fisicamente relevante $|\Psi\rangle$ relativa a todos os elétrons é muito difícil de ser descrita devido às suas fortes oscilações perto dos núcleos atômicos. O método transforma $|\Psi\rangle$ em uma função suave e computacionalmente adequada: a função auxiliar $|\tilde{\Psi}\rangle$. As oscilações da função real nas regiões próximas aos núcleos atômicos são recuperadas através da transformação $|\Psi\rangle=\tau|\tilde{\Psi}\rangle$. Um conjunto de esferas de raio $\mathrm{r}_{c}$, centradas em cada átomo, delimitam as regiões onde existem oscilações. O valor esperado de um operador $\hat{A}$ no espaço de Hilbert das funções de onda relativas ao potencial real, a partir deste formalismo, pode ser obtido a partir das funções auxiliares mais suaves. Assim, define-se dois espaços de Hilbert, os das funções all-electron (AE) e outro das pseudo-funções (PS). Mapea-se, então, as funções de onda de valência AE sobre as PS de onda. Cada função de onda $|\tilde{\Psi}\rangle$ (pseudo) será expandida em ondas parciais $\left|\tilde{\phi}_{i}\right\rangle$ (pseudo)

$$
|\tilde{\Psi}\rangle=\sum_{i \in R}\left|\tilde{\phi}_{i}\right\rangle c_{i}, \quad \text { para }|\vec{r}-\vec{R}|<r_{c},
$$

onde o índice $i$ refere-se ao sítio atômico $R$, ao número quântico do momento angular $L=(\ell, m)$ e a um índice adicional $n$ para rotular diferentes ondas parciais no mesmo sítio e momento angular. A função de onda AE correspondente é obtida da função auxiliar por meio da transformação $\tau$

$$
|\Psi\rangle=\tau|\tilde{\Psi}\rangle
$$

A função de onda auxiliar dentro de cada região atômica é modificada pela transformação $\tau$, de modo que a nova função de onda passa a ter a estrutura nodal correta. Podemos escrever a transformação $\tau$ como a soma do operador identidade 
com o operador das contribuições atômicas, representadas por $S_{R}$, na forma

$$
\tau=1+\sum_{R} S_{R}
$$

onde $R$ é um índice para especificar o sítio atômico. Podemos tratar separadamente as funções de caroço, pois estas não se espalham até os átomos vizinhos.

Uma função de onda parcial auxiliar $\left|\tilde{\phi}_{i}\right\rangle$ é escolhida para cada uma das funções parciais $\left|\phi_{i}\right\rangle$. Tomando

$$
\left|\phi_{i}\right\rangle=\left(1+S_{R}\right)\left|\tilde{\phi}_{i}\right\rangle \quad \text { para } \quad i \in R
$$

tem-se que

$$
S_{R}\left|\tilde{\phi}_{i}\right\rangle=\left|\phi_{i}\right\rangle-\left|\tilde{\phi}_{i}\right\rangle
$$

o que define a contribuição local de $S_{R}$ no operador transformação $\tau$. Uma vez que $\left(1+S_{R}\right)$ irá modificar somente localmente a função de onda auxiliar, então, a função parcial $\left|\phi_{i}\right\rangle$, assim como sua auxiliar $\left|\tilde{\phi}_{i}\right\rangle$ correspondente, devem ser idênticas, para regiões além de um certo raio $\mathrm{r}_{c}$, ou seja,

$$
\phi_{i}(r) \equiv \tilde{\phi}_{i}(r) \quad \text { se } \quad i \in R \quad \text { e } \quad|\vec{r}-\vec{R}|>r_{c, R}
$$

As funções projetoras $\left|\tilde{p}_{i}\right\rangle$ são escolhidas de tal maneira que

$$
|\tilde{\Psi}(\vec{r})\rangle=\sum_{i}\left|\tilde{\phi}_{i}(\vec{r})\right\rangle\left\langle\tilde{p}_{i} \mid \tilde{\Psi}(\vec{r})\right\rangle \quad \text { para } \quad|\vec{r}-\vec{R}|<r_{c}
$$

Definindo

$$
\sum_{i}\left|\tilde{\phi}_{i}\right\rangle\left\langle\tilde{p}_{i}\right|=1 \quad \text { e }\left\langle\tilde{p}_{i} \mid \tilde{\phi}_{j}\right\rangle=\delta_{i j}
$$

e, utilizando as equações (2.32), (2.34) e (2.36), obtemos a expressão

$$
\tau=1+\sum_{i}\left(\left|\phi_{i}\right\rangle-\left|\tilde{\phi}_{i}\right\rangle\right)\left\langle\tilde{p}_{i}\right| .
$$


A função de onda total $|\Psi\rangle$ do elétron de valência é obtida, utilizando as equações (2.31) e (2.38), através de

$$
|\Psi\rangle=|\tilde{\Psi}\rangle+\sum_{i}\left(\left|\phi_{i}\right\rangle-\left|\tilde{\phi}_{i}\right\rangle\right)\left\langle\tilde{p}_{i} \mid \tilde{\Psi}\right\rangle
$$

o qual será designado por

$$
|\Psi\rangle=|\tilde{\Psi}\rangle+\left|\Psi^{1}\right\rangle-\left|\tilde{\Psi}^{1}\right\rangle
$$

Em resumo, o método PAW escreve a função de onda total de valência $\Psi$ em termos de três componentes. A figura 2.1 ilustra a função $\Psi$ como combinação de três funções:

- $\tilde{\Psi}$ : suave em toda a região e exata fora da região de caroço ou região aumentada $\left(r<r_{c}\right)$;

- $\Psi^{1}$ : exata na região aumentada $\left(r<r_{c}\right)$, incorporando toda a estrutura nodal da função exata, e suave, tendendo a zero, na região fora do caroço (região intersticial);

- $\Psi^{1}$ : suave em toda região, sendo idêntica à $\tilde{\Psi}$ na região aumentada e à $\Psi^{1}$ na região intersticial.

Os estados de caroço $|\Psi\rangle^{c}$ são decompostos de uma maneira similar aos de valência. Eles possuem três contribuições: uma pseudofunção de onda de caroço $|\tilde{\Psi}\rangle^{c}$, idêntica aos estados verdadeiros fora da região aumentada e com uma continuação suave dentro; uma onda parcial AE $|\phi\rangle^{c}$ que são idênticas aos estados de caroço AE e são expressas como funções radiais multiplicadas por harmônicos esféricos; e uma pseudo-onda parcial de caroço, que são idênticas aos pseudoestados de caroço $\left|\tilde{\phi}^{c}\right\rangle$, mas representadas também como funções radiais multiplicadas por harmônicos esféricos. Dessa forma, os estados de caroço são expressos na forma

$$
|\Psi\rangle^{c}=|\tilde{\Psi}\rangle^{c}+|\phi\rangle^{c}-|\tilde{\phi}\rangle^{c}
$$




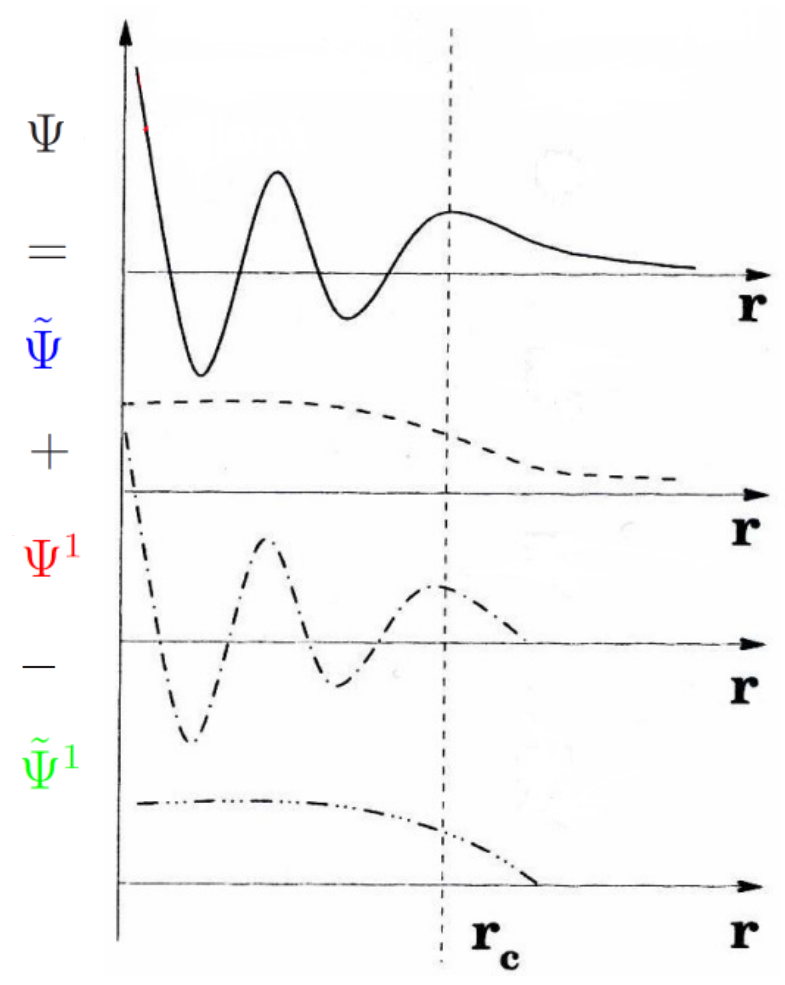

Figura 2.1: Função de onda total de valência $\Psi$ (linha contínua) em termos de três componentes: $\tilde{\Psi}$ (linha tracejada), $\Psi^{1}$ (linha traço-ponto) e $\Psi^{1}$ (linha traço-três pontos). A posição atômica está na origem e $r<r_{c}$ indica a região de caroço ou região aumentada (augmented region) e $r>r_{c}$ é a região intersticial. Esta representação esquemática mostra a principal ideia do método PAW na construção da função de onda total: $\Psi=\tilde{\Psi}+\Psi^{1}-\Psi^{1}$.

Ao contrário dos estados de valência, não são necessárias funções projetoras para os estados de caroço. Além disso, os estados de caroço são importados do átomo isolado.

Portanto, no método PAW também se tem uma divisão do espaço, assim como no LAPW, e a função de onda AE é decomposta em termos de uma pseudofunção de onda suave mais uma contribuição localizada. A função de onda AE (verdadeira) e a pseudofunção de onda são relacionadas por uma transformação linear, dada pela equação (2.39). Embora não estritamente necessário, no método PAW pode-se aplicar a aproximação de caroço congelado, ou seja, congelar os orbitais de 
caroço em uma configuração de referência, utilizando apenas as funções de onda de valência, exatamente como no método de pseudopotencial. Isto indica que é totalmente possível disponibilizar o método PAW no modelo pseudopotencial. A pseudo-função de onda atômica pode ser construída da mesma forma que é feita no contexto de geração do pseudopotencial. Ou seja, é possível obter pseudopotenciais a partir do método PAW. Até o presente, o método PAW parece ser um dos métodos mais poderosos para os cálculo de estrutura eletrônica de cristais, pois combina a eficiência dos pseudopotenciais com a precisão dos métodos baseados no APW, sendo a metodologia utilizada neste trabalho. O método PAW é uma abordagem geral, possuindo o APW como um caso particular [40] e o método de pseudopotenciais como uma aproximação bem definida [39].

A figura 2.2 apresenta o orbital $p-\sigma$ da molécula de $\mathrm{Cl}_{2}$, obtida pelo método PAW [40], onde está ilustrado o comportamento de cada umas das três parcelas $|\tilde{\Psi}\rangle,\left|\Psi^{1}\right\rangle$ e $\left|\Psi^{1}\right\rangle$ que compõem a função de onda all electron $|\Psi\rangle$.

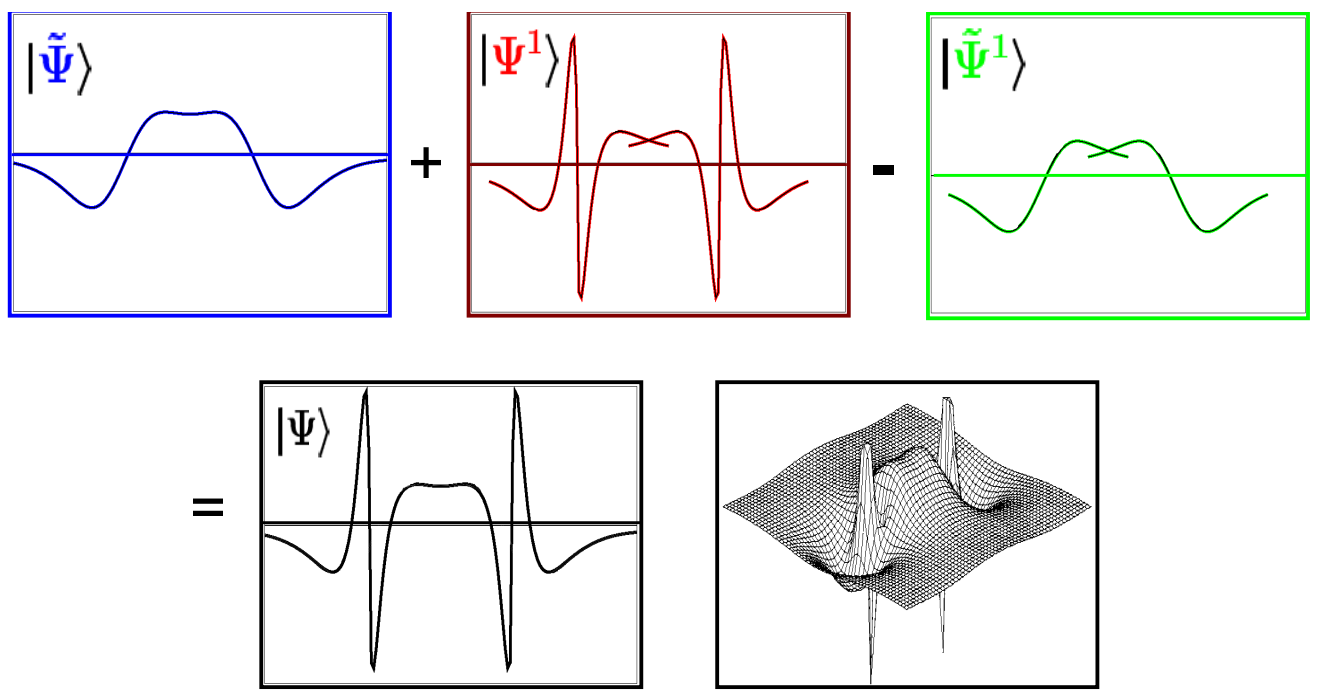

Figura 2.2: Representação das três funções de onda de valência que compõem a função de onda AE no método PAW, onde $|\Psi\rangle=|\tilde{\Psi}\rangle+\left|\Psi^{1}\right\rangle-\left|\Psi^{1}\right\rangle[40]$. 


\subsection{Cálculo de fônons por primeiros princípios}

Para calcular as frequências de vibração (fônons) por primeiros princípios devemos utilizar o potencial efetivo $V_{\text {ef }}$ a que os íons estão sujeitos. De acordo com a equação (2.5), este potencial é dado por

$$
V_{e f}=V_{N N}+E_{n}(\vec{R})
$$

Seja $u(\ell k)$ o deslocamento de um átomo $k$ na célula $\ell$ de um cristal com $n$ átomos por célula unitária. Considerando que $V_{e f}$ é uma função da posição instantânea de todos os átomos, expande-se o potencial efetivo $V_{e f}$, em uma série de Taylor, em potências do deslocamento $u_{\alpha}(\ell k)$ na direção $\alpha$ [41] como:

$$
V_{e f}=V_{0}+\left.\sum_{\ell k \alpha} \frac{\partial V_{e f}}{\partial u_{\alpha}(\ell k)}\right|_{0} u_{\alpha}(\ell k)+\frac{1}{2} \sum_{\ell k, \ell^{\prime} k^{\prime}} \sum_{\alpha \beta} \phi_{\alpha \beta}\left(\ell k, \ell^{\prime} k^{\prime}\right) u_{\alpha}(\ell k) u_{\beta}\left(\ell^{\prime} k^{\prime}\right)+\ldots
$$

onde $V_{0}$ é constante e é o potencial a qual os íons estão sujeitos quando na posição de equilíbrio e

$$
\phi_{\alpha \beta}\left(\ell k, \ell^{\prime} k^{\prime}\right)=\left.\frac{\partial^{2} V_{e f}}{\partial u_{\alpha}(\ell k) \partial u_{\beta}\left(\ell^{\prime} k^{\prime}\right)}\right|_{0} .
$$

O valor da constante $V_{0}$ na equação (2.43) pode ser considerado nulo. O segundo termo, também, é nulo, pois a força em cada átomo quando na posição de equilíbrio é nula. Na aproximação harmônica, os termos maiores do que os de segunda ordem (termos quadráticos) não são considerados na expansão e, portanto, o potencial efetivo a que os íons estão sujeitos escreve-se

$$
V_{h a r m}=\frac{1}{2} \sum_{\ell k, \ell^{\prime} k^{\prime}} \sum_{\alpha \beta} \phi_{\alpha \beta}\left(\ell k, \ell^{\prime} k^{\prime}\right) u_{\alpha}(\ell k) u_{\beta}\left(' \ell k^{\prime}\right) .
$$

Assim, as equações de movimento para os íons fica dada por [41]

$$
m_{k} \ddot{u}_{\alpha}(\ell k)=\sum_{\ell^{\prime} k^{\prime} \beta} \phi_{\alpha \beta}\left(\ell k, \ell^{\prime} k^{\prime}\right) u_{\beta}\left({ }^{\prime} \ell k^{\prime}\right)
$$


onde $m_{k}$ é a massa do k-ésimo átomo $(\alpha=\mathrm{x}, \mathrm{y}, \mathrm{z})$ e $\phi$ é a matriz de força interatômica, em que a força linear negativa em um átomo ( $\ell k)$ na direção $\alpha$, devido a um deslocamento do átomo $\left(\ell^{\prime} k^{\prime}\right)$ na direção $\beta$ é representada por $\phi_{\alpha \beta}\left(\ell k, \ell^{\prime} k^{\prime}\right) u_{\beta}\left(\ell^{\prime} k^{\prime}\right)$. Podemos utilizar a simetria de translação do cristal e escrever a matriz de constantes de força como

$$
\phi_{\alpha \beta}\left(\ell k, \ell^{\prime} k^{\prime}\right)=\phi_{\alpha \beta}\left(0 k,\left(\ell^{\prime}-\ell\right) k^{\prime}\right)
$$

permitindo escrever a equação (2.46) como

$$
m_{k} \ddot{u}_{\alpha}(\ell k)=\sum_{\ell^{\prime} k^{\prime} \beta} \phi_{\alpha \beta}\left(0 k, \ell^{\prime} k^{\prime}\right) u_{\beta}\left(\ell^{\prime} k^{\prime}\right) .
$$

Vamos supor uma solução para esta equação da forma

$$
u_{\alpha}(\ell k)=\frac{1}{\sqrt{m_{k}}} \sum_{q} U_{\alpha}(q, k) \mathrm{e}^{[\mathrm{i}(\mathrm{qx}(\ell)-\omega \mathrm{t})]},
$$

em que o vetor posição de equilíbrio da $\ell$-ésima célula unitária é dado por $x(\ell), \omega$ é a frequência característica, e $U_{\alpha}(q, k)$ uma constante a ser determinada que não depende de $\ell$. Substituindo-se essa solução na equação (2.48), obtém-se

$$
\omega^{2} U_{\alpha}(q, k)=\sum_{k^{\prime} \beta} D_{\alpha \beta}\left(k k^{\prime} \mid q\right) U_{\beta}\left(q, k^{\prime}\right),
$$

cuja solução não trivial é obtida resolvendo o determinante

$$
\left|D_{\alpha \beta}\left(k k^{\prime} \mid q\right)-\omega^{2} \delta_{\alpha \beta} \delta_{k k^{\prime}}\right|=0
$$

onde $D_{\alpha \beta}$ é a matriz dinâmica do sistema e é dada por

$$
D_{\alpha \beta}\left(k k^{\prime} \mid q\right)=\frac{1}{\sqrt{m_{k} m_{k^{\prime}}}} \sum_{\ell^{\prime}} \phi_{\alpha \beta}\left(0 k, \ell^{\prime} k^{\prime}\right) \mathrm{e}^{\left[\mathrm{iqx}\left(\ell^{\prime}\right)\right]} .
$$

Para uma célula unitária com $n$ átomos, a matriz dinâmica é uma matriz $3 n \times 3 n$, possuindo, portanto, $3 n$ autovalores, correspondentes aos $3 n$ graus de liberdade da célula unitária. Como $D_{\alpha \beta}$ é uma matriz hermitiana, seus autovalores $\omega^{2}$ são reais 
e esta é uma condição necessária, mas não suficiente, para o cristal ser considerado estável. As frequências de vibração do cristal são obtidas diagonalizando-se a matriz dinâmica, dada pela equação (2.51).

O cálculo da matriz dinâmica pode ser feito diretamente, deslocando-se um átomo da célula e calculando as forças que aparecem no sistema através do teorema de Hellman-Feynman. No entanto, este método requer a utilização de supercélulas, as quais devem ser grandes o suficiente para que os elementos $\phi_{\alpha \beta}\left(0 k, \ell^{\prime} k^{\prime}\right)$ sejam pequenos o bastante nas bordas da célula. Podem ser necessários, também, muitos deslocamentos para os cálculos das forças em todos os átomos. Uma alternativa é o uso da teoria de pertubação do funcional da densidade (DFPT-Density Funcional Pertubation Theory). Este foi o método usado neste trabalho e que passaremos a expor a seguir.

Considere que o potencial externo das equações de KS (2.17) e (2.18), aqui denotado por $V$, dependa de algum parâmetro $\lambda$, tal que

$$
V_{\lambda}(\vec{r}) \approx V(\vec{r})+\lambda \frac{\partial V(\vec{r})}{\partial \lambda}+\frac{1}{2} \lambda^{2} \frac{\partial^{2} V(\vec{r})}{\partial \lambda^{2}}+\ldots
$$

onde as derivadas são calculadas em $\lambda=0$. Desenvolvendo-se a densidade de carga e 0 funcional energia do sistema em potências de $\lambda$, temos

$$
\begin{gathered}
n_{\lambda}(\vec{r}) \approx n(\vec{r})+\lambda \frac{\partial n(\vec{r})}{\partial \lambda}+\frac{1}{2} \lambda^{2} \frac{\partial^{2} n(\vec{r})}{\partial \lambda^{2}}+\ldots \\
E_{\lambda} \approx E+\lambda \frac{\partial E}{\partial \lambda}+\frac{1}{2} \lambda^{2} \frac{\partial^{2} E}{\partial \lambda^{2}}+\ldots
\end{gathered}
$$

De acordo com o teorema de Hellman-Feynman, a derivada de primeira ordem da energia $(\partial E / \partial \lambda)$ não depende de nenhuma derivada da densidade $n(\vec{r})$ e assim

$$
\frac{\partial E}{\partial \lambda}=\int n(\vec{r}) \frac{\partial V(\vec{r})}{\partial \lambda} d \vec{r}
$$

A derivada de segunda ordem da energia $\left(\partial^{2} E / \partial \lambda^{2}\right)$ depende de derivadas de primeira ordem da densidade como 


$$
\frac{\partial^{2} E}{\partial \lambda^{2}}=\int \frac{\partial V(\vec{r})}{\partial \lambda} \frac{\partial n(\vec{r})}{\partial \lambda} d \vec{r}+\int n(\vec{r}) \frac{\partial^{2} V(\vec{r})}{\partial \lambda^{2}} d \vec{r} .
$$

Este resultado pode ser generalizado para variáveis mistas, tal que

$$
\frac{\partial^{2} E}{\partial \lambda \partial \mu}=\int \frac{\partial V(\vec{r})}{\partial \lambda} \frac{\partial n(\vec{r})}{\partial \mu} d \vec{r}+\int n(\vec{r}) \frac{\partial^{2} V(\vec{r})}{\partial \lambda \partial \mu} d \vec{r} .
$$

A derivada de ordem $(2 n+1)$ da energia, em geral, depende apenas de derivadas até ordem $n$ da densidade de carga (teorema $2 n+1$ ) [42-44]. A derivada de primeira ordem da densidade de carga pode ser obtida de maneira tradicional através da teoria de resposta linear. Aplicando a teoria de pertubação na hamiltoniana de Kohn-Sham temos

$$
\frac{\partial \phi_{v}(\vec{r})}{\partial \lambda}=\sum_{c} \phi_{c}(\vec{r}) \frac{1}{\varepsilon_{v}-\varepsilon_{c}}\left\langle\phi_{c}\left|\frac{\partial V_{K S}}{\partial \lambda}\right| \phi_{v}\right\rangle,
$$

onde $v$ denota estados ocupados e $c$ estados vazios. A resposta autoconsistente do potencial

$$
\frac{\partial V_{K S}(\vec{r})}{\partial \lambda}=\frac{\partial V(\vec{r})}{\partial \lambda}+\int \frac{1}{\left|\vec{r}-\vec{r}^{\prime}\right|} \frac{\partial n\left(\vec{r}^{\prime}\right)}{\partial \lambda} d \vec{r}^{\prime}+\int \frac{\delta V_{x c}(\vec{r})}{\delta n\left(\vec{r}^{\prime}\right)} \frac{\partial n\left(\vec{r}^{\prime}\right)}{\partial \lambda} d \vec{r}^{\prime}
$$

depende da variação em primeira ordem da densidade de carga

$$
\frac{\partial n\left(\vec{r}^{\prime}\right)}{\partial \lambda}=2 \operatorname{Re} \sum_{v} \phi_{v}^{*}(\vec{r}) \frac{\partial \phi_{v}(\vec{r})}{\partial \lambda} .
$$

Assim, $\partial \phi_{v}(\vec{r}) / \partial \lambda$ e todas outras quantidades necessárias podem ser determinadas, de maneira autoconsistente, resolvendo-se um conjunto de equações lineares. 
Fundamentos Teóricos e Metodologia

\subsection{Detalhes computacionais}

Utilizando a teoria do funcional da densidade (DFT) com aproximações LDA e GGA para o termo de troca e correlação e a metodologia PAW, calculamos as propriedades estruturais de todos os sistemas aqui simulados. As propriedades dinâmicas desses sistemas foram obtidas através da teoria de perturbação do funcional da densidade (DFPT). Os cálculos foram realizados dentro do pacote computacional Quantum ESPRESSO [45].

Para todos as estruturas estudadas, consideramos convergidas as interações auto-consistentes, entre duas interações consecutivas, quando a diferença de energia entre elas era menor do que $10^{-4} \mathrm{eV}$. As estruturas foram otimizadas utilizando o método de dinâmica molecular com célula variável [46].

\subsubsection{Parâmetros de convergência}

O Quantum ESPRESSO utiliza uma base de ondas planas para descrever a densidade do sistema. Infelizmente, não é possível utilizar uma quantidade infinita de ondas planas e é preciso limitar o seu número. Isto é feito considerando apenas os vetores de onda $\vec{k}$ tais que $k<k_{\text {máx }}$, ou seja, apenas os vetores $k$ dentro de uma esfera de raio $k_{m a ́ x}$, centrada na origem, no espaço recíproco são considerados. Todos os vetores dentro desta esfera são levados em conta na base da função de onda. Ao invés de se usar $k_{m a ́ x}$, utiliza-se como parâmetro a energia de um elétron livre correspondente a $k_{m a ́ x}$ :

$$
E_{\text {cut }}=\frac{\hbar^{2} k_{\text {máx }}^{2}}{2 m_{e}}
$$

chamada de energia de corte. Quanto maior esta energia, uma quantidade maior de ondas planas são utilizadas e, portanto, espera-se que o cálculo seja mais preciso, mas o custo computacional também é maior. Por isso, no início de qualquer cálculo de primeiros princípios, é necessário se estabelecer uma energia de corte ideal, para a qual o cálculo seja o mais preciso possível com o menor custo computacional. O teste de convergência tem como objetivo, então, encontrar um balanço entre 
precisão e tempo de cálculo. Estes estudos de convergência dos resultados com o número de ondas planas utilizadas na base foram efetuados para todos os sistemas.

Foram realizados cálculos eletrônicos para diferentes valores de $E_{c u t}$, variando desde 40 Ry até 110 Ry. Como exemplo, a figura 2.3 mostra o gráfico da variação da energia total do grafeno como função da energia de corte.

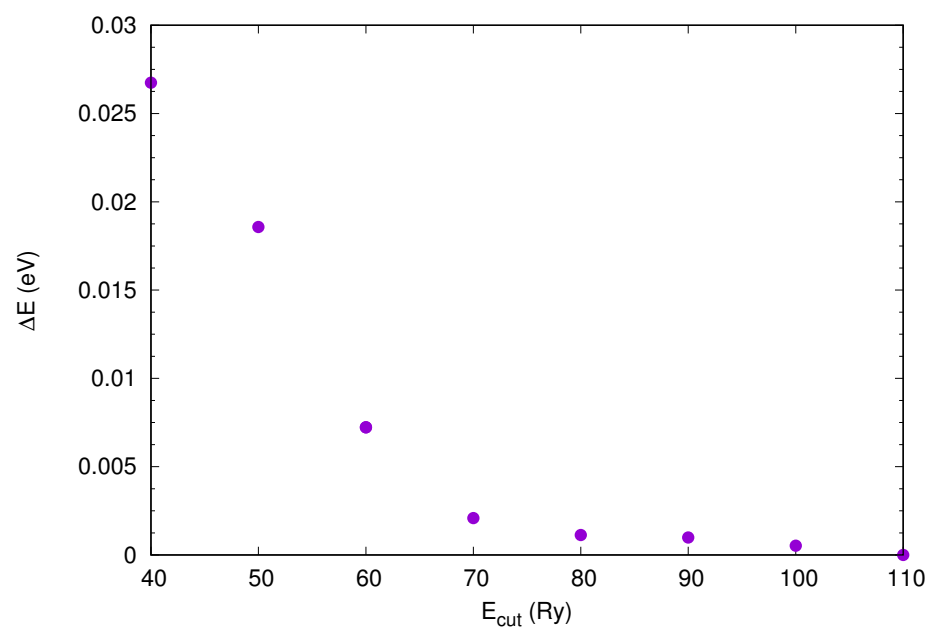

Figura 2.3: Energia total relativa $(\Delta E)$ do grafeno em função do valor da energia de corte $\left(E_{\text {cut }}\right)$, com respeito àquela de valor mais baixo, que foi deslocado para o zero de energia. A integração na primeira zona de Brillouin foi efetuda com a utilização de uma malha de pontos $k$ de $32 \times 32 \times 4$.

Podemos observar, a partir da figura 2.3, que a variação na energia total do sistema passa a ser muito pequena ( $\Delta E \approx 10^{-3} \mathrm{eV}$ para valores de $E_{\text {cut }} \geq 70 \mathrm{Ry}$ ). Assim, utilizou-se 70 Ry para a energia de corte no grafeno. Além da energia de corte, também é importante realizar um estudo da convergência com relação à quantidade de pontos $k$ utilizados para efetuar a integração na primeira zona de Brillouin. Estas análises foram feitas para todos os compostos e estruturas estudados neste trabalho, não apenas para a energia total, mas também para as forças e para o stress, já que estes últimos possuem uma convergência mais lenta do que a energia.

A figura 2.4 apresenta a variação da energia total do grafeno como função da malha de pontos $k_{x}$. Para os sistemas estudados neste trabalho $k_{x}=k_{y}$ e a malha de total de pontos $k$, utilizada para efetuar a integração na primeira zona de Brillouin, 


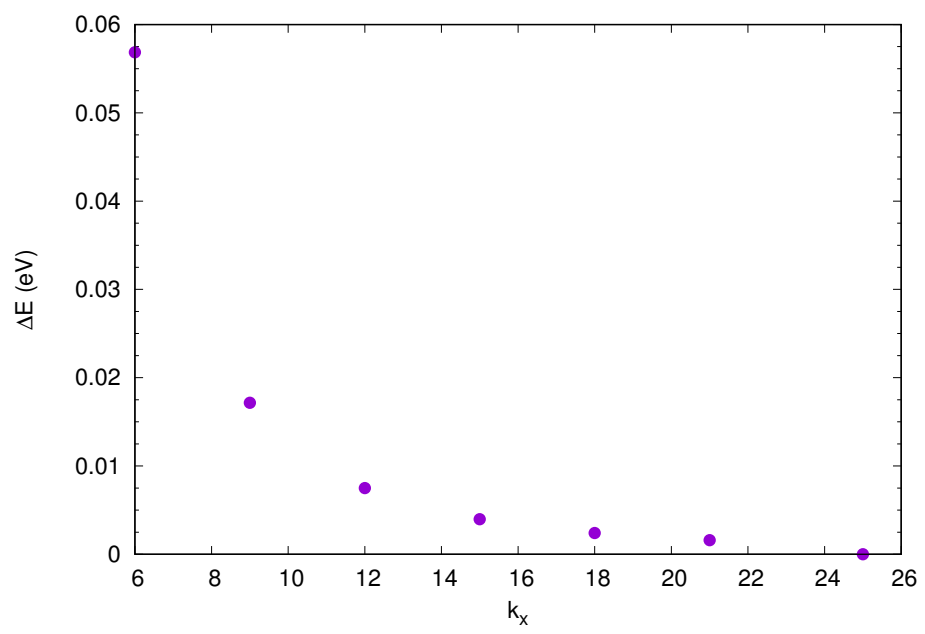

Figura 2.4: Variação da energia total $\Delta E$, do grafeno, em relação ao número de pontos $k_{x}\left(k=k_{x} \times k_{y} \times 1\right.$, onde $\left.k_{x}=k_{y}\right)$, com respeito à malha de valor de energia total mais baixa. A energia de corte utilizada foi $E_{c u t}=70 \mathrm{Ry}$.

é dada por $k=k_{x} \times k_{y} \times 1$.

Assim como para o estudo de convergência de $E_{c u t}$, observou-se que $\Delta E \approx 10^{-3}$ $\mathrm{eV}$ para uma malha com 256 pontos $(16 \times 16 \times 1)$ e, portanto, foi usada esta malha de pontos para integração na primeira zona de Brillouin.

Apresentamos na tabela 2.1 os valores da energia de corte e as malhas de pontos $k$ utilizados para cada estrutura de cada material estudado.

Tabela 2.1: Valores de energia de corte $\left(E_{\text {cut }}\right)$, em unidades de Ry, e da rede de pontos $k$ utilizados para cada sistema, em suas respectivas estruturas.

\begin{tabular}{||l|c|c|c||}
\hline \hline Sistema & Estrutura & $E_{c u t}$ & pontos $k$ \\
\hline \hline Grafeno & & 70 & $16 \times 16 \times 1$ \\
Grafite & & 70 & $16 \times 16 \times 16$ \\
g-SiC & bicamada AB' & 70 & $16 \times 16 \times 1$ \\
g-SiC & bicamada AB & 70 & $16 \times 16 \times 1$ \\
g-CN & grafeno & 80 & $16 \times 16 \times 1$ \\
g-CN & bicamada AB' & 80 & $16 \times 16 \times 1$ \\
CNH & & 80 & $16 \times 16 \times 1$ \\
\hline \hline
\end{tabular}


Fundamentos Teóricos e Metodologia

\subsubsection{Simulação de sistemas bidimensionais}

Obtivemos as propriedades dos sistemas bidimensionais utilizando o tratamento de supercélulas. Esta representação permite tratar as configurações não periódicas do arranjo cristalino dentro de um esquema com condições periódicas, permitindo o uso de métodos de cálculos de estrutura de faixas.

As estruturas bidimensionais estudadas neste trabalho apresentam propriedades periódicas no plano do sistema, mas não na direção perpendicular. Assim, utilizamos uma célula primitiva do sistema hexagonal, tridimensional, com parâmetro de rede $c$ fixo, contendo, no plano perpendicular, a célula primitiva hexagonal do sistema bidimensional, que é periódico e tem propriedades translacionais. Esse espaço entre as camadas, rotulado de região de vácuo, faz parte da supercélula e permite o uso de periodicidade da rede na direção $c$. O valor do parâmetro $c$ define a distância entre camadas sucessivas do cristal bidimensional e deve ser grande o suficiente para evitar que exista interações inter-camadas.

Um estudo sistemático das propriedades dos sistemas estudados foi realizado utilizando-se supercélulas de diferentes tamanhos, ou seja, diferentes valores de $c$, para fornecer uma estimativa das incertezas computacionais provenientes das interações artificiais entre camadas localizadas em supercélulas adjacentes. O valor utilizado para o parâmetro de rede, para todos os sistemas bidimensionais, foi $c=15,0 \AA$, pois com este valor obtivemos que as interações entre camadas adjacentes podem ser negligenciadas. 



\section{Capítulo 3}

\section{Grafeno e Grafite: Estudos de Casos}

A grafite é a forma mais estável de carbono sob condições padrões de temperatura e pressão (273 K e $1 \mathrm{~atm}$ ). Ela cristaliza-se no sistema hexagonal regular com simetria rômbica, é um sólido escuro, bom condutor elétrico e razoavelmente maleável. A estrutura da grafite é formada pelo empilhamento de infinitas camadas de átomos de carbono hibridizados na configuração eletrônica $s p^{2}$. Em cada camada, conhecida como folha de grafeno, cada átomo de carbono é tri-coordenado formando um arranjo hexagonal plano, onde as nuvens eletrônicas da camada de valência formam um ângulo de $120^{\circ}$ entre si. Nesta configuração, o quarto elétron dos átomos de carbono ocupa um orbital delocalizado e não hibridizado $p_{z}$, perpendicular ao plano. A interação inter-planar é fraca e se dá a partir de forças de van der Waals, que mantêm as folhas de grafeno unidas.

A estrutura do grafeno foi concebida teoricamente há mais de 70 anos, desde o estudo da grafite por técnicas de difração de raios-X [47]. No entanto, o isolamento dos planos de grafeno individuais a partir da grafite só foi realizado em 2004 pelo grupo do professor Geim, da Universidade de Manchester [9]. Eles tiveram sucesso em isolar o grafeno através de um processo de esfoliação mecânica da grafite com uma espécie de fita adesiva, obtendo flocos de grafeno com propriedades eletrônicas de alta qualidade. O grafeno apresenta grande instabilidade mecânica, sendo susceptível a deformações na sua estrutura planar, tornando-se uma estrutura amorfa 
Grafeno e Grafite

ou se enrolando ou aglomerando. Vários avanços têm sido obtidos nas técnicas de crescimento de grafeno e a primeira revisão importante sobre este assunto foi publicada pelo grupo da Universidade de Manchester [48].

O grafeno é o bloco básico, ou a matriz, para a formação de materiais de diferentes dimensionalidades. Ele pode ser embrulhado em fulerenos, sistemas de dimensão zero (0D), enrolados em nanotubos unidimensionais (1D) ou empilhados em grafite formando estruturas tridimensionais (3D) [48].

Neste capítulo, são apresentados os estudos teóricos desenvolvidos para a grafite e o grafeno. Estudamos a grafite por ser o protótipo de um sistema onde a inclusão das interações de van der Waals são essenciais para uma descrição apropriada de suas propriedades. Por outro lado, estudamos o grafeno por ser um sistema bidimensional que apresenta características similares às das estruturas investigadas neste trabalho. Estes resultados servirão como referência ou padrão, validando o estudo dos sistemas que serão apresentados nos próximos capítulos.

\subsection{Grafite}

\subsubsection{Propriedades estruturais e eletrônicas}

A estrutura da grafite é composta de camadas hexagonais de átomos de carbono, ou folhas de grafeno. Duas camadas consecutivas são empilhadas em um padrão $\mathrm{AB}$, onde a camada B está relacionada com a camada A por uma translação e uma rotação de $60^{\circ}$. Metade dos átomos de uma camada estão diretamente acima e abaixo de átomos de carbono das camadas adjacentes, com a outra metade diretamente acima e abaixo do centro dos hexágonos.

A estrutura cristalina da grafite é uma rede hexagonal com uma base de 4 átomos de carbono. Os vetores primitivos da rede são $(1,0,0) a,(-1 / 2, \sqrt{3} / 2,0) a$ e $(0,0, c / a) a$, onde $a$ e $c$ são os parâmetros da rede. Os átomos de carbono da base estão nas posições $(1 / 3,2 / 3,0),(2 / 3,1 / 3,0),(1 / 3,2 / 3,1 / 2)$ e $(0,0,1 / 2)$, em relação aos parâmetros de rede $a$ e $c$ da célula primitiva. A figura 3.1 mostra uma representação do arranjo dos átomos da estrutura hexagonal da grafite. 
Grafeno e Grafite

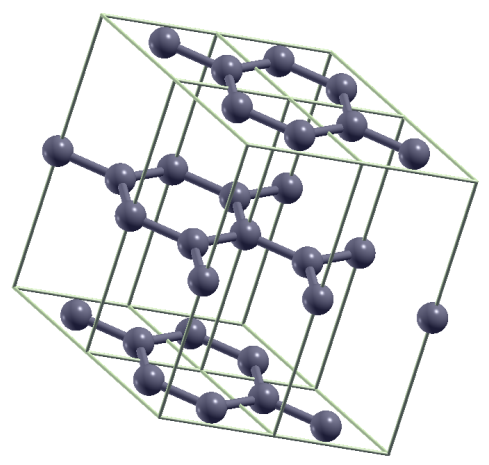

Figura 3.1: Ilustração da estrutura cristalina da grafite, mostrando o empilhamento $\mathrm{AB}^{\prime}$ das camadas hexagonais de átomos de carbono, representados pelas esferas cinzas.

No estudo das propriedades estruturais da grafite obtivemos os valores dos parâmetros de rede $a$ e $c$ utilizando um método de dinâmica molecular de célula variável [46]. A tabela 3.1 apresenta os parâmetros de rede obtidos através de diferentes aproximações para o termo de troca e correlação, juntamente resultados experimentais.

Analisando os dados da tabela, podemos observar que os valores obtidos para o parâmetro de rede $a$ utilizando os funcionais LDA, GGA (PBE) e optB88-vdW estão em excelente acordo com o valor experimental. Como o valor deste parâmetro está relacionado com a distância de ligação C-C no plano dos hexágonos, a qual esta primordialmente relacionada com ligações covalentes, as três aproximações descrevem muito bem estas interações. Por outro lado, o valor do parâmetro de rede $c$ esta relacionado com as interações intercamadas hexagonais de carbono, de longo alcance, as quais não são descritas corretamente pelas aproximações LDA

Tabela 3.1: Parâmetros de rede $a$ e $c$ da grafite, em $\AA$, obtidos com a utlização dos funcionais LDA, GGA e optB88-vdW. Os dados experimentais são da referência [49].

\begin{tabular}{||c|c|c|c|c|c||}
\hline \hline Material & & LDA & PBE & optB88-vdW & Exp. \\
\hline \hline Grafite & $a$ & 2,45 & 2,47 & 2,47 & 2,46 \\
& $c$ & 6,64 & 7,99 & 6,68 & 6,71 \\
\hline \hline
\end{tabular}


Grafeno e Grafite

e GGA (PBE). O valor obtido para o parâmetro $c$ com a aproximação optB88vdW esta em excelente acordo com o valor experimental. O valor do parâmetro $c$ obtido com a GGA (PBE) está superestimado em aproximadamente 20\%, enquanto aquele obtido com a LDA está subestimado em menos de 1\%. Embora os métodos LDA e GGA (PBE) não descrevam corretamente as interações eletrônicas de longo alcance, responsáveis pelas forças de van der Waals (vdW), a LDA descreve bem as propriedades estruturais da grafite. As razões para este aparente sucesso da LDA tem sido extensivamente discutido em termos da delocalização entre camadas e a energia de troca-correlação. [50-53].

O cálculo da estrutura de bandas de energia para a grafite foi efetuado nas direções e pontos de alta simetria da primeira zona de Brillouin (ZB) da rede hexagonal, mostrada na figura 3.2.

Utilizando os valores dos parâmetros de rede $a$ e $c$ determinados teoricamente, com a aproximação optB88-vdW, obtivemos a estrutura de faixas de energia da grafite, mostrada na figura 3.3 ao longo das principais direções de alta simetria da ZB, onde a energia de Fermi foi tomada como energia de referência e foi deslocada para o zero de energia.

Como a célula primitiva contém quatro átomos de carbono, contribuindo com 16 elétrons de valência, então temos 8 bandas ocupadas. Podemos observar que para a maioria dos pontos e direções da zona de Brillouin, existe um gap bem definido e variável, em função da direção, entre as bandas ocupadas e vazias, com exceção do ponto $\mathrm{H}$ e na região conectando os pontos $\mathrm{H}$ e $\mathrm{K}$ (o segmento HK é

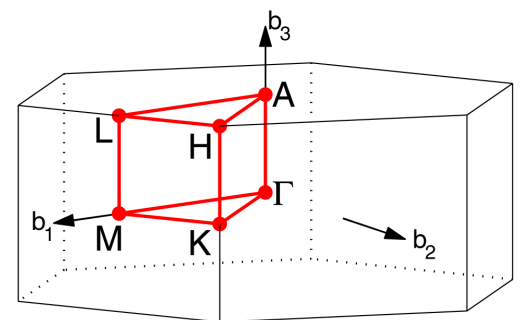

Figura 3.2: Primeira zona de Brillouin de uma rede hexagonal, com os pontos e direções de alta simetria [54]. 


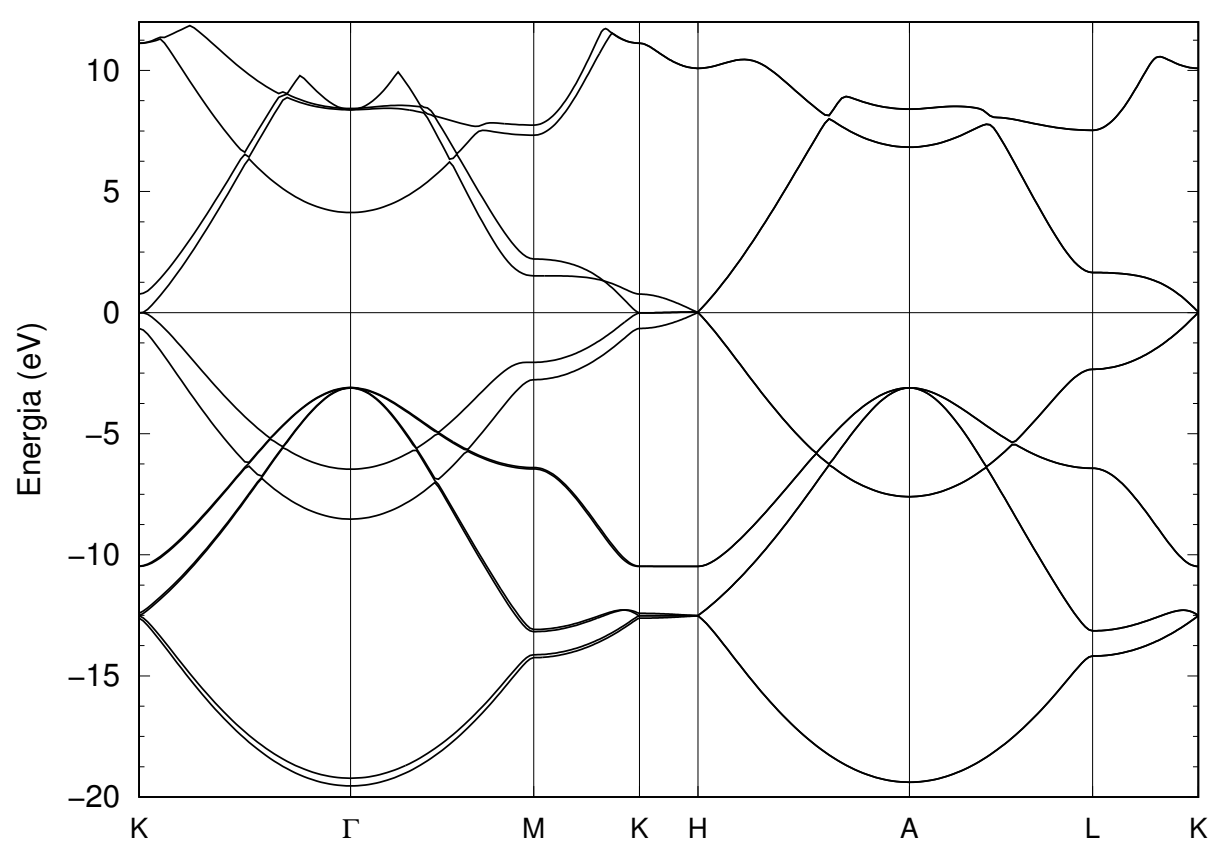

Figura 3.3: Estrutura de bandas de energia, ao longo das principais direções de simetria da ZB para a grafite.

paralelo ao eixo $b_{3}$ da figura 3.2). Nessa região temos gap nulo, o que classifica a grafite como um semimetal. Nossos resultados estão em excelente acordo com praticamente todos os resultados até hoje reportados na literatura [55].

\subsubsection{Estabilidade dinâmica}

Nós aplicamos a teoria de fônons, abordada no capítulo anterior, para estudar o espectro de vibração da grafite. A estabilidade dinâmica de um material pode ser analisada pela dispersão de fônons, que deve apresentar somente frequências com valores positivos.

A estrutura hexagonal da grafite (Fig. 3.1) possui uma base de quatro átomos, o que corresponde a 12 graus de liberdade e, portanto, 12 frequências normais de vibração, totalizando doze ramos de vibração, sendo 3 ramos acústicos e 9 ramos ópticos. Utilizamos uma malha de $8 \times 8 \times 8$ pontos $q$ para obter o espectro de fônons. 
Grafeno e Grafite

A figura 3.4 mostra a dispersão de fônons que foi obtida utilizando-se o funcional optB88-vdW, nos pontos e direções de alta simetria da primeira zona de Brillouin de uma rede hexagonal (figura 3.2), no plano.

Os três ramos com origem no ponto $\Gamma$ correspondem ao modos acústicos: um modo transversal, rotulado por TA, e um modo longitudinal, rotulado por LA, ambos no plano de hexágonos, e um modo na direção perpendicular ao plano, rotulado por ZA. Os outros nove correspondem aos ramos ópticos: três modos na direção perpendicular ao plano, um rotulado por ZO* e dois rotulados por ZO, três modos transversais no plano de hexágonos, um rotulado por TO* e dois por TO e, os últimos três ramos, são longitudinais no plano de hexágonos, um rotulado por LO* e dois por LO.

Os modos TA e LA apresentam uma variação linear em $q$ para $q \rightarrow 0$ no ponto $\Gamma$, enquanto o modo ZA apresenta uma dispersão quadrática em $q\left(q^{2}\right)$ na região próxima ao ponto $\Gamma$, em acordo com resultados teóricos e experimentais $[56,57]$.

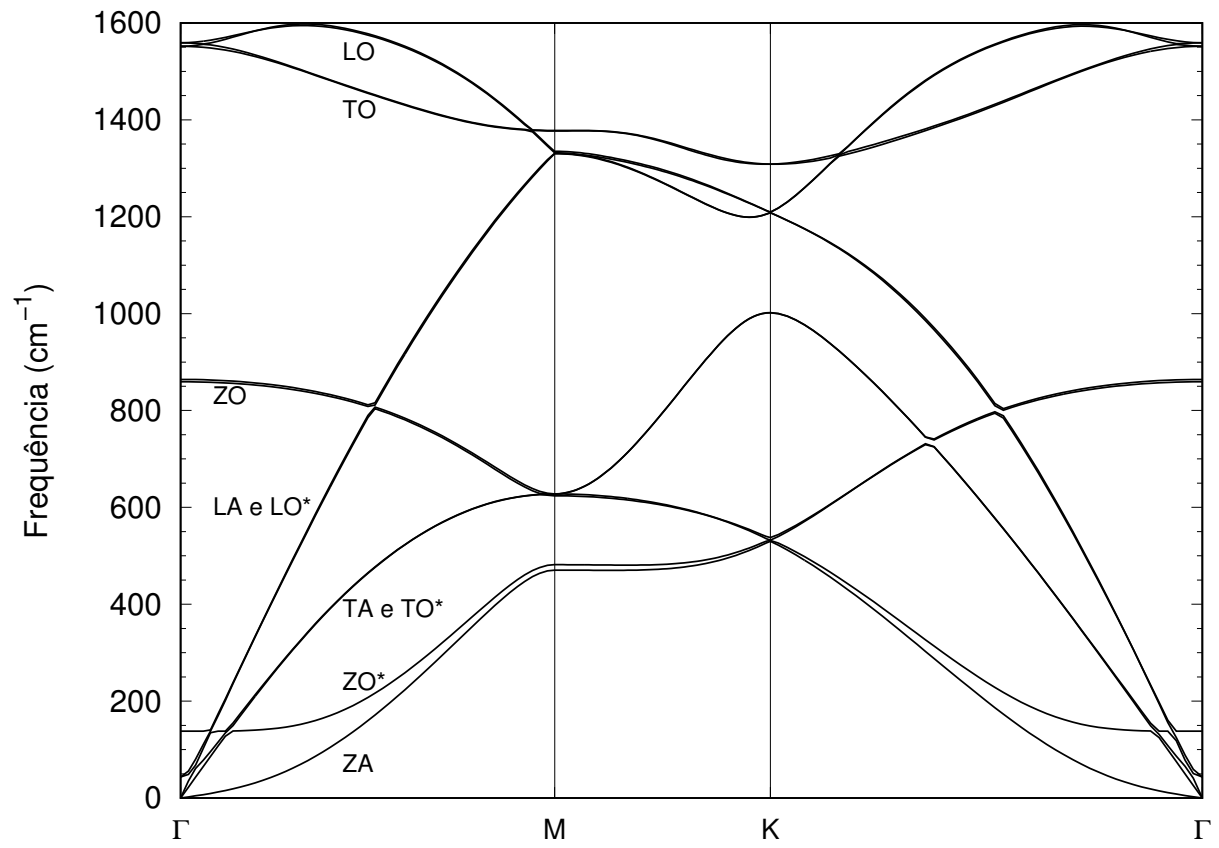

Figura 3.4: Dispersão de fônons da grafite nos pontos e direções de alta simetria da primeira zona de Brillouin de uma rede hexagonal, no plano. 
Grafeno e Grafite

Os modos identificados com asterisco: $\mathrm{ZO}^{*}, \mathrm{TO}^{*}$ e $\mathrm{LO}^{*}$ são aqueles onde os dois átomos de carbono em uma das camadas oscilam juntos e em oposição de fase aos dois átomos das camadas adjacentes [56].

\subsection{Grafeno}

\subsubsection{Propriedades estruturais e eletrônicas}

O grafeno tem uma estrutura planar hexagonal e a célula primitiva contém 2 átomos de carbono. Os vetores primitivos da rede são $(1,0,0) a,(-1 / 2, \sqrt{3} / 2,0) a$ e $(0,0, c / a) a$, onde $a$ e $c$ são os parâmetros da rede. Os átomos de carbono estão dispostos nas posições $(1 / 3,2 / 3,0)$ e $(2 / 3,1 / 3,0)$, em relação aos parâmetros de rede. A figura 3.5 mostra uma representação do arranjo dos átomos de carbono na estrutura hexagonal do grafeno.

As propriedades estruturais do grafeno, dentro do esquema de supercélula, foram simuladas utilizando o funcional optB88-vdW para o termo de exchangecorrelação e um método de dinâmica molecular de célula variável [46]. Para o valor mínimo de energia total o valor da constante de rede obtido foi $a=2,47 \AA$ e a distância de ligação $\mathrm{C}-\mathrm{C}$ foi $d_{\mathrm{C}-\mathrm{C}}=1,42 \AA$.

Utilizando o valor do parâmetro de rede $a$ determinado teoricamente, obtivemos a estrutura de faixas de energia do grafeno, mostrada na figura 3.6 ao longo das principais direções de alta simetria da ZB (vide figura 3.2), juntamente com a densidade de estados total (DOS-Density of States). A energia de Fermi foi tomada

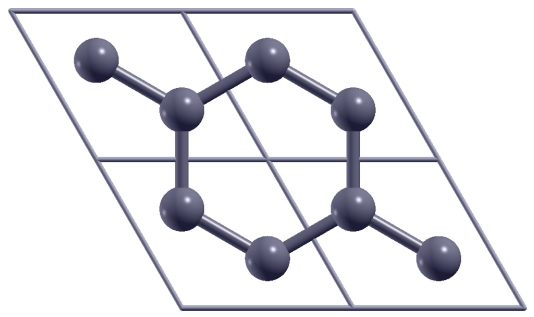

Figura 3.5: Ilustração do grafeno, que tem uma estrutura planar, mostrando quatro células primitivas com dois átomos de carbono cada. O átomo de carbono está representado por uma esfera cinza. 
Grafeno e Grafite
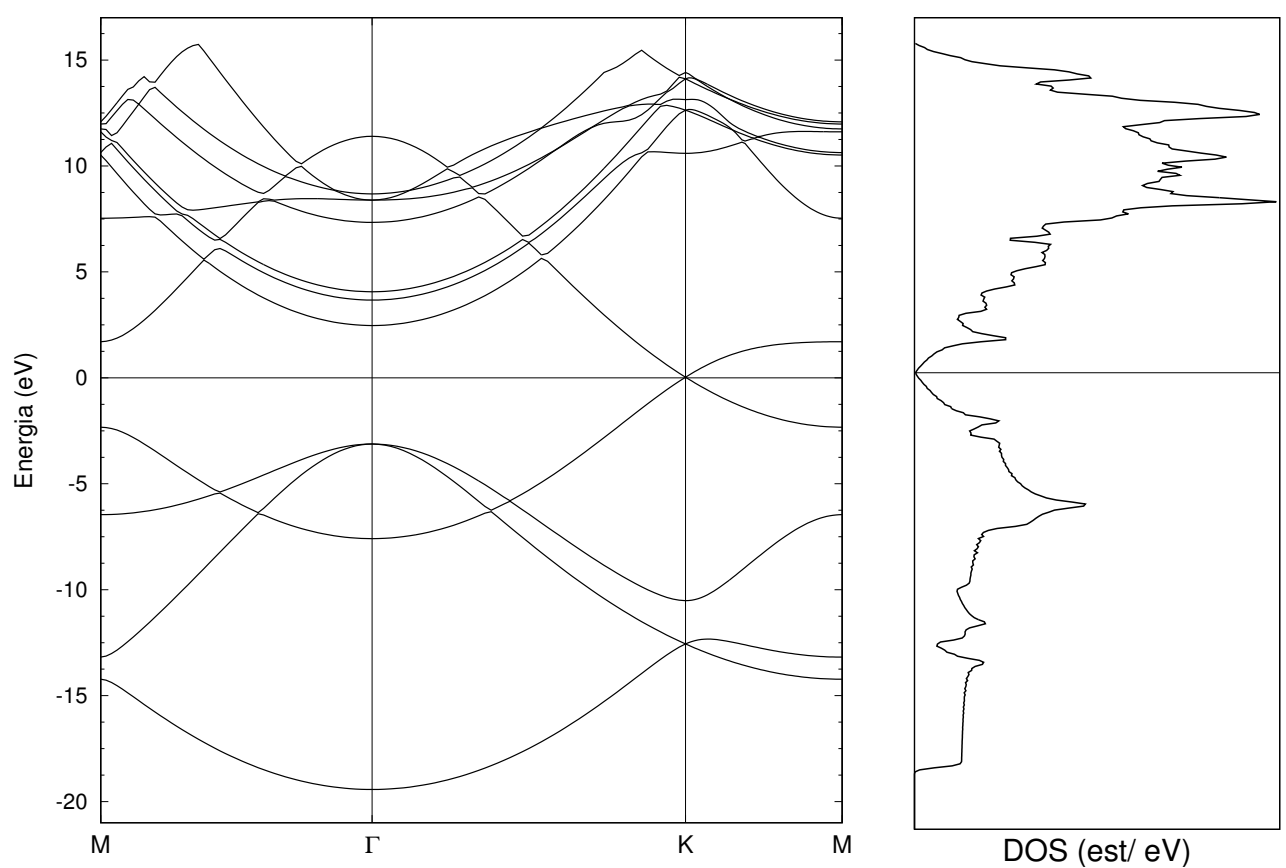

Figura 3.6: Estrutura de bandas de energia do grafeno, ao longo das principais direções de alta simetria da ZB, e a densidade de estados, em unidades de número de estados/eV.

como energia de referência e foi deslocada para o zero de energia.

A estrutura de bandas e a DOS mostram que o grafeno é um material semicondutor de gap zero. A dispersão é linear nas proximidades dos pontos K (pontos de Dirac). Estes resultados estão de acordo com praticamente todos os resultados até hoje reportados na literatura $[58,59]$.

\subsubsection{Estabilidade dinâmica}

Nós aplicamos a teoria de fônons, abordada no capítulo anterior, para estudar o espectro de fônos do grafeno. Utilizou-se a célula primitiva hexagonal (Fig. 3.5) e uma malha de pontos $q$ de $6 \times 6 \times 2$ para calcular as frequências dos modos normais de vibração da rede, onde a célula primitiva possui uma base com dois átomos de C. Isso corresponde a 6 graus de liberdade e 6 frequências de vibração, sendo 3 ramos acústicos e 3 ramos ópticos. A figura (3.7) mostra a dispersão de fônons obtida 
com utilização do funcional optB88-vdW. Os três ramos com origem no ponto $\Gamma$ correspondem ao modos acústicos: um modo transversal TA e um modo longitudinal LA, ambos no plano, e um modo na direção perpendicular ao plano ZA. Os outros três modos correspondem aos ramos ópticos: um na direção perpendicular ao plano ZO, e dois modos no plano, um transversal TO e um longitudinal LO.

Os modos acústicos TA e LA apresentam uma variação linear em $q$ para $q \rightarrow 0$ no ponto $\Gamma$, enquanto o modo ZA apresenta uma dispersão quadrática em $q\left(q^{2}\right)$ na região próxima ao ponto $\Gamma$, em acordo com resultados reportados na literatura [56]. O modo óptico ZO também apresenta uma dispersão quadrática em $q$ na região próxima ao ponto $\Gamma$, evidenciando que na direção perpendicular não há a propagação de ondas elásticas. O grafeno, diferentemente da grafite, não possui os modos com asterisco, pois contém apenas uma camada hexagonal de átomos de carbono. No entanto, a sua dispersão de fônons é muito similar a da grafite, principalmente nos pontos e direções de alta simetria no plano da ZB, já que as interações

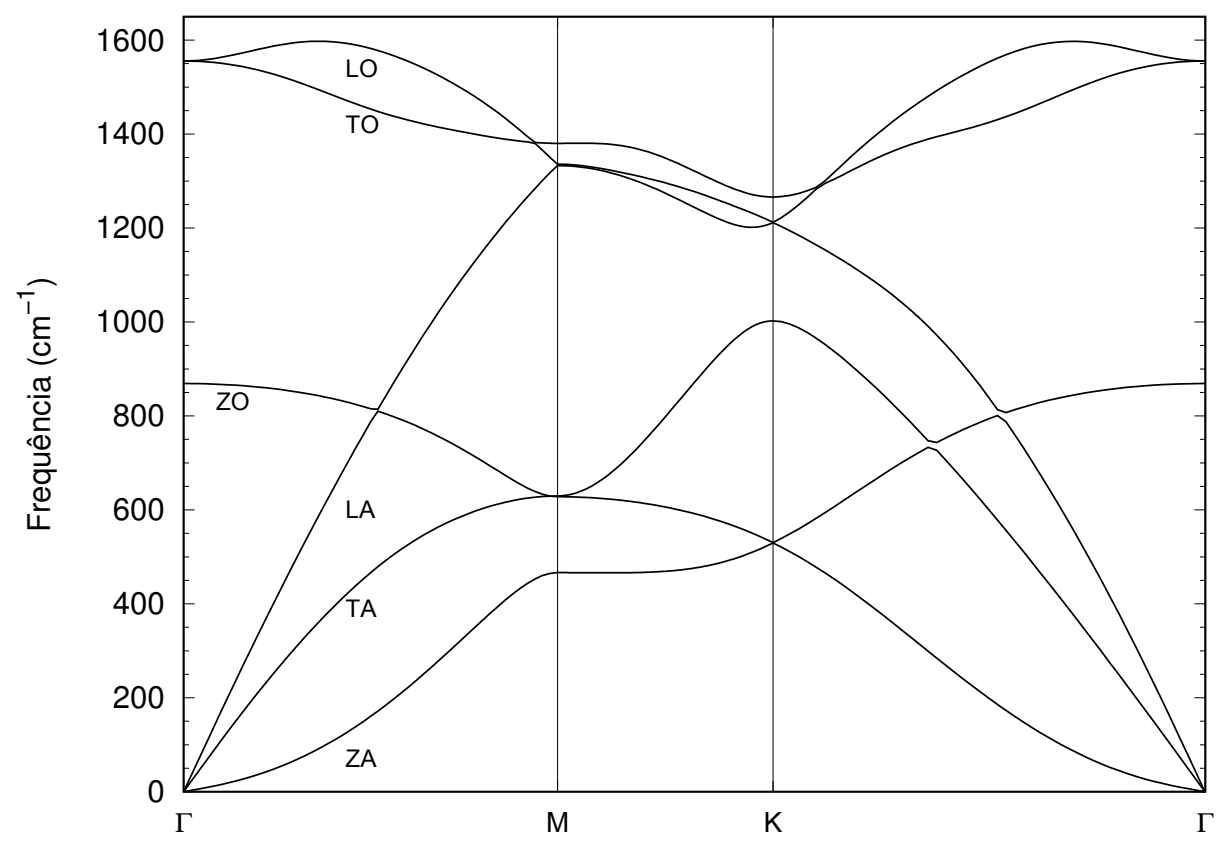

Figura 3.7: Dispersão de fônons do grafeno nos pontos e direções de alta simetria da primeira zona de Brillouin de uma rede hexagonal bidimensional. 
inter-camadas são fracas do tipo vdW. Não existem ramos com valores negativos de frequência, mostrando uma das condições necessária para a estabilidade das folhas de grafeno.

\subsection{Conclusão}

Neste capítulo estudamos as propriedades estruturais, eletrônicas e vibracionais da grafite e do grafeno. Nossos resultados teóricos para as propriedades da grafite e do grafeno mostraram boa concordância com os dados teóricos e experimentais, indicando que o método utilizado, incluindo as interações de van der Waals, é aplicável a outros sistemas onde estas interações podem ser importantes e descreve muito bem estruturas bidimensionais do tipo grafeno, validando os resultados obtidos para as propriedades dos sistemas que estudamos neste trabalho. 


\section{Capítulo 4}

\section{Sistemas bidimensionais $\mathrm{SiC}$}

Diversos materiais do tipo grafeno têm sido propostos e discutidos na literatura, nos últimos anos, tais como carbeto de silício [60,61], siliceno [62,63], germâneno [64,65], nitreto de boro $[66,67]$ e óxido de zinco [68]. Neste capítulo apresentamos os resultados dos estudos das propriedades eletrônicas, estruturais e da estabilidade dinâmica de bicamadas bidimensionais de planos de SiC do tipo grafeno. Com estes resultados, investigou-se a estabilidade da adsorção de um átomo de Li nestes materiais, onde o objetivo é tentar entender se este material pode ser pensado como um candidato a ânodo de bateria de íons de lítio. Neste trabalho foram estudadas as estruturas de $\mathrm{SiC}$ compostas de duas camadas hexagonais de átomos de carbono e de silício empilhadas em uma configuração do tipo grafite, em dois empilhamentos diferentes rotulados por $\mathrm{AB}^{\prime}$ e $\mathrm{AB}$.

No formato $\mathrm{AB}^{\prime}$, também rotulado como empilhamento do tipo grafite $\mathrm{AB}^{\prime}$, as duas camadas são empilhadas em um padrão tal que os átomos de Si da camada $\mathrm{B}^{\prime}$ estão diretamente acima de átomos de Si da camada $\mathrm{A}$, e os átomos de $\mathrm{C}$ da camada B' estão diretamente acima do centro dos hexágonos da camada A. Esta configuração está ilustrada na figura 4.1, onde os átomos de Si estão representados por esferas amarelas e os átomos de $\mathrm{C}$ por esferas cinzas.

No formato $\mathrm{AB}$, também rotulado como empilhamento do tipo grafite $\mathrm{AB}$, as duas camadas são empilhadas em um padrão de modo que os átomos de $\mathrm{C}$ da camada B estão diretamente acima de átomos de Si da camada $\mathrm{A}$, e os átomos de Si 

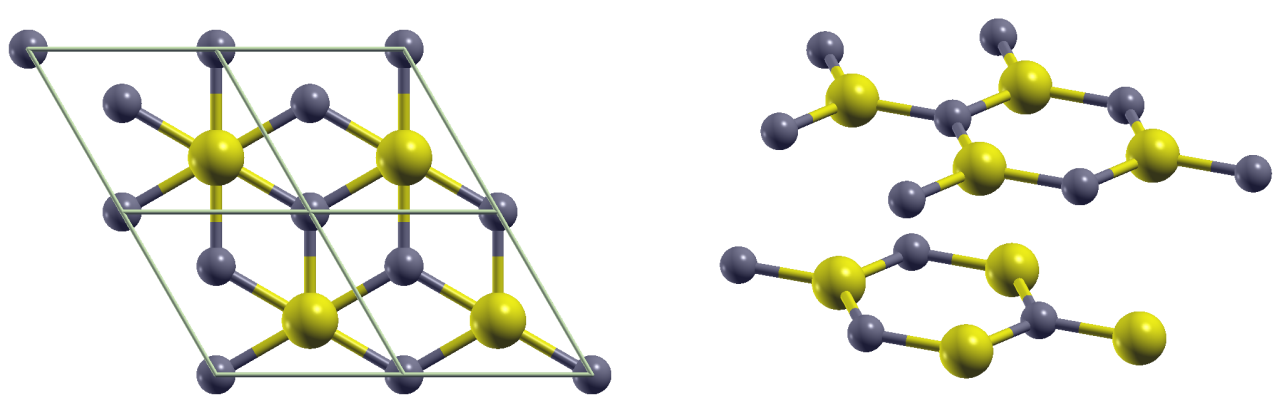

Figura 4.1: Ilustração da bicamada de $\mathrm{SiC}$ com empilhamento tipo grafite $\mathrm{AB}^{\prime}$, onde os átomos de silício, esferas amarelas, da camada $\mathrm{B}^{\prime}$ estão diretamente acima dos átomos de Si da camada $\mathrm{A}$, enquanto os átomos de carbono, esferas cinzas, da camada B' estão diretamente acima do centro dos hexágonos da camada A.

da camada B estão diretamente acima do centro dos hexágonos. Esta configuração está ilustrada na figura 4.2.

\subsection{Bicamada de $\mathrm{SiC}$ tipo grafite $\mathrm{AB}^{\prime}$}

\subsubsection{Propriedades estruturais e eletrônicas}

Como mostrado na figura 4.1, a célula primitiva foi construída com 4 átomos, 2 de $\mathrm{C}$ e dois de Si. Os vetores primitivos da rede são $(1,0,0) a,(-1 / 2, \sqrt{3} / 2,0) a$ e
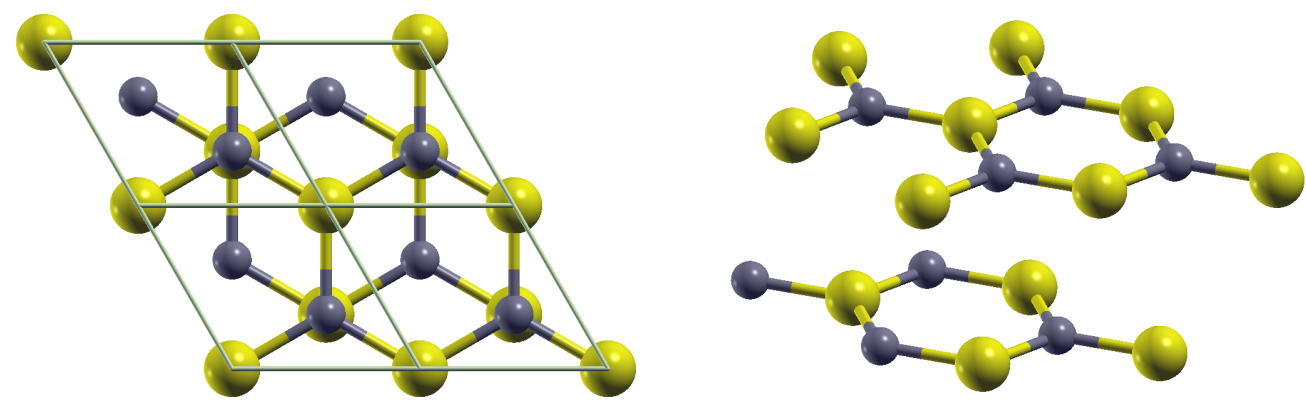

Figura 4.2: Ilustração da bicamada de $\mathrm{SiC}$ com empilhamento tipo grafite $\mathrm{AB}$, onde os átomos de carbono, esferas cinzas, da camada B estão diretamente acima dos átomos de Si da camada A, enquanto os átomos de silício, esferas amarelas, da camada B estão diretamente acima do centro dos hexágonos da camada A. 
Sistemas bidimensionais $\mathrm{SiC}$

$(0,0, c / a) a$, onde $a$ e $c$ são os parâmetros da rede, $\operatorname{com} c=15 \AA$, valor este mantido fixo durante todo o processo de obtenção das propriedades do sistema. Os átomos de carbono estão nas posições $(1 / 3,2 / 3,0)$ e $(0,0,24 / 100)$; os átomos de silício estão nas posições $(2 / 3,1 / 3,0)$ e $(2 / 3,1 / 3,24 / 100)$, em relação aos parâmetros de rede $a$ e $c$.

O valor do parâmetro de rede teórico da estrutura foi obtido através do método de dinâmica molecular de célula variável [46]. Após o processo de relaxação total do sistema, sem nenhuma restrição de simetria ou confinamento planar, cada uma das camadas do sistema continua planar, em acordo com a estrutura da monocada de $\mathrm{SiC}$ [69], mantendo a configuração de camadas paralelas.

A tabela 4.1 apresenta o parâmetro de rede, a distância entre os átomos Si-C no plano, a distância entre planos e o valor da faixa proibida de energia, obtidos através da utilização das aproximações LDA e optB88-vdW para o termo de troca e correlação, juntamente com outros resultados teóricos reportados na literatura, os quais utilizam as aproximações LDA e DFT-D2 [70,71].

Analisando os dados da tabela, podemos observar que os valores obtidos para a constante de rede $a=3,07 \AA$, a distância de ligação Si-C no plano $d_{\mathrm{Si}-\mathrm{C}}=1,77$ $\AA$ e a distância entre camadas $d=3,41 \AA$, com a utilização do funcional LDA, estão em excelente acordo com resultados teóricos da literatura [70,71], os quais foram obtidos com a utilização da aproximação LDA. Podemos verificar que os valores dos parâmetros $a$ e $d_{\mathrm{Si}-\mathrm{C}}$ obtidos com a aproximação optB88-vdW são praticamente iguais àqueles obtidos com a aproximação LDA. Entretanto, o valor

Tabela 4.1: Parâmetro de rede $a$ da bicamada $\mathrm{AB}^{\prime}-\mathrm{SiC}$, distância entre os átomos no plano, $d_{\mathrm{Si}-\mathrm{C}}$, distância $d$ entre camadas e energia do gap $\mathrm{E}_{g}$, obtidos com as aproximações LDA e optB88-vdW. As distâncias estão em $\AA$ e a energia em eV.

\begin{tabular}{||c|c|c|c|c|c|c||}
\hline \hline Material & & LDA & optB88-vdW & LDA [70] & LDA [71] & DFT-D2 [71] \\
\hline \hline $\mathrm{AB}^{\prime}-\mathrm{SiC}$ & $a$ & 3,07 & 3,10 & 3,05 & - & - \\
& $d_{\mathrm{Si}-\mathrm{C}}$ & 1,77 & 1,79 & - & - & - \\
& $d$ & 3,41 & 3,60 & 3,40 & 3,407 & 3,396 \\
& $\mathrm{E}_{g}$ & 1,51 & 1,65 & 1,56 & - & - \\
\hline \hline
\end{tabular}


Sistemas bidimensionais $\mathrm{SiC}$

da distância $d$ obtido com a aproximação optB88-vdW é da ordem de $6 \%$ maior quando comparado com aquele obtido com a aproximação LDA. Esta observação sugere que uma boa descrição da interação inter-camadas deve incluir as correções devidas às interações de vdW, pois como observamos no capítulo anterior, a LDA descreve bem as propriedades estruturais de sistemas do tipo grafite, mas porque existe um duplo erro de cancelamento interno [51-53]. Utilizamos o funcional LDA para termos resultados que pudessem ser comparados com outros resultados teóricos da literatura.

Finalmente, vamos comparar nosso resultado para o valor de $d$ obtido com o funcional optB88-vdW com aquele da literatura, obtido com a utilização da aproximação DFT-D2, onde a inclusão de interações de longo alcance é feita adicionandose um termo de dispersão atrativo da forma $-C^{6} / r^{6}$ à energia total, enquanto a que utilizamos neste trabalho inclui a interação não local no funcional de exchangecorrelação, fazendo com que o parâmetro $C^{6}$ dependa do ambiente, pois é obtido varicionalmente. O resultado com a DFT-D2 é muitíssimo parecido com o valor obtido por LDA e o nosso resultado é da ordem de $6 \%$ maior, evidenciando as diferentes aproximações utilizadas para introduzir o termo dispersivo no funcional de troca e correlação.

A distância entre camadas de $d=3,60 \AA$ é maior do que a distância entre camadas na grafite de $3,34 \AA$, aspecto este positivo uma vez que foi demonstrado que o espaçamento maior entre camadas poderia ser importante para o aprimoramento da capacidade de armazenamento nas baterias de íons de Li [50].

Utilizando os valores do parâmetro de rede $a$ e a distância $d$ determinados teoricamente com o funcional optB88-vdW, obtivemos a estrutura de faixas de energia da bicamada $\mathrm{AB}^{\prime}-\mathrm{SiC}$, mostrada na figura 4.3, ao longo das principais direções de alta simetria da ZB (vide figura 3.2), juntamente com as densidades de estados total (TDOS-Total Density of States) e projetada (PDOS - Projected Density of States) nos estados $s$ e $p$ dos átomos de C e Si. O topo da banda de valência $\left(E_{v}\right)$ foi tomado como energia de referência e foi deslocado para o zero de energia. 
A estrutura de bandas e a DOS mostram que o sistema AB'-SiC é um material semicondutor de gap direto, $\mathrm{E}_{g}=1,65 \mathrm{eV}$, pois tanto o topo da banda de valência quanto o fundo da banda de condução situam-se no ponto K. O fundo da banda de condução é composto, primordialmente, pelos estados do tipo $p$ dos átomos de Si, com pequena contribuição dos estados $p$ dos átomos de C. Por outro lado, os estados que compõem a banda de valência, na região entre 0 e $-8 \mathrm{eV}$, são primordialmente estados do tipo $p$ dos átomos de $\mathrm{C}$ com alguma contribuição de estados do tipo $p$ dos átomos de Si. Na região entre -10 e -14 eV a banda de valência é composta essencialmente pelos estados do tipo $s$ dos átomos de C e Si. Comparando este resultado com aquele da monocamada planar de $\mathrm{SiC}$ do tipo grafeno, podemos perceber que a banda é levemente perturbada pela interação entre camadas, mostrando
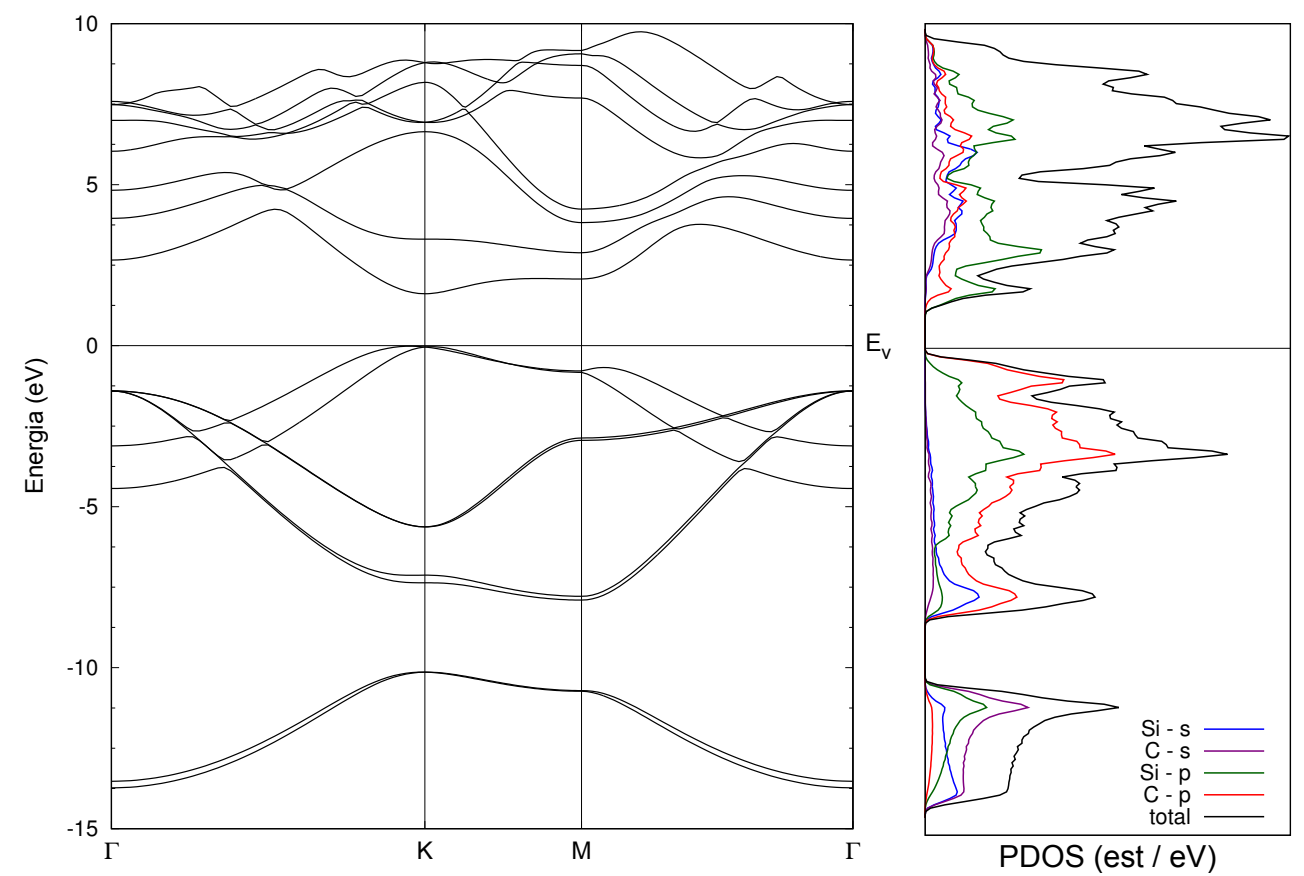

Figura 4.3: Estrutura de bandas de energia da bicamada de $\mathrm{SiC}$ com empilhamento tipo grafite $\mathrm{AB}^{\prime}$ ( $\mathrm{AB}^{\prime}-\mathrm{SiC}$ ), ao longo das principais direções de alta simetria da $\mathrm{ZB}$, e as densidades de estados total (preto) e projetadas nos orbitais do tipo $s$ do $\mathrm{C}$ (roxo) e do Si (azul) e nos orbitais do tipo $p$ do $\mathrm{C}$ (vermelho) e do Si (verde), em unidades de número de estados $/ \mathrm{eV} . \mathrm{E}_{\mathrm{v}}$ designa o topo da banda de valência, que foi deslocado para o zero de energia. 
Sistemas bidimensionais $\mathrm{SiC}$

que a interação inter-camadas é bem fraca. As larguras das bandas de valência e proibida ficam praticamente inalteradas, as bandas não degeneradas passam a ser quase bidegeneradas, como se houvesse uma superposição das bandas individuais de cada camada, peturbando mais a banda que define o topo da banda de valência, com uma quebra de degenerescência. A interação também modifica a curvatura do fundo da banda de condução, em comparação com a monocamada [69], diminuindo o valor da massa efetiva de condução.

\subsubsection{Estabilidade dinâmica}

Nós aplicamos a metodologia de fônons, abordada no capítulo 2, para estudar o espectro de fônons da bicamada $\mathrm{AB}^{\prime}$-SiC. Utilizou-se a célula primitiva hexagonal e uma malha de pontos $q$ de $6 \times 6 \times 6$ para calcular as frequências dos modos normais de vibração da rede. Como a base possui 2 átomos de $\mathrm{C}$ e 2 átomos de Si, isso corresponde a 12 graus de liberdade e 12 frequências normais de vibração, sendo 3 ramos acústicos e 9 ramos ópticos. A figura 4.4 mostra a dispersão de fônons obtida utilizando o funcional optB88-vdW.

Os três ramos com origem no ponto $\Gamma$ correspondem ao modos acústicos: um modo transversal TA e um modo longitudinal LA, ambos planares, e um modo ZA na direção perpendicular aos planos. Os outros nove correspondem aos ramos ópticos: três modos na direção perpendicular aos planos, um ZO* e dois ZO, três modos transversais planares, um $\mathrm{TO}^{*}$ e dois $\mathrm{TO}$ e, os últimos três ramos, são longitudinais planares, um LO* e dois LO. Os modos LO e TO apresentam frequências bem separadas das dos outros modos de vibração. O modo óptico fora do plano mistura-se com os modos acústicos. Estas características são encontradas em sistemas planares bidimensionais do tipo grafeno.

Os modos TA e LA apresentam uma variação linear em $q$ para $q \rightarrow 0$ no ponto $\Gamma$, enquanto o modo ZA apresenta uma dispersão quadrática em $q\left(q^{2}\right)$ na região próxima ao ponto $\Gamma$, a qual também é observada no grafeno [56]. Os modos identificados com asterisco, assim como na grafite (Cap. 3) são aqueles onde os dois átomos de uma das camadas oscilam juntos e em oposição de fase 


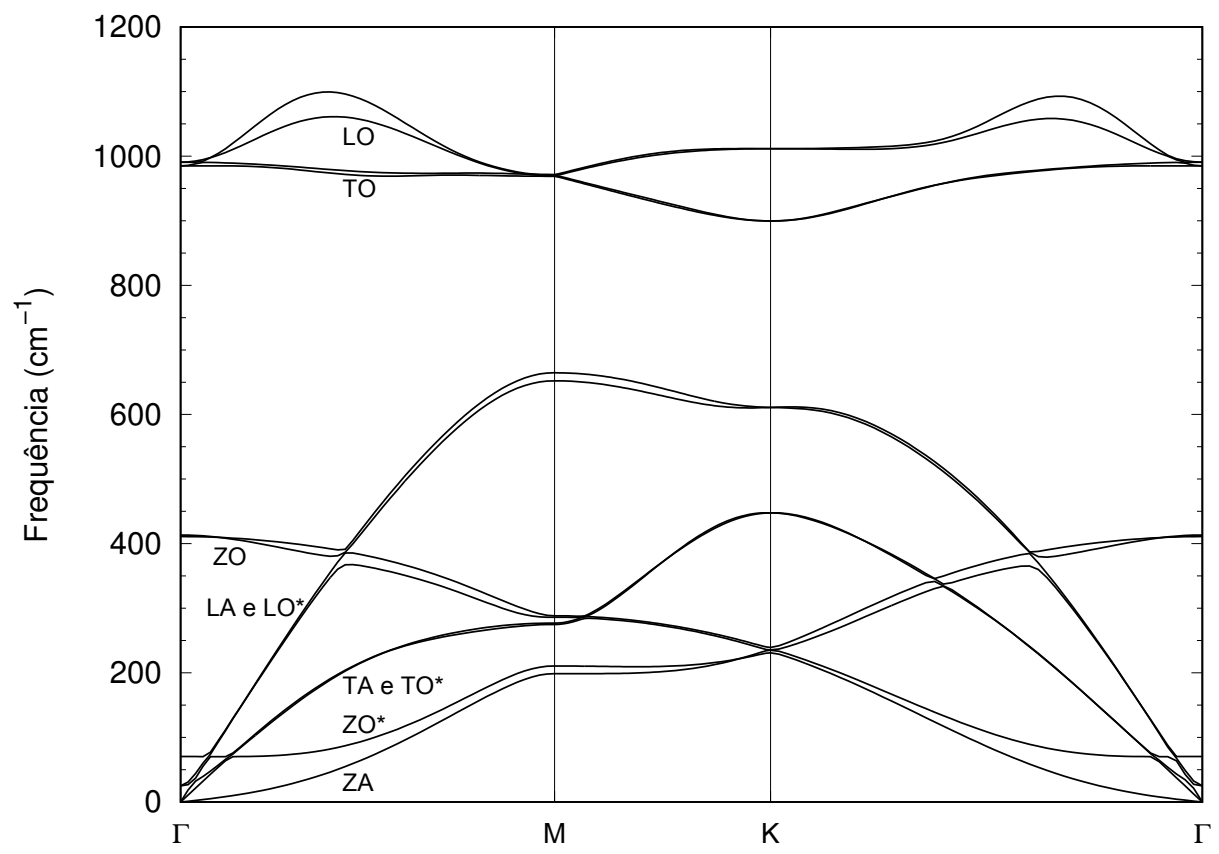

Figura 4.4: Dispersão de fônons da bicamada AB'-SiC, obtida utilizando-se o funcional optB88-vdW, nos pontos e direções de alta simetria da primeira zona de Brillouin de uma rede hexagonal.

aos dois átomos da outra camada [56], muito parecido com o que ocorre com a bicamada de grafeno [72]. Uma constatação importante é que todos os modos têm frequência positiva, o que significa que a bicamada $\mathrm{AB}^{\prime}-\mathrm{SiC}$ é estável, assim como a monocamada planar de $\mathrm{SiC}$.

\subsubsection{Adsorção de um átomo de Li na estrutura $\mathrm{AB}^{\prime}$-SiC}

A fraca interação do tipo van der Waals entre as folhas de $\mathrm{SiC}$, na estrutura $\mathrm{AB}^{\prime}$ $\mathrm{SiC}$, faz com que a distância inter-camadas seja grande. Nossos resultados mostram $d=3,60 \AA$. Assim, átomos de Li podem ser intercalados entre as folhas, como sugerido na literatura para outros tipos de sistemas onde as interações entre camadas são fracas [73].

Para testar a estabilidade estrutural da adsorção de um átomo de Li entre as folhas da bicamada $\mathrm{AB}^{\prime}-\mathrm{SiC}$, adotamos uma supercélula $3 \times 3$, com 36 átomos, 18 
átomos de C e 18 de Si. Esta escolha se faz necessária para evitar que existam interações entre átomos de Li, ou seja, a interação entre o átomo de Li em um sítio da rede na supercélula e sua imagem nas células vizinhas. Vamos rotular este sistema de $\mathrm{AB}^{\prime}-\mathrm{Li} \mathrm{Si}_{18} \mathrm{C}_{18}$.

Utilizamos 3 diferentes configurações para iniciar as simulações. Na primeira configuração, rotulada de configuração ponte, mostrada na figura 4.5, o átomo de Li foi colocado entre as camadas, mais próximo de uma delas e no ponto médio da distância entre dois átomos de carbono de um mesmo anel. Na segunda configuração, rotulada de configuração central, o átomo de Li foi introduzido na posição central da supercélula, a qual fica acima (abaixo) do centro de um hexágono de uma das camadas e abaixo(acima) da posição de um átomo de carbono da outra camada, como mostra a figura 4.6. Na última configuração, rotulada de configuração intersticial, o átomo de Li foi colocado no ponto médio da distância entre dois átomos de $\mathrm{Si}$, um em cada camada, como mostra a figura 4.7.

Utilizando o método de dinâmica molecular de célula variável [46], após o processo de relaxação total do sistema, sem nenhuma restrição de simetria ou confinamento, os três sistemas apresentaram a mesma configuração final, independente da configuração inicial. Na configuração final o átomo de Li fica na posição central,
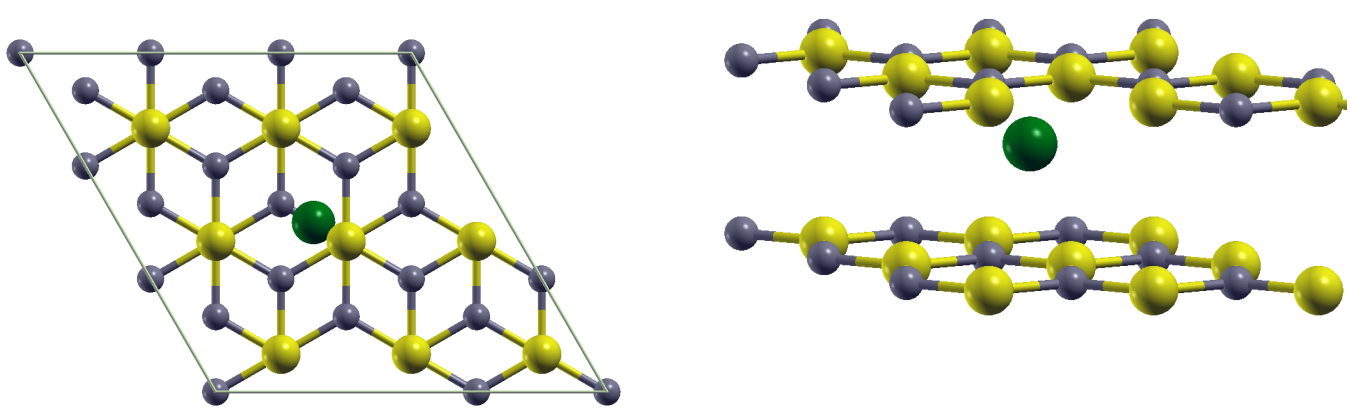

Figura 4.5: Ilustração da bicamada de $\mathrm{SiC}$ tipo grafite $\mathrm{AB}^{\prime}$ ( $\mathrm{AB}^{\prime}-\mathrm{SiC}$ ), com um átomo de Li (esfera verde) na posição ponte, que é entre as camadas, mais próximo de uma delas, e no ponto médio da distância entre dois átomos de carbono de um mesmo anel. As esferas cinzas representam átomos de $\mathrm{C}$ e as amarelas átomos de Si. 

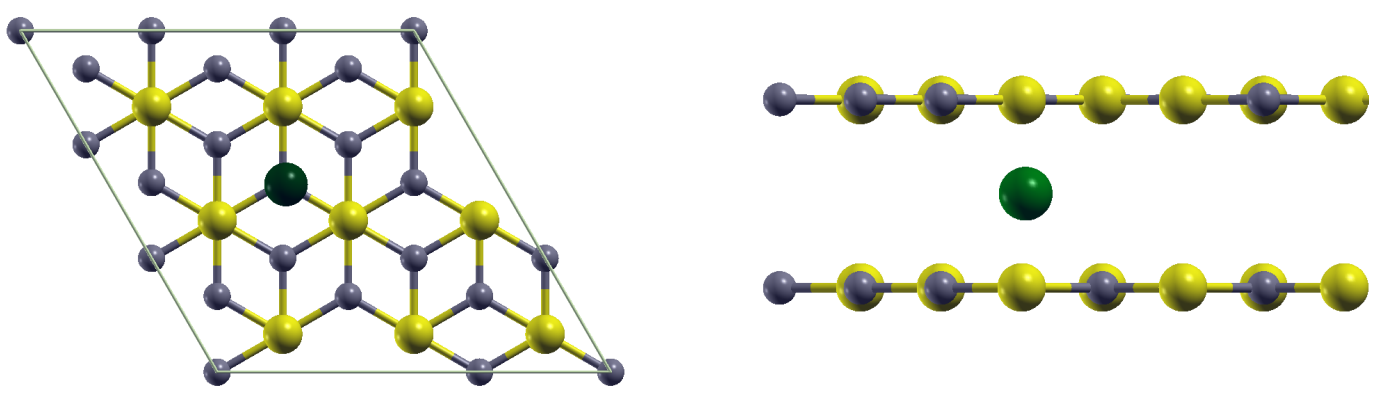

Figura 4.6: Ilustração da bicamada de $\mathrm{SiC}$ tipo grafite $\mathrm{AB}^{\prime}$ ( $\mathrm{AB}^{\prime}-\mathrm{SiC}$ ), com um átomo de Li (esfera verde) na posição central da supercélula, a qual fica acima (abaixo) do centro de um hexágono de uma das camadas e abaixo (acima) da posição de um átomo de carbono da outra camada. As esferas cinzas representam átomos de $\mathrm{C}$ e as amarelas átomos de $\mathrm{Si}$.

a uma distância de 2,08 $\AA$ do átomo de $\mathrm{C}$ de uma das camadas e a uma distância de 1,71 A do centro de um hexágono da outra camada. Este resultado mostra que o átomo de Li se posiciona de maneira tal a ocupar as regiões mais afastadas dos átomos do sistema, em posicões intersticiais, como acontece no processo de intercalação de Li na grafite [50], material este usado, atualmente, para compor o ânodo de baterias de íons de Li.

A distância entre camadas, na região onde o Li se encontra, é de 3,79 Å, maior

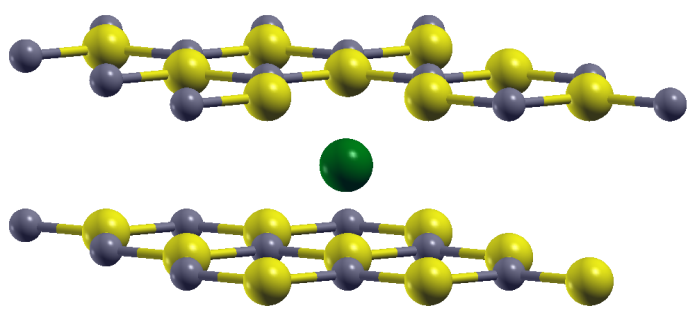

Figura 4.7: Ilustração da bicamada de $\mathrm{SiC}$ tipo grafite $\mathrm{AB}^{\prime}$ ( $\mathrm{AB}^{\prime}-\mathrm{SiC}$ ), com um átomo de Li (esfera verde) na posição correspondente ao ponto médio da distância entre dois átomos de $\mathrm{Si}$, um em cada camada. As esferas cinzas representam átomos de $\mathrm{C}$ e as amarelas átomos de $\mathrm{Si}$. 


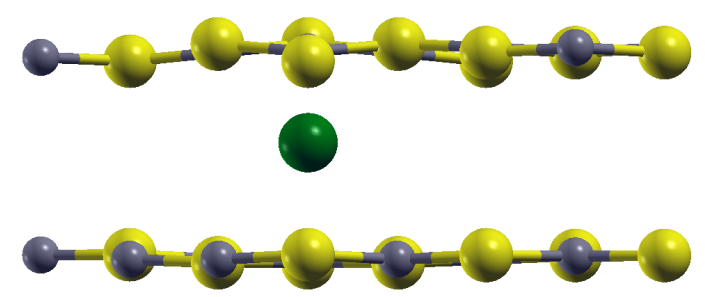

Figura 4.8: Ilustração da configuração estrutural do sistema $\mathrm{AB}^{\prime}-\mathrm{Li} \mathrm{Si}_{18} \mathrm{C}_{18}$, após a relaxação total, sem qualquer tipo de restrição. A esfera verde representa o átomo de $\mathrm{Li}$, as esferas cinzas representam átomos de $\mathrm{C}$ e as amarelas átomos de $\mathrm{Si}$.

que aquela de 3,60 Å sem sua introdução. A distância de ligação Si-C nas proximi-

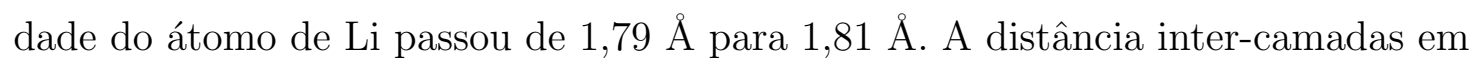
uma região longe da posição do Li, passou a ser de 1,53 Å. As distorções causadas pela introdução do átomo de Li são pequenas, como podemos observar na figura 4.8. Essa é uma grande vantagem para que este sistema seja utilizado como ânodo de bateria de íons de Li, pois uma grande expansão do volume do ânodo durante a carga/descarga pode levar a deformação do material e, consequentemente, fazer diminuir a vida útil do mesmo.

Mostramos na figura 4.9 as densidades de estados total (preto) e projetada no orbital do tipo $s$ do Li, para analisar o sistema do ponto de vista das propriedades eletrônicas. Primeiramente, devemos notar que a adsorção do Li praticamente não modifica a densidade de estados do sistema. Os estados de energia associados aos orbitais do tipo $s$ do Li são essencialmente ressonantes na banda de condução, indicando que o elétron de valência do Li, intercalado na posição central da bicamada AB'-SiC, fica delocalizado nas camadas adjacentes, ou seja, é acomodado no fundo da banda de condução. Podemos, portanto, concluir que na região ao redor do átomo de Li existe um excesso de carga positiva. Estas observações indicam que este sistema é estabilizado através de um processo de troca de elétrons entre as camadas hospedeiras e o átomo de lítio, da mesma maneira que nos compostos de 


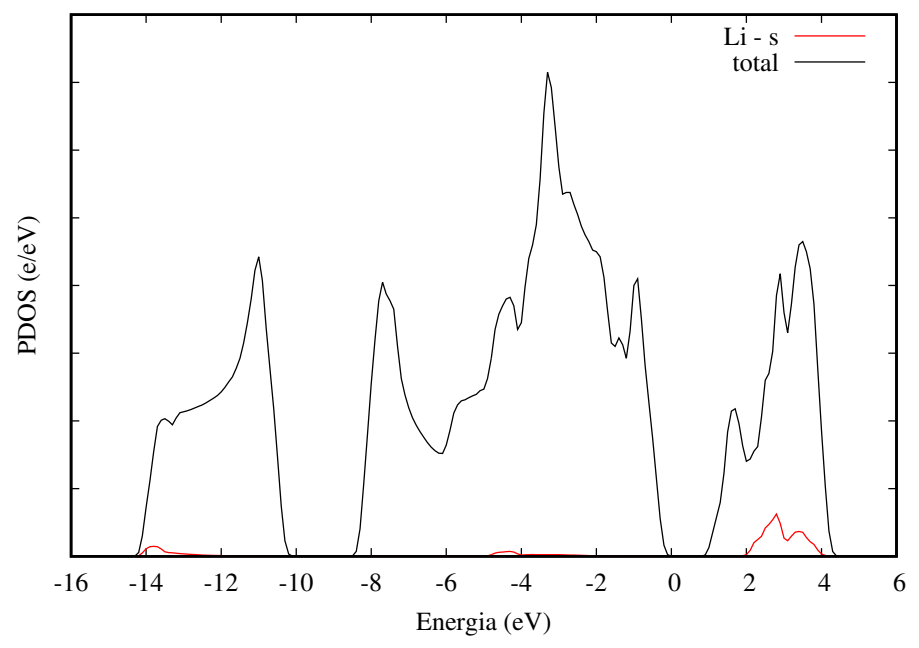

Figura 4.9: Densidades de estados total (preto) e projetada nos orbitais do tipo $s$ do $\mathrm{Li}$ (vermelho), do sistema $\mathrm{AB}^{\prime}-\mathrm{Li} \mathrm{Si}_{18} \mathrm{C}_{18}$, em unidades de número de estados/eV.

grafite intercalados com Li [50]. Esta constatação indica que adsorção de átomos de Li na bicamada $\mathrm{AB}^{\prime}-\mathrm{SiC}$, do ponto de vista da estrutura eletrônica, apresenta propriedades vantajosas para ser aplicado como ânodo de bateria de íons de Li.

A energia de ligação para a adsorção de um átomo de Li na posição central da bicamada da $\mathrm{AB}^{\prime}-\mathrm{SiC}$ é de aproximadamente $-1,8 \mathrm{eV}$, de acordo com os resultados apresentados no apêndice A. Este valor é similar ao encontrado no estudo teórico da adsorção de um átomo de Li na grafite, onde os valores da energia de ligação variam de -1,6 eV a -2,8 eV, dependendo do tipo de empilhamento, da distância entre as camadas e do método teórico utilizado [50]. Portanto, este material poderia ser usado para compor o ânodo de baterias de íons de Li.

A máxima capacidade específica teórica $(C)$ do ânodo é dada pela equação [74]:

$$
C=\frac{1}{\mathrm{M}_{\mathrm{SiC}}}\left(z \times x_{\max } \times F \times 10^{3}\right) .
$$

onde $z$ é o número de valência ( $z=1$ para o Li), $x_{\text {max }}$ é a maior concentração de Li na estrutura $\mathrm{AB}^{\prime}-\mathrm{SiC}, F$ é a constante de Faraday (26,810 Ahmol ${ }^{-1}$ ) e $\mathrm{M}_{\mathrm{SiC}}$ é a massa atômica do sistema $\mathrm{AB}^{\prime}$-SiC. A maior concentração de Li que a grafite alcança é de $1 / 6\left(\mathrm{LiC}_{6}\right)$, o que leva a uma capacidade específica $C=372 \mathrm{mAhg}^{-1}$ 
Sistemas bidimensionais $\mathrm{SiC}$

[7]. Embora a massa atômica da bicamada $\mathrm{AB}^{\prime}-\mathrm{SiC}$ seja grande, comparada com a da grafite, pode-se obter uma capacidade específica maior que a da grafite com uma concentração de átomos de Li $x_{\max } \geq 0,55$.

\subsection{Bicamada de $\mathrm{SiC}$ tipo grafite $\mathrm{AB}$}

\subsubsection{Propriedades estruturais e eletrônicas}

Como mostrado na figura 4.1, a célula primitiva foi construída com 4 átomos, 2 de $\mathrm{C}$ e 2 de $\mathrm{Si}$. Os vetores primitivos da rede são $(1,0,0) a,(-1 / 2, \sqrt{3} / 2,0) a$ e $(0,0, c / a) a$, onde $a$ e $c$ são os parâmetros da rede, $\operatorname{com} c=15 \AA$, valor este mantido fixo durante todo o processo de obtenção das propriedades do sistema. Os átomos de carbono estão nas posições (1/3, 2/3, 0$)$ e (2/3,1/3,23/100); os átomos de silício estão nas posições $(2 / 3,1 / 3,0)$ e $(0,0,23 / 100)$, em relação aos parâmetros de rede $a$ e $c$.

O valor do parâmetro de rede teórico da estrutura foi obtido através do método de dinâmica molecular de célula variável [46]. Após o processo de relaxação total do sistema, sem nenhuma restrição de simetria ou confinamento planar, cada uma das camadas do sistema continua planar, em acordo com a estrutura da monocada de $\mathrm{SiC}$ [69], mantendo a configuração de camadas paralelas.

A tabela 4.2 apresenta o parâmetro de rede, a distância entre os átomos Si-C no plano, a distância entre planos e o valor da faixa proibida de energia, obtidos através da utilização da aproximação optB88-vdW para o termo de troca e correlação, juntamente com outros resultados teóricos reportados na literatura, os quais utilizam as aproximações GGA, LDA e DFT-D2 [70,71,75].

A constante de rede otimizada é de $3,10 \AA$, a distância de ligação Si-C é de $1,79 \AA$ e a distância entre camadas $d$ é de $3,46 \AA$. Analisando os dados da tabela, podemos observar que os valores obtidos para a constante de rede $a=3,10 \AA$ e a distância de ligação Si-C no plano $d_{\mathrm{Si}-\mathrm{C}}=1,79 \AA$ estão em excelente acordo com resultados teóricos da literatura $[70,75]$. Entretanto, o valor da distância $d$ obtido com a aproximação optB88-vdW é maior quando comparado com aqueles obtidos 
Tabela 4.2: Parâmetro de rede $a$ da bicamada AB-SiC, distância entre os átomos no plano, $d_{\mathrm{Si}-\mathrm{C}}$, distância $d$ entre camadas e energia do gap $\mathrm{E}_{g}$, obtidos com a aproximação optB88-vdW. As distâncias estão em $\AA$ e a energia em eV.

\begin{tabular}{||c|c|c|c|c|c|c||}
\hline \hline Material & & vdW-B88 & GGA [75] & LDA [70] & LDA [71] & DFT-D2 [71] \\
\hline \hline AB-SiC & $a$ & 3,10 & - & 3,05 & - & - \\
& $d_{\mathrm{Si}-\mathrm{C}}$ & 1,79 & 1,78 & - & - & - \\
& $d$ & 3,46 & 3,66 & 3,18 & 3,205 & 3,221 \\
& $\mathrm{E}_{g}$ & 1,89 & - & 1,98 & - & - \\
\hline \hline
\end{tabular}

com as aproximações LDA e DFT-D2, menor em relação ao obtido com GGA.

A distância entre camadas de $d=3,46 \AA$, apesar de menor do que o da bicamada $\mathrm{AB}^{\prime}-\mathrm{SiC}$, ainda é maior do que a distância entre camadas na grafite de $3,34 \AA$ e este aspecto é positivo [50], como mencionado na discussão do sistema $\mathrm{AB}^{\prime}$-SiC.

Utilizando os valores do parâmetro de rede $a$ e a distância $d$ determinados teoricamente com o funcional optB88-vdW, obtivemos a estrutura de faixas de energia da bicamada AB-SiC, mostrada na figura 4.10, ao longo das principais direções de alta simetria da ZB (vide figura 3.2), juntamente com as densidades de estados total (TDOS-Total Density of States) e projetada (PDOS - Projected Density of States) nos estados $s$ e $p$ dos átomos de C e Si. O topo da banda de valência $\left(E_{\mathrm{v}}\right)$ foi tomado como energia de referência e foi deslocado para o zero de energia.

A estrutura de bandas e a DOS mostram que o sistema AB-SiC é um material semicondutor de gap direto com $\mathrm{E}_{g}=1,89 \mathrm{eV}$, pois tanto o topo da banda de valência quanto o fundo da banda de condução situam-se no ponto K. Assim como para o sistema AB'-SiC, o fundo da banda de condução é composto, especialmente, pelos estados do tipo $p$ dos átomos de $\mathrm{Si}$, com pequena contribuição dos estados $p$ dos átomos de C. Por outro lado, os estados que compõem a banda de valência, na região entre 0 e -8 eV, são compostos por estados do tipo $p$ dos átomos de $\mathrm{C}$ com alguma contribuição de estados do tipo $p$ dos átomos de Si. Na região entre -10 e -14 eV a banda de valência é composta primordialmente pelos estados do tipo $s$ dos átomos de $\mathrm{C}$ e $\mathrm{Si}$. Comparando este resultado com aquele da monocamada 

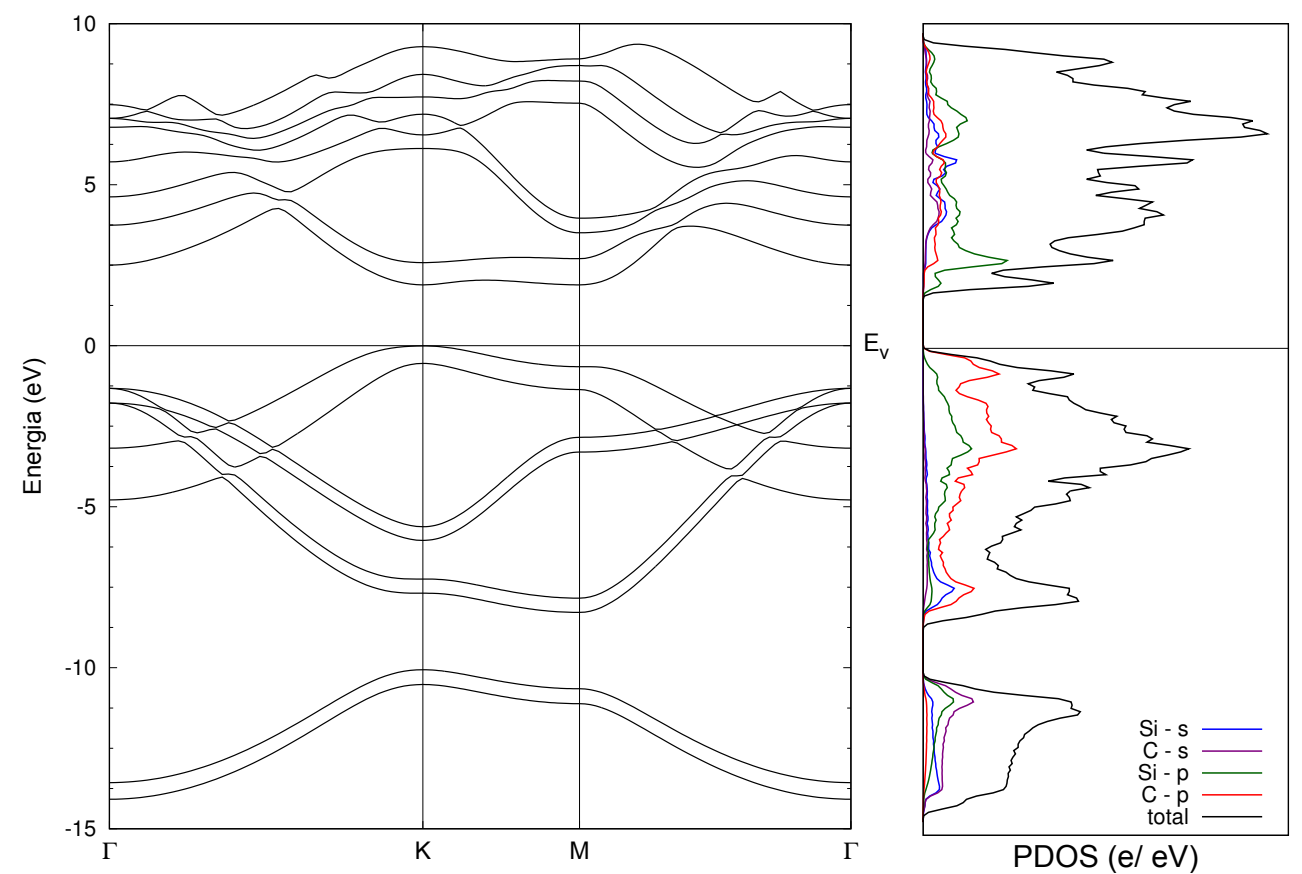

Figura 4.10: Estrutura de bandas de energia da bicamada de SiC com empilhamento tipo grafite $\mathrm{AB}$ ( $\mathrm{AB}-\mathrm{SiC})$, ao longo das principais direções de alta simetria da ZB, e as densidades de estados total (preto) e projetadas nos estados $s$ do $\mathrm{C}$ (roxo) e do Si (azul) e nos estados $p$ do C (vermelho) e do Si (verde), em unidades de número de estados/eV. $\mathrm{E}_{\mathrm{v}}$ designa o topo da banda de valência, que foi deslocado para o zero de energia.

planar de SiC do tipo grafeno [69] e com o sistema AB'-SiC, apresentado anteriormente, podemos perceber que a banda é levemente perturbada pela interação entre camadas, mostrando que a interação inter-camadas é bem fraca. As larguras das bandas de valência e proibida ficam praticamente inalteradas, as bandas são duplicadas em relação à monocamada e parece que a degenerescência das bandas de energia do sistema $\mathrm{AB}^{\prime}$-SiC são quebradas quando a configuração passa a ser AB-SiC. É como se houvesse uma superposição das bandas individuais de cada camada, perturbadas pela interação fraca entre as camadas. 


\subsubsection{Estabilidade dinâmica}

Aplicando a metodologia de fônons, abordada no capítulo 2, obtivemos o espectro de fônos da bicamada AB-SiC. Utilizou-se a célula primitiva hexagonal e uma malha de pontos $q$ de $6 \times 6 \times 6$ para calcular as frequências dos modos normais de vibração da rede. Do mesmo modo que para o sistema AB'-SiC, este sistema apresenta 12 frequências normais de vibração, sendo 3 ramos acústicos e 9 ramos ópticos. A figura 4.11 mostra a dispersão de fônons obtida utilizando o funcional optB88-vdW.

Os três ramos com origem no ponto $\Gamma$ correspondem ao modos acústicos: um modo transversal TA e um modo longitudinal LA, ambos planares, e um modo ZA na direção perpendicular aos planos. Os outros nove correspondem aos ramos ópticos: três modos na direção perpendicular aos planos, um ZO* e dois ZO, três modos transversais planares, um TO* e dois TO e, os últimos três ramos,

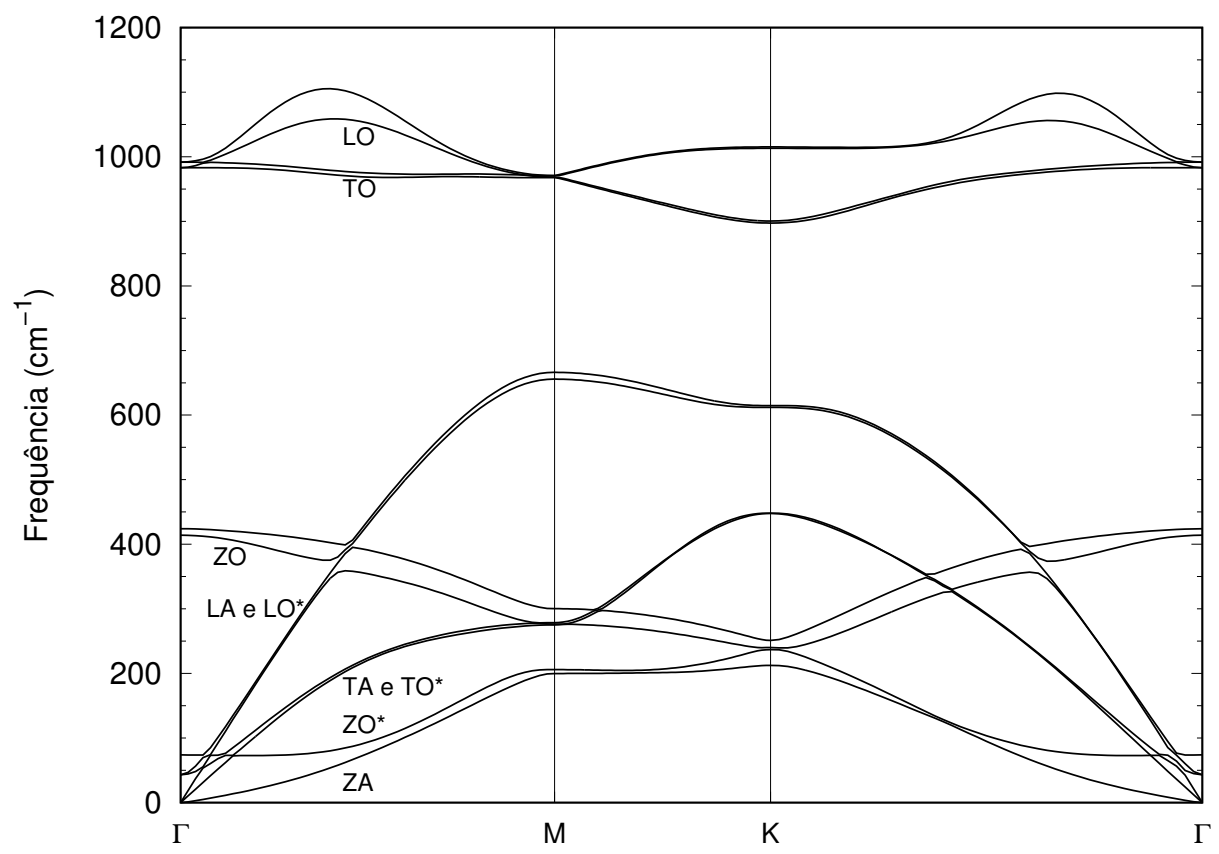

Figura 4.11: Dispersão de fônons da bicamada AB-SiC, obtida utilizando-se o funcional optB88-vdW, nos pontos e direções de alta simetria da primeira zona de Brillouin de uma rede hexagonal. 
Sistemas bidimensionais $\mathrm{SiC}$

são longitudinais planares, um LO* e dois LO. Os modos LO e TO apresentam frequências bem separadas das dos outros modos de vibração. O modo óptico fora do plano mistura-se com os modos acústicos. Estas características são encontradas em sistemas planares bidimensionais do tipo grafeno.

Os modos TA e LA apresentam uma variação linear em $q$ para $q \rightarrow 0$ no ponto $\Gamma$, enquanto o modo ZA apresenta uma dispersão quadrática em $q\left(q^{2}\right)$ na região próxima ao ponto $\Gamma$, a qual também é observada no grafeno [56]. Os modos identificados com asterisco, assim como na grafite (Cap. 3) são aqueles onde os dois átomos de uma das camadas oscilam juntos e em oposição de fase aos dois átomos da outra camada [56], muito parecido com o que ocorre com a bicamada de grafeno [72]. De qualquer modo, nossos resultados indicam que todos os modos têm frequência positiva, o que significa que a bicamada $\mathrm{AB}^{\prime}-\mathrm{SiC}$ é estável, assim como a monocamada planar de $\mathrm{SiC}$, o que nos permite continuar com nossa investigação e estudar a adsorção de Li nesta estrutura.

\subsubsection{Adsorção de um átomo de Li na estrutura AB-SiC}

Assim como para o caso da bicamada $\mathrm{AB}^{\prime}$-SiC, o teste da estabilidade estrutural da adsorção de um átomo de Li entre as folhas da bicamada AB-SiC foi efetuado com a utilização de uma supercélula $3 \times 3$, com 36 átomos, 18 átomos de $\mathrm{C}$ e 18 de Si. Vamos rotular este sistema de $\mathrm{AB}-\mathrm{Li} \mathrm{Si}_{18} \mathrm{C}_{18}$.

Utilizamos 5 diferentes configurações para iniciar as simulações, pois diferentemente da bicamada $\mathrm{AB}^{\prime}$-SiC, neste empilhamento existem dois tipos de configuração ponte, dois tipos de configuração central e um tipo de configuração intersticial.

Nas duas configurações ponte, o átomo de Li foi colocado entre as camadas, mais próximo de uma delas, ou no ponto médio da distância entre dois átomos de carbono de um mesmo anel, como na figura 4.12, ou no ponto médio da distância entre dois átomos de silício de um mesmo anel, mostrada na figura 4.13.

Nas duas configurações do tipo central, o átomo de Li foi introduzido na posição central da supercélula, tendo acima e abaixo um átomo de carbono e o centro de 

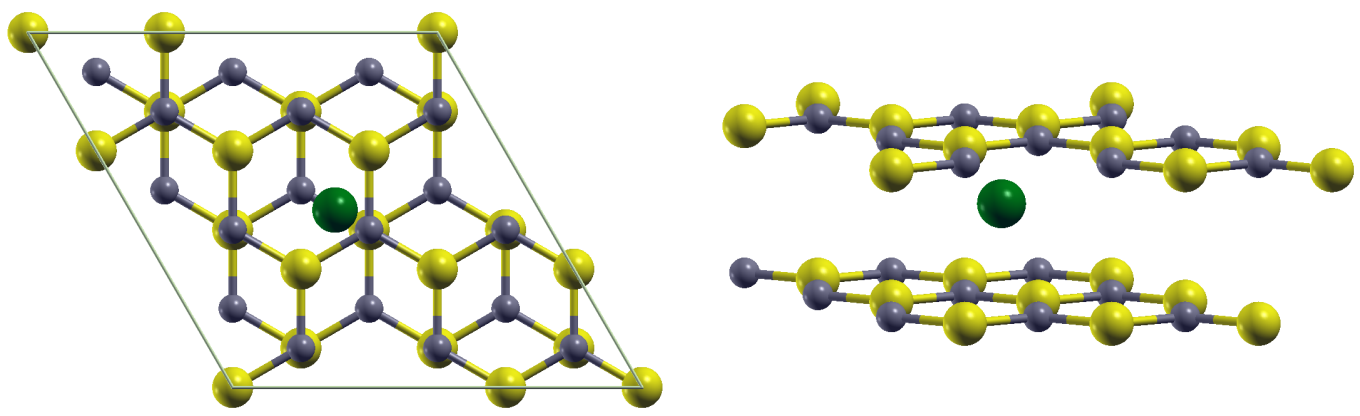

Figura 4.12: Ilustração da bicamada de SiC tipo grafite AB (AB-SiC), com um átomo de Li (esfera verde) na posição ponte, que é entre as camadas, mais próximo de uma delas, e no ponto médio da distância entre dois átomos de silício de um mesmo anel. As esferas cinzas representam átomos de $\mathrm{C}$ e as amarelas átomos de Si.

um hexágono, como na figura 4.14, ou tendo acima e abaixo um átomo de silício e o centro de um hexágono, como na figura 4.15. Na configuração intersticial, o átomo de Li foi colocado no ponto médio da distância entre um átomo de carbono e um átomo de silício, um em cada camada, como mostra a figura 4.16.

Utilizando o método de dinâmica molecular de célula variável [46], após o processo de relaxação total do sistema, sem nenhuma restrição de simetria ou confinamento, independente do tipo da configuração inicial, não houve estabilização estrutural, indicando que esta bicamada de $\mathrm{SiC}$ do tipo grafite não é capaz de
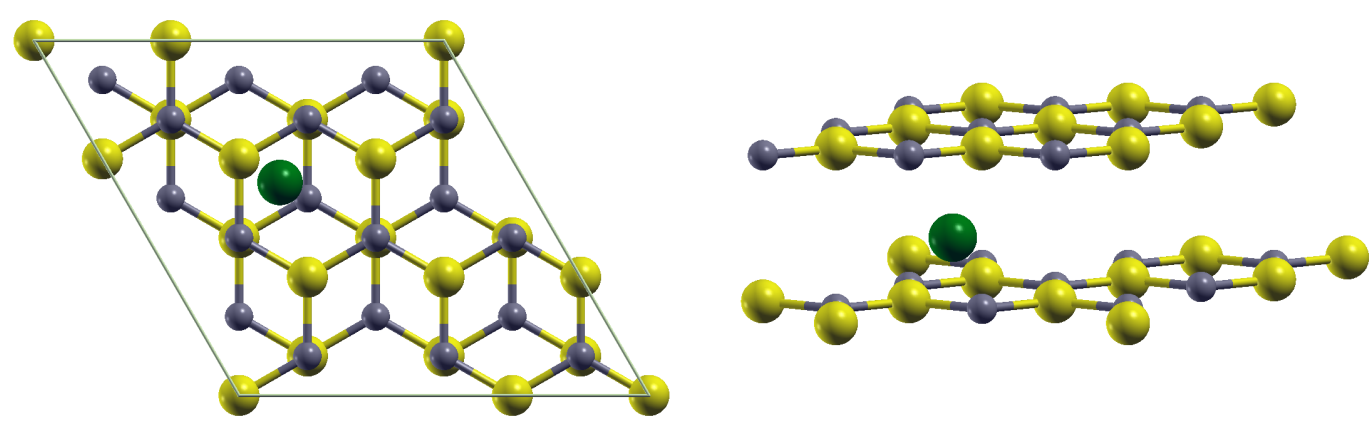

Figura 4.13: Ilustração da bicamada de SiC tipo grafite AB (AB-SiC), com um átomo de Li (esfera verde) na posição ponte, que é entre as camadas, mais próximo de uma delas, e no ponto médio da distância entre dois átomos de carbono de um mesmo anel. As esferas cinzas representam átomos de $\mathrm{C}$ e as amarelas átomos de Si. 

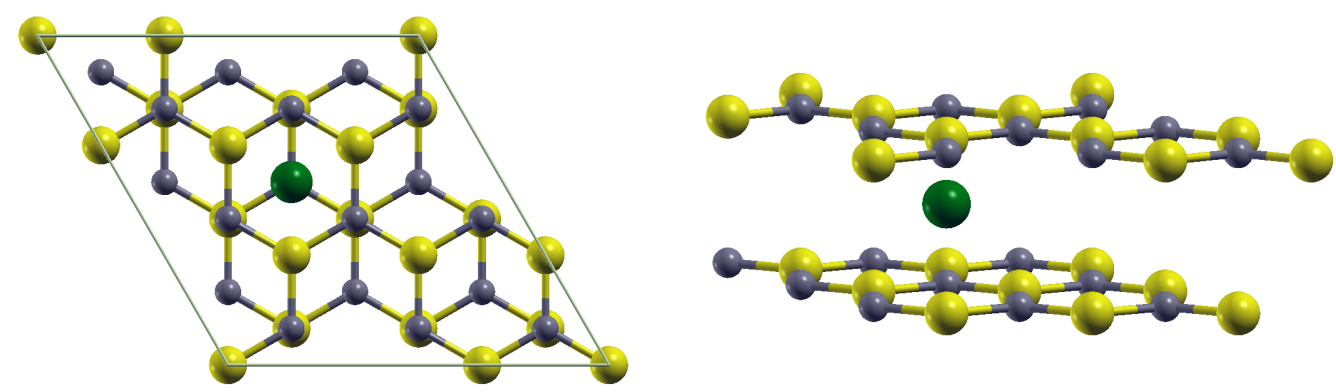

Figura 4.14: Ilustração da bicamada de SiC tipo grafite AB (AB-SiC), com um átomo de Li (esfera verde) na posição central da supercélula, a qual fica acima (abaixo) do centro de um hexágono de uma das camadas e abaixo (acima) da posição de um átomo de carbono da outra camada. As esferas cinzas representam átomos de $\mathrm{C}$ e as amarelas átomos de $\mathrm{Si}$.

adsorver um átomo de Li.

\subsection{Conclusão}

Neste capítulo foram estudadas as propriedades estruturais, eletrônicas e vibracionais das bicamadas $\mathrm{SiC}$ em dois empilhamentos distintos, $\mathrm{AB}$ e $\mathrm{AB}^{\prime}$. Os resultados mostram que ambas estruturas são semicondutoras de gap direto no ponto $\mathrm{K}$ e são dinamicamente estáveis, uma vez que a dispersão de fônons apresentou apenas
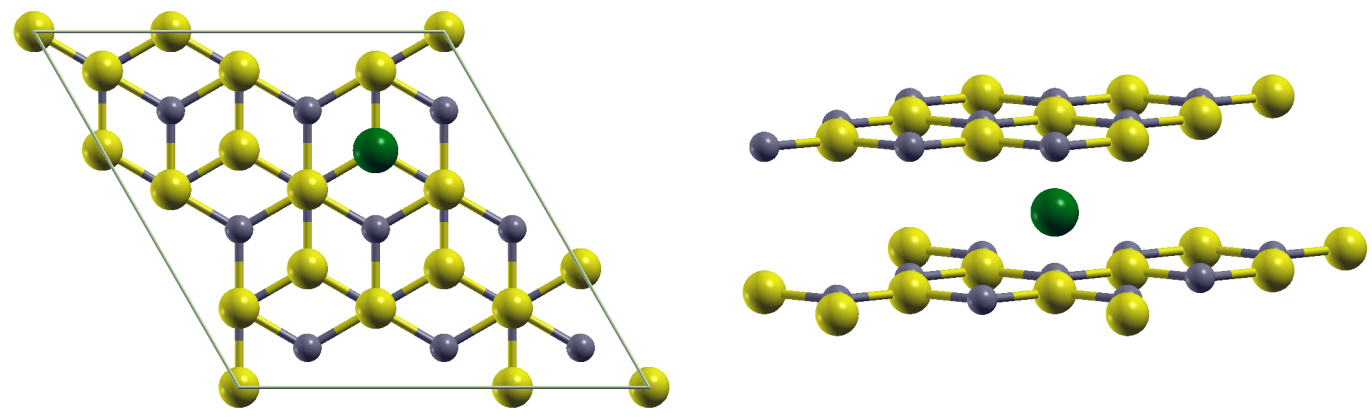

Figura 4.15: Ilustração da bicamada de $\mathrm{SiC}$ tipo grafite $\mathrm{AB}$ (AB-SiC), com um átomo de Li (esfera verde) na posição central da supercélula, a qual fica acima (abaixo) do centro de um hexágono de uma das camadas e abaixo (acima) da posição de um átomo de silício da outra camada. As esferas cinzas representam átomos de $\mathrm{C}$ e as amarelas átomos de $\mathrm{Si}$. 


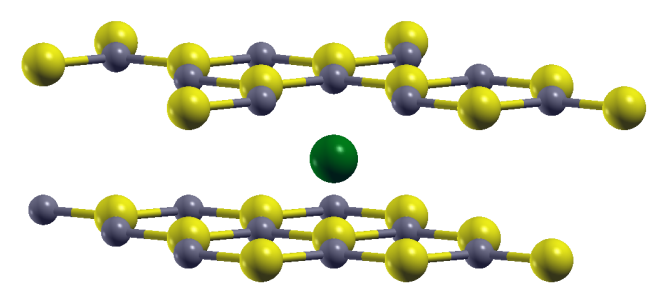

Figura 4.16: Ilustração da bicamada de SiC tipo grafite AB (AB-SiC), com um átomo de Li (esfera verde) na posição correspondente ao ponto médio da distância entre os átomos de Si e C, um em cada camada. As esferas cinzas representam átomos de $\mathrm{C}$ e as amarelas átomos de $\mathrm{Si}$.

frequências positivas. Investigou-se, então, a estabilidade da adsorção intersticial de um átomo de Li nestes materiais e foi observado que a bicamada $\mathrm{AB}^{\prime}$-SiC é capaz de adsorver um átomo de Li na posição central através de um processo de troca de elétrons entre as camadas hospedeiras e o átomo de Li. No entanto, embora a estrutura $\mathrm{AB}-\mathrm{SiC}$ seja energeticamente mais favorável em comparação a $\mathrm{AB}^{\prime}$-SiC, da ordem de 0,01 eV (apêndice A), a bicamada AB-SiC tem suas ligações quebradas com a adsorção intersticial de um átomo de Li, ou seja, não se estabiliza estruturalmente.

As distorções causadas pela introdução do átomo de Li na posição central da bicamada da $\mathrm{AB}^{\prime}-\mathrm{SiC}$ são pequenas. Essa é uma grande vantagem para que este sistema seja utilizado como ânodo de bateria de íons de Li, pois uma grande expansão do volume do material durante a carga/descarga pode levar a deformação e, consequentemente, levar a diminuição da sua vida útil. Além disso, a energia de ligação para a adsorção de um átomo de Li é de aproximadamente -1,8 eV, a qual é similar a encontrada no estudo teórico da adsorção de um átomo de Li na grafite. Portanto, este material tem características importantes para poder compor o ânodo de baterias de íons de Li. 



\section{Capítulo 5}

\section{Sistemas bidimensionais CN}

Como já mencionado no capítulo anterior, vários estudos estão sendo realizados para o desenvolvimento de novos materiais do tipo grafeno. A dopagem do grafeno com átomos de $\mathrm{N}$, onde se substitui átomos de $\mathrm{C}$ por $\mathrm{N}$, vem sendo estudada $\mathrm{e}$ aplicada a dispositivos, tais como LIBs, ultracapacitores e células combustíveis [76]. A máxima concentração de átomos de nitrogênio obtida experimentalmente é de 21,66 wt \% [77], o que corresponde a uma composição de $x=19,1 \%$ para a estrutura favo de mel $\mathrm{C}_{1-x} \mathrm{~N}_{x}$. No entanto, é possível alcançar, em teoria, uma concentração $x=37,5 \%$ sem que a estrutura se torne dinamicamente instável [78]. Além disso, um trabalho teórico recente reporta meios de conseguir uma concentração de $50 \%$ [79].

Neste capítulo são apresentados os resultados dos estudos das propriedades eletrônicas e estruturais e da estabilidade dinâmica de sistemas bidimensionais CN. Neste trabalho foram estudadas a folha de g-CN com uma estrutura planar, a folha de CNH que, diferentemente da g-CN, é buckled; e a bicamada de CN que é empilhada no formato $\mathrm{AB}^{\prime}$, a qual é similar a estrutura estudada no capítulo anterior, onde os átomos Si foram substituídos por átomos de $\mathrm{N}$.

As figuras 5.1, 5.2 e 5.3 mostram a folha g-CN, a bicamada de $\mathrm{CN}$ no formato $\mathrm{AB}^{\prime}$ e a folha $\mathrm{CNH}$, respectivamente, onde o átomo de carbono é representado pela cor cinza, o de nitrogênio pela cor azul e o de hidrogênio pela cor verde. 


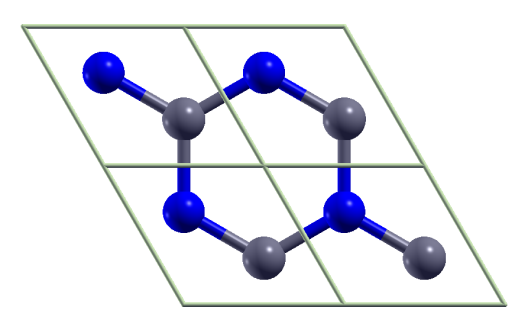

Figura 5.1: Ilustração da folha g-CN, que tem uma estrutura planar, mostrando quatro células primitivas com um átomo de carbono e um de nitrogênio em cada uma delas. O átomo de carbono está representado por uma esfera cinza e o de nitrogênio por uma azul.
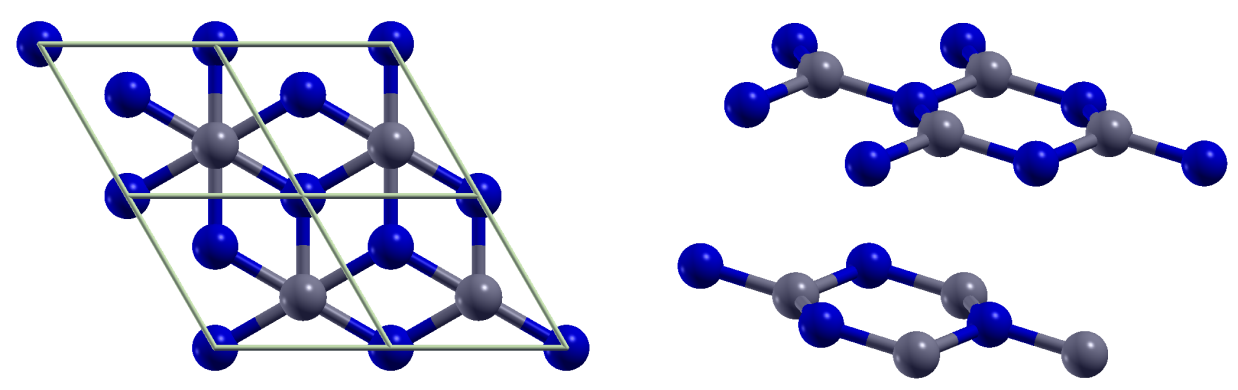

Figura 5.2: Ilustração da bicamada de $\mathrm{CN}$ com empilhamento tipo grafite $\mathrm{AB}^{\prime}$, onde os átomos de nitrogênio, esferas azuis, da camada $\mathrm{B}^{\prime}$ estão diretamente acima dos átomos de $\mathrm{N}$ da camada $\mathrm{A}$, enquanto os átomos de carbono, esferas cinzas, da camada $\mathrm{B}^{\prime}$ estão diretamente acima do centro dos hexágonos da camada A.
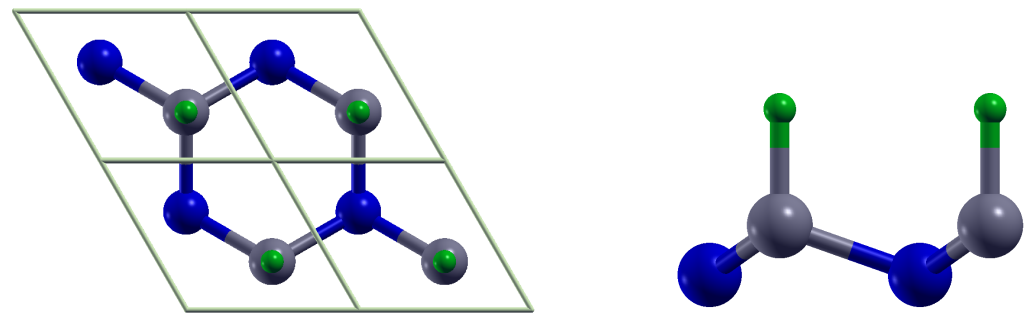

Figura 5.3: Ilustração da folha CNH, que tem uma estrutura buckled, mostrando, na figura da esquerda, quatro células primitivas com um átomo de carbono, um de nitrogênio e um de hidrogênio em cada uma delas. A figura da direita mostra uma perspectiva lateral. O átomo de carbono está representado por uma esfera cinza, o de nitrogênio por uma azul e o hidrogênio por uma verde. 


\subsection{Folha de CN tipo grafeno (g-CN)}

\subsubsection{Propriedades estruturais e eletrônicas}

A figura 5.1 mostra a folha g-CN que tem uma estrutura planar hexagonal, onde a célula primitiva contém 2 átomos na base, um de carbono e outro de nitrogênio. Os vetores primitivos da rede são $(1,0,0) a,(-1 / 2, \sqrt{3} / 2,0) a$ e $(0,0, c / a) a$, onde $a$ e $c$ são os parâmetros da rede. O átomo de carbono (esfera cinza) esta disposto na posição $(1 / 3,2 / 3,0)$ e o de nitrogênio (esfera azul) na posição $(2 / 3,1 / 3,0)$, em relação aos parâmetros de rede.

As propriedades estruturais da g-CN, dentro do esquema de supercélula, foram obtidas utilizando o método de dinâmica molecular de célula variável e o funcional optB88-vdW para o termo de exchange-correlação [46]. Para o valor de mínimo de energia total, o valor da constante de rede obtido foi $a=2,40 \AA$ e a distância de ligação C-N foi de $d_{\mathrm{C}-\mathrm{N}}=1,38 \AA$.

A partir dos valores teóricos encontrados para o parâmetro $a$, foi calculada a estrutura de bandas da estrutura g-CN, a qual é mostrada na figura 5.4, ao longo das principais direções de alta simetria da ZB, juntamente com as densidades de estados total (TDOS-Total Density of States) e projetadas (PDOS -Projected Density of States) nos orbitais do tipo $s$ e $p$ dos átomos de C e N.

Este material apresenta característica de metal, como pode ser observado na estrutura de bandas e nas DOS. A configuração eletrônica do N é [He] $2 \mathrm{~s}^{2} 2 \mathrm{p}^{3}$ e a do C é $[\mathrm{He}] 2 \mathrm{~s}^{2} 2 \mathrm{p}^{2}$ e, ao se agruparem para formar a folha CN, os estados eletrônicos na região do nível de Fermi apresentam características dos orbitais do tipo $p$ dos átomos de carbono e nitrogênio. 

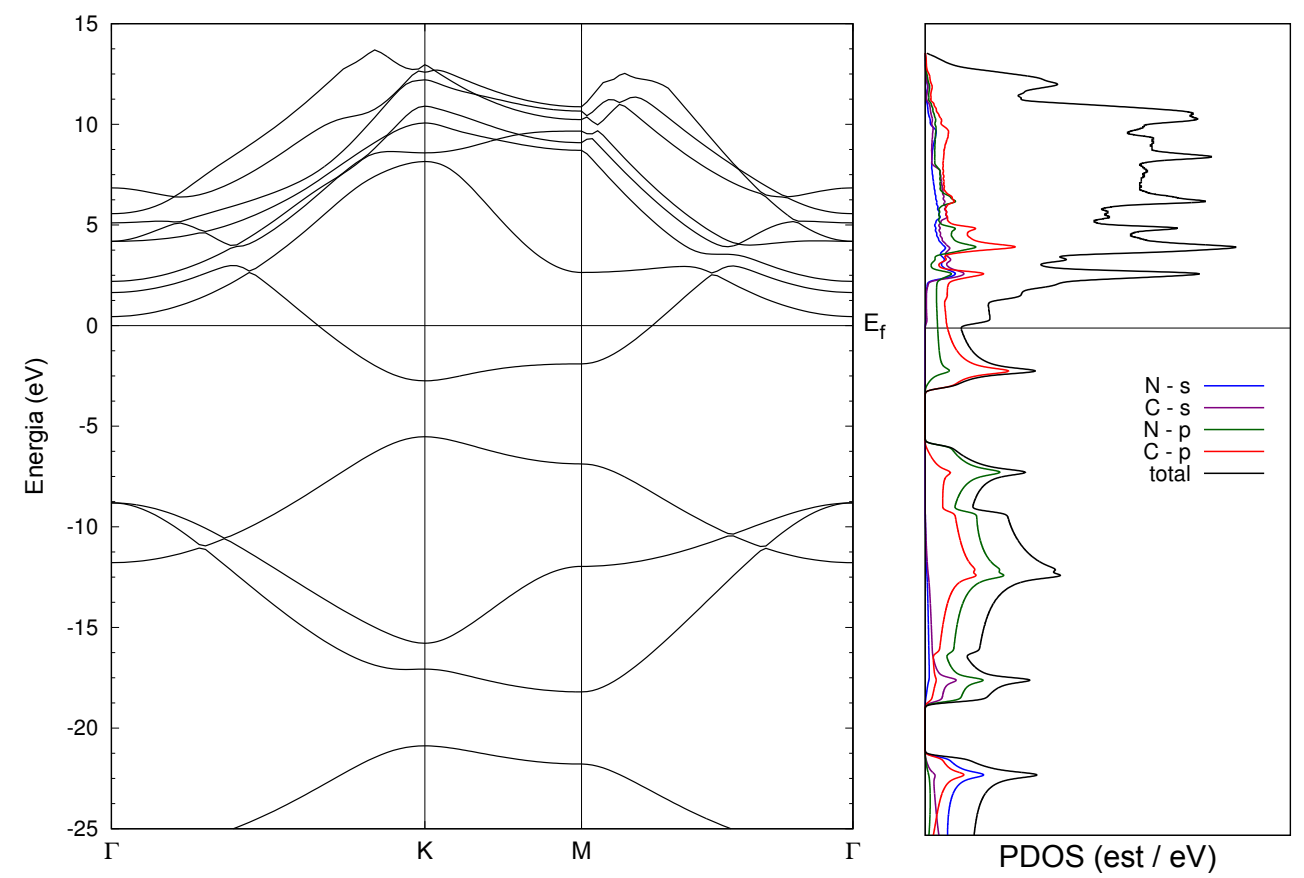

Figura 5.4: Estrutura de bandas de energia da folha g-CN, ao longo das principais direções de alta simetria da ZB, e as densidades de estados total (preto) e projetadas nos orbitais do tipo $s$ do $\mathrm{C}$ (roxo) e do $\mathrm{N}$ (azul) e nos orbitais do tipo $p$ do $\mathrm{C}$ (vermelho) e do $\mathrm{N}$ (verde), em unidades de número de estados/eV. $\mathrm{E}_{\mathrm{f}}$ é a energia de Fermi.

\subsubsection{Estabilidade dinâmica}

Para se estudar o espectro de fônons foi usada a célula primitiva hexagonal (Fig. 5.1) e uma malha de pontos $q$ de $8 \times 8 \times 2$ para calcular as frequências dos modos normais de vibração da folha.

Como a base possui 1 átomo de $\mathrm{C}$ e 1 átomo de $\mathrm{N}$, isso corresponde a 6 graus de liberdade e 6 frequências normais de vibração, sendo 3 ramos acústicos e 3 ramos ópticos. A figura (5.5) mostra a dispersão de fônons utilizando o funcional optB88-vdW, a qual esta de acordo com a referência [80].

Os três ramos com origem no ponto $\Gamma$ correspondem ao modos acústicos: um modo transversal TA e um modo longitudinal LA, ambos no plano da folha, e um modo ZA na direção perpendicular à folha. Os outros três correspondem aos ramos ópticos: um na direção perpendicular ao plano ZO e dois modos no plano 


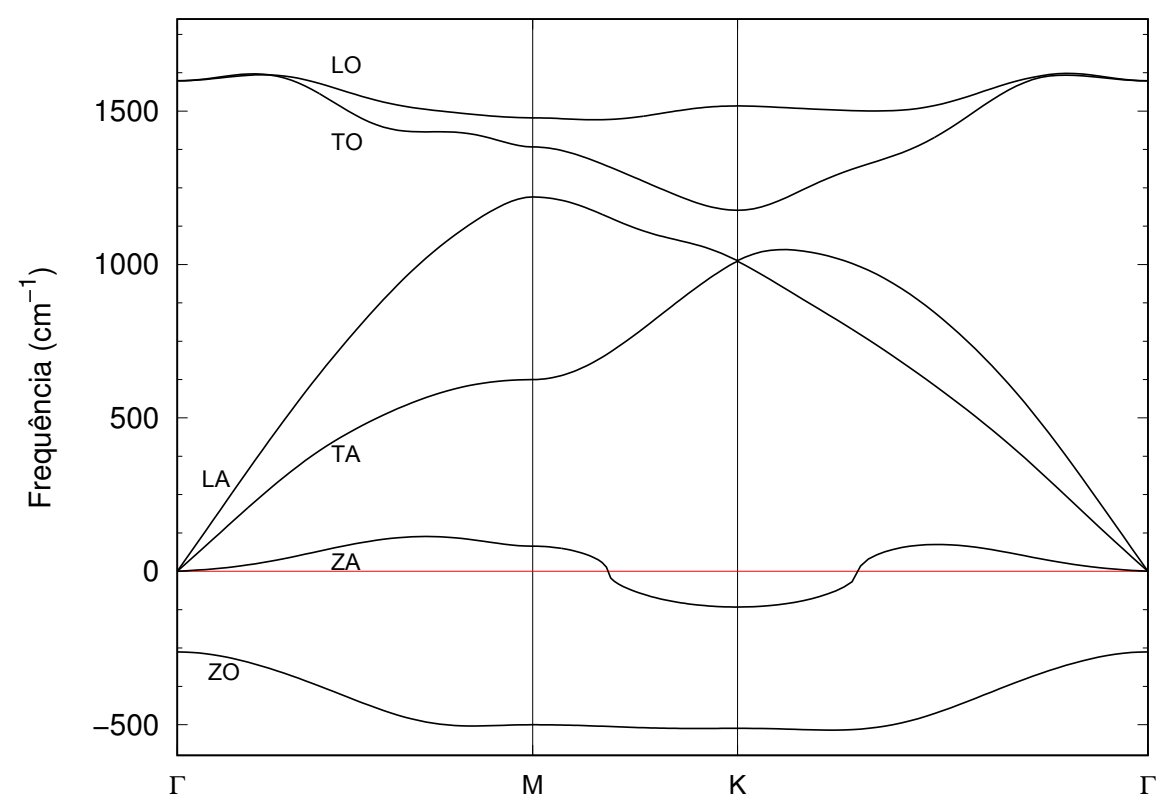

Figura 5.5: Dispersão de fônons da folha de g-CN, obtida utilizando-se o funcional optB88-vdW, nos pontos e direções de alta simetria da primeira zona de Brillouin de uma rede hexagonal.

da folha, um transversal TO e um longitudinal LO. Como esperado, Os modos TA e LA apresentam uma variação linear em $q$ para $q \rightarrow 0$ no ponto $\Gamma$, assim como para as outras estruturas já estudas neste trabalho. No entanto, os modos ZA e ZO apresentam frequências imaginárias que foram representadas por valores negativos na figura (5.5), indicando instabilidade dinâmica e, portanto, difícil de ser sintetizado em laboratório.

Um estudo teórico recente mostrou que estruturas de grafeno com concentração de átomos de nitrogênio maiores que 3/8 (37,5\%) são instáveis [78]. No entanto, um outro estudo apresenta uma maneira de solucionar a instabilidade para concentração de $1 / 2(50 \%)$, que é equivalente a estrutura proposta neste trabalho, dopando a estrutura com buracos e aplicando tensão no sistema [79]. Então, as estruturas propostas a seguir são tentativas de encontrar um modo de estabilizar a folha de CN. 


\subsection{Bicamada de $\mathrm{CN}$ tipo grafite tipo $\mathrm{AB}^{\prime}$}

\subsubsection{Propriedades estruturais e eletrônicas}

Como mostrado na figura 5.2, a célula primitiva foi construída com 4 átomos, dois de $\mathrm{C}$ e dois de Si. Os vetores primitivos da rede são $(1,0,0) a,(-1 / 2, \sqrt{3} / 2,0) a$ e $(0,0, c / a) a$, onde $a$ e $c$ são os parâmetros da rede, com $c=15 \AA$, valor mantido constante durante todo o processo de obtenção das propriedades do sistema. Os átomos de nitrogênio estão nas posições $(1 / 3,2 / 3,1 / 100)$ e $(0,0,21 / 100)$; os átomos de carbono estão nas posições $(2 / 3,1 / 3,0)$ e $(2 / 3,1 / 3,22 / 100)$, em relação aos parâmetros de rede $a$ e $c$.

O valor obtido para a constante de rede otimizada $a$ é de $2,39 \AA$, para a distância de ligação C-N no plano da folha é de 1,39 Å, para a distância C-C entre camadas é de $3,30 \AA$ e para a distância $\mathrm{C}-\mathrm{N}$ no eixo z, $\Delta z$, é de $0,15 \AA$, indicando que a estrutura é levemente buckled, como mostrada no lado direito aa figura 5.2. Os valores teóricos supracitados foram calculados com o método de dinâmica molecular de célula variável [46]. A figura 5.6 mostra a estrutura de faixas de energia da bicamada AB'-CN e as densidades de estados total (TDOS-Total Density of States) e projetadas (PDOS - Projected Density of States) nos estados do tipo $s$ e $p$ dos átomos de $\mathrm{C}$ e $\mathrm{N}$.

Observa-se que, assim como no caso da folha g-CN, que o sistema é metálico. Comparando este resultado com aquele da monocamada de CN do tipo grafeno, podemos perceber que a estrutura de bandas é praticamente como se houvesse uma superposição das bandas individuais de cada camada, levemente perturbada pela interação entre camadas, mostrando que a interação inter-camadas é bem fraca. Os estados eletrônicos na região do nível de Fermi apresentam características dos orbitais do tipo $p$ dos átomos de carbono e nitrogênio. 

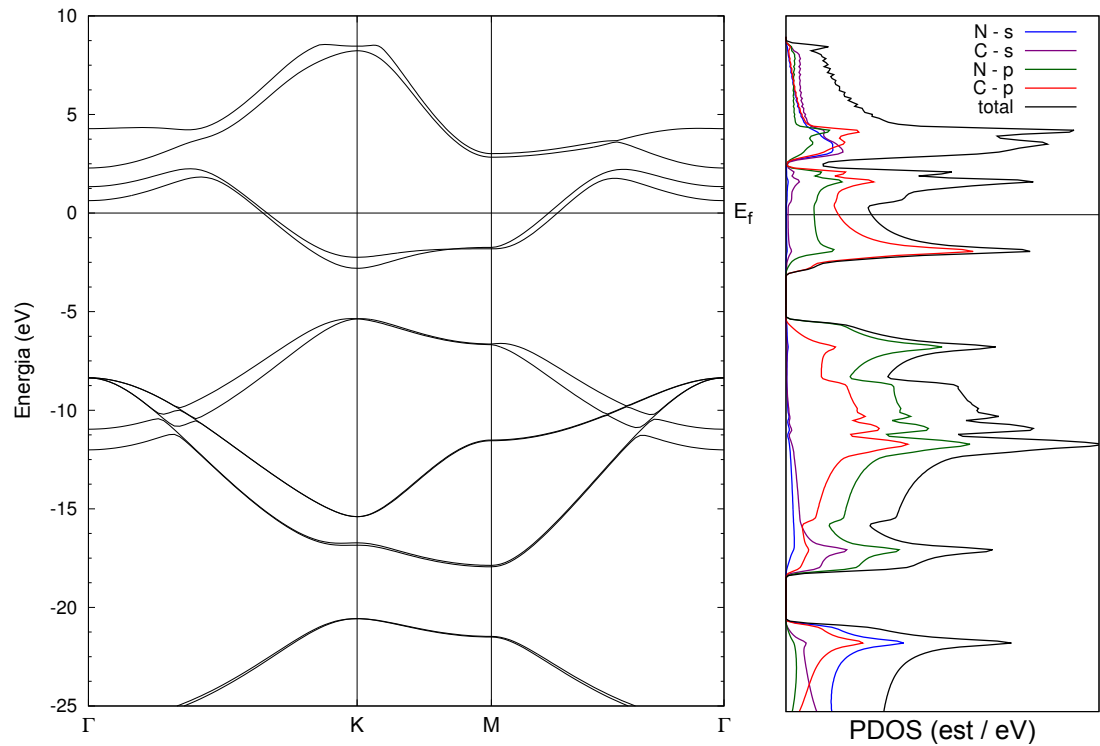

Figura 5.6: Estrutura de bandas de energia do sistema $\mathrm{AB}^{\prime}-\mathrm{CN}$, ao longo das principais direções de alta simetria da $\mathrm{ZB}$, e as densidades de estados total (preto) e projetadas nos orbitais do tipo $s$ do $\mathrm{C}$ (roxo) e do $\mathrm{N}$ (azul) e nos orbitais do tipo $p$ do $\mathrm{C}$ (vermelho) e do $\mathrm{N}$ (verde), em unidades de número de estados/eV. $\mathrm{E}_{\mathrm{f}}$ é a energia de fermi.

\subsubsection{Estabilidade dinâmica}

Nós aplicamos a metodologia de fônons, abordada no capítulo 2, para estudar o espectro de fônons da bicamada $\mathrm{AB}^{\prime}-\mathrm{CN}$. Utilizou-se a célula primitiva hexagonal e uma malha de pontos $q$ de $8 \times 8 \times 2$. Esta estrutura possui uma base com quatro átomos, dois de $\mathrm{C}$ e dois de $\mathrm{N}$, o que corresponde a 12 graus de liberdade e 12 frequências de vibração, sendo 3 ramos acústicos e 9 ramos ópticos. A figura (5.7) mostra a dispersão de fônons obtida com a utilização do funcional optB88-vdW.

Os três ramos com origem no ponto $\Gamma$ correspondem ao modos acústicos. Assim como para a folha g-CN, os modos TA e LA continuam apresentando uma variação linear em $q$ para $q \rightarrow 0$ no ponto $\Gamma$. O modo ZA, que é perpendicular ao plano das folhas, apresenta frequências imaginárias. Os outros nove correspondem aos ramos ópticos: três modos na direção perpendicular ao plano das folhas, um ZO* e dois ZO, três modos transversais planares, um TO* e dois TO e, os últimos três ramos, são longitudinais planares, um LO* e dois LO. Os modo óptico ZO passa a 


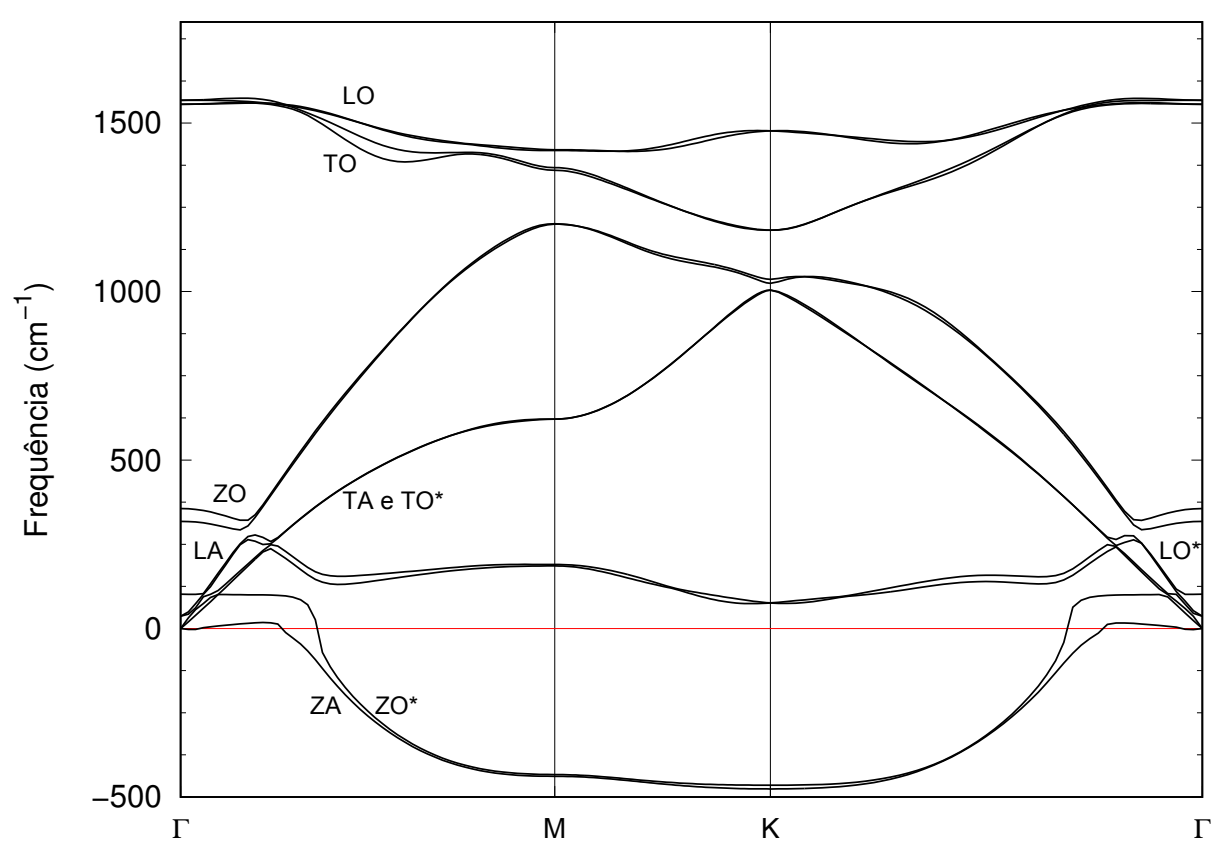

Figura 5.7: Dispersão de fônons da bicamada $\mathrm{AB}^{\prime}-\mathrm{CN}$, obtida utilizando-se o funcional optB88-vdW, nos pontos e direções de alta simetria da primeira zona de Brillouin de uma rede hexagonal.

apresentar apenas frequências positivas, quando comparamos com a dispersão da folha g-CN, mas o modo ZO*, que é caracterizado pela oscilação em defasagem dos dois átomos de uma das camadas em relação aos dois átomos da outra camada, apresenta frequências imaginárias. Portanto, a proposta de empilhar as folhas como um modo de estabilizar o folha $\mathrm{CN}$ do tipo grafite $\mathrm{AB}^{\prime}$ não pode ser uma alternativa à dopagem por buracos para tentar solucionar o problema dos elétrons excedentes em átomos de N [79], pois continua indicando instabilidade dinâmica.

\subsection{Folha de CNH}

\subsubsection{Propriedades estruturais e eletrônicas}

A célula primitiva da folha CNH contém uma base de 3 átomos, um de carbono, um de nitrogênio e outro de hidrogênio. Do lado esquerdo da figura 5.3 estão ilustradas quatro células primitivas. Os vetores primitivos da rede são $(1,0,0) a$, 
$(-1 / 2, \sqrt{3} / 2,0) a$ e $(0,0, c / a) a$, onde $a$ e $c$ são os parâmetros da rede, com $c=15 \AA$, mantido fixo. As propriedades estruturais da folha $\mathrm{CNH}$ foram simuladas utilizando o funcional optB88-vdW para o termo de exchange-correlação e um método de dinâmica molecular de célula variável [46]. Após o processo de relaxação total do sistema, sem nenhuma restrição de simetria ou confinamento planar, a folha de $\mathrm{CNH}$, diferentemente da g-CN, sofre uma deformação na estrutura, inicialmente plana, apresentando uma configuração buckled.

O sítio do átomo de carbono é na posição $(2 / 3,1 / 3,3 / 100)$, o do nitrogênio na posição $(1 / 3,2 / 3,0)$ e o do hidrogênio na posição $(2 / 3,1 / 3,13 / 100)$. Para o valor mínimo de energia total encontramos o valor da constante de rede de 2,38 A, uma distância de ligação $\mathrm{C}-\mathrm{N}, d_{\mathrm{C}-\mathrm{N}}$ de 1,46 A, uma distância de ligação C-H de $d_{\mathrm{C}-\mathrm{H}}=1,14 \AA$ e a distância de buckling $\Delta z=0,48 \AA$. A figura 5.3 mostra a representação do arranjo dos átomos da estrutura $\mathrm{CNH}$ em duas visões diferentes (topo e lateral).

Utilizando o valor do parâmetro de rede $a$ determinado teoricamente, obtivemos a estrutura de faixas de energia da estrutura $\mathrm{CNH}$, mostrada na figura 5.8, ao longo das principais direções de alta simetria da ZB, juntamente com as densidades de estados total (TDOS-Total Density of States) e projetadas (PDOS - Projected Density of States) nos estados do tipo $s$ e $p$ dos átomos de $\mathrm{C}$ e $\mathrm{N}$ e do orbital do tipo $s$ do H. O topo da banda de valência $\left(\mathrm{E}_{\mathrm{v}}\right)$ foi tomado como energia de referência e foi deslocado para o zero de energia.

A estrutura de bandas e a DOS mostram que o sistema CNH é um material isolante. O gap é indireto com $\mathrm{E}_{g}=4,72 \mathrm{eV}$, onde o topo da banda de valência está na direção $\Gamma-\mathrm{K}$ e o fundo da banda de condução no ponto $\Gamma$. O topo da banda de valência é composto, primordialmente, pelos estados do tipo $p$ do átomo de $\mathrm{N}$, com pequena contribuição dos estados do tipo $s$ do átomo de H. Por outro lado, os estados que compõem a banda de condução, são estados do tipo $p$ do átomo de $\mathrm{C}$ e $s$ do átomo de $\mathrm{H}$. 

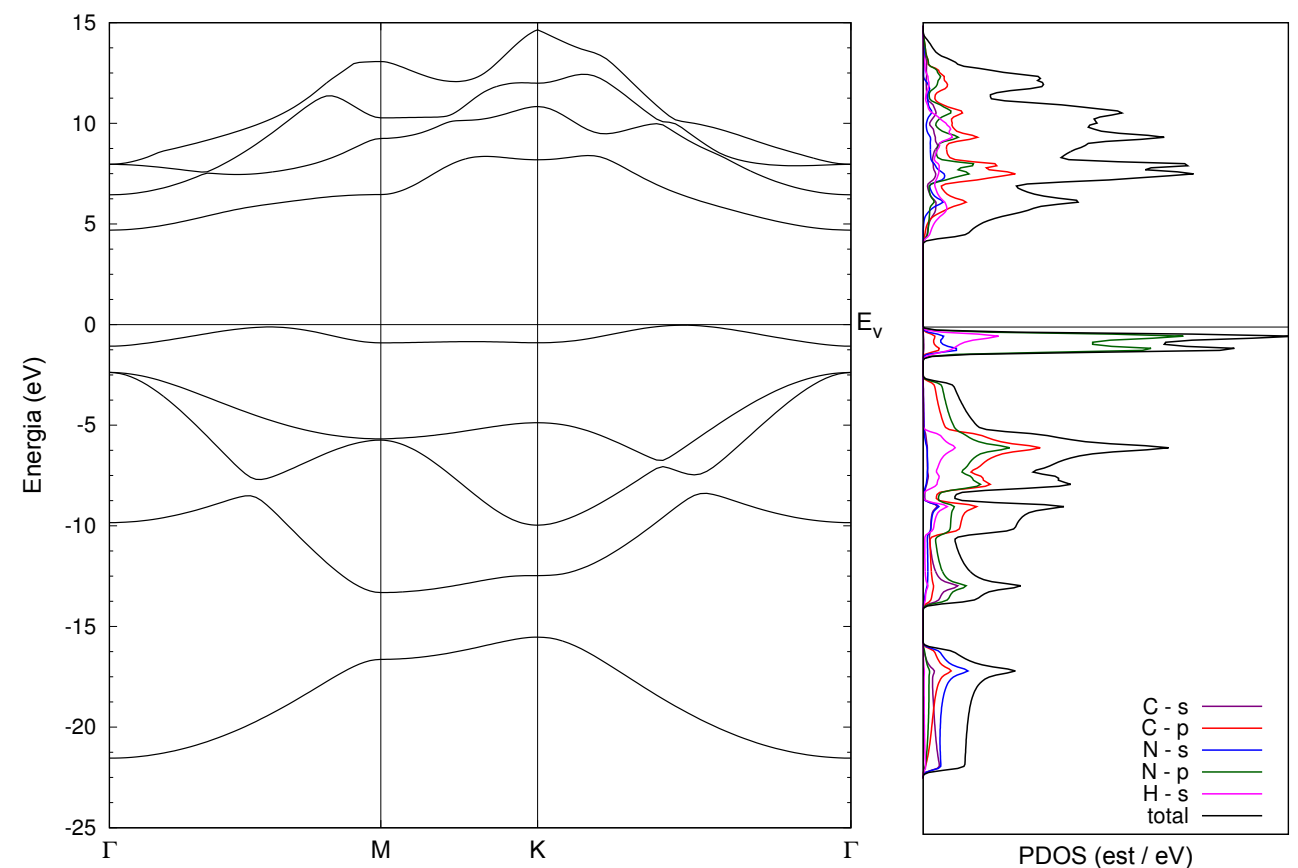

Figura 5.8: Estrutura de bandas de energia da folha $\mathrm{CNH}$, ao longo das principais direções de alta simetria da ZB, e as densidades de estados total (preto) e projetadas nos orbitais do tipo $s$ do $\mathrm{C}$ (roxo), do $\mathrm{N}$ (azul) e do $\mathrm{H}$ (rosa), e nos orbitais do tipo $p$ do $\mathrm{C}$ (vermelho) e do $\mathrm{N}$ (verde), em unidades de número de estados/eV. $\mathrm{E}_{\mathrm{v}}$ designa o topo da banda de valência, que foi deslocado para o zero de energia.

\subsubsection{Estabilidade dinâmica}

Para se estudar o espectro de fônons do sistema $\mathrm{CNH}$, utilizou-se a célula primitiva hexagonal (Fig. 5.3) e uma malha de pontos $q$ de $8 \times 8 \times 2$ para calcular as frequências dos modos normais de vibração da da folha. Como a estrutura possui uma base com três átomos, um de $\mathrm{C}$, um de $\mathrm{N}$ e um de $\mathrm{H}$, existem 9 graus de liberdade e 9 frequências de vibração, sendo 3 ramos acústicos e 6 ramos ópticos. A figura (5.9) mostra a dispersão de fônons obtida utilizando o funcional optB88$\mathrm{vdW}$.

Os três ramos com origem no ponto $\Gamma$ correspondem aos modos acústicos: um modo transversal TA e um modo longitudinal LA, ambos planares, e um modo ZA na direção perpendicular aos planos. Os outros seis correspondem aos ramos ópticos: um modo ZO na direção perpendicular ao plano, dois modos no plano, 
um longitudinal LO e um transversal TO e outros três modos normais de vibração associados ao átomo de $\mathrm{H}$ [81]; dois modos bending LB e TB e um modo stretching ZS de maior frequência. Estas frequências mais altas relacionadas ao hidrogênio também são observadas no grafano (grafeno hidrogenado) [82].

Embora a estrutura CN tipo grafeno (g-CN) não seja dinâmicamente estável, ou seja, possua frequências imaginárias (Fig. 5.5), a introdução de átomos de $\mathrm{H}$ ligados aos átomos de $\mathrm{C}$ torna a estrutura dinâmicamente estável, pois todas as frequências são positivas. Portanto, a princípio, o sistema CNH pode ser sintetizado em laboratório, pois sua entalpia de formação é de $0,5 \mathrm{eV}$, implicando que o crescimento de uma folha $\mathrm{CN}$ em ambiente rico em hidrogênio seria uma maneira de solucionar a instabilidade do sistema g-CN para concentração de 1/2 (50\%).

Esperamos, no futuro, investigar a possibilidade deste sistema ser estável estruturalmente e dinamicamente com a adsorção de átomos de Li.

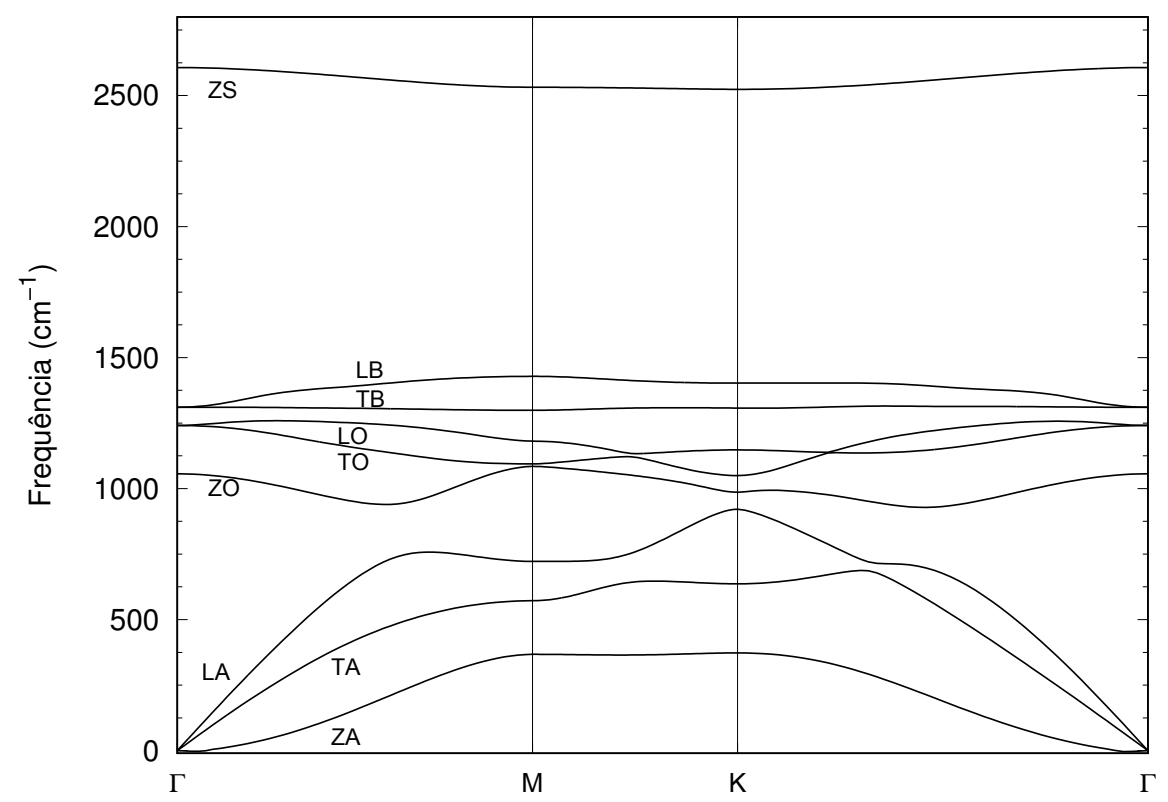

Figura 5.9: Dispersão de fônons da folha de CNH, obtida com o uso do funcional optB88-vdW, nos pontos de alta simetria da primeira zona de Brillouin de uma rede hexagonal. 



\section{Capítulo 6}

\section{Conclusões}

Neste trabalho foram estudadas as propriedades físicas de nanoestruturas do tipo grafeno utilizando cálculos ab initio baseados na teoria do funcional da densidade, onde se utilizou o método PAW e aproximação van der Waals (optB88-vdW). O primeiro passo foi estudar a grafite e o grafeno, onde o objetivo foi verificar se o método escolhido reproduzia adequadamente as propriedades estruturais e eletrônicas. Foram obtidos valores para os parâmetros de rede da grafite $(a=2,47 \AA$ e $c=6,68$ $\AA)$ e do grafeno $(a=2,47 \AA)$, com estes valores se calculou as estruturas de bandas e as dispersões de fônons de ambas estruturas. Os valores estão, dentro do que é esperado para cálculos desta natureza, em acordo com valores experimentais e teóricos.

Estudou-se, então, sistemas bidimensionais $\mathrm{SiC}$ em duas fases distintas (bicamada tipo grafite no formato $\mathrm{AB}$ e $\mathrm{AB}^{\prime}$ ). Para a estrutura $\mathrm{AB}^{\prime}$ foram calculados o parâmetro de rede $a$, distância de ligação Si-C, gap de energia e a distância entre camadas $d$ com duas aproximações diferentes (LDA e optB88-vdW). O parâmetro de rede encontrado foi $a=3,07 \AA$, distância de ligação Si-C foi 1,77 $\AA$, gap de energia $\mathrm{E}_{g}=1,514 \mathrm{eV}$ e a distância entre camadas $d=3,41 \AA$, quando se usou a LDA. Os valores obtidos com o cálculo LDA, para as propriedades estruturais e eletrônicas, estão em acordo com valores teóricos da literatura. No entanto, sabe-se que cálculos LDA não descrevem corretamente as interações eletrônicas de longo alcance, responsáveis pelas forças de van der Waals (vdW). Com a aproximação 
optB88-vdW, o parâmetro de rede encontrado foi $a=3,10 \AA$, distância de ligação Si-C foi $1,79 \AA$, gap de energia $\mathrm{E}_{g}=1,653 \mathrm{eV}$ e a distância entre camadas $d=3,60$ A. No empilhamento AB com o funcional optB88-vdW, o parâmetro de rede encontrado foi $a=3,10 \AA$, distância de ligação Si-C foi 1,79 A, gap de energia $\mathrm{E}_{g}=1,896 \mathrm{eV}$ e a distância entre camadas $d=3,46 \AA$ Com estes valores teóricos obtidos para as duas estruturas, calculou-se a estrutura de bandas, a densidade de estados projetada (PDOS) e a dispersão de fônons. As frequências obtidas no estudo da estabilidade dinâmica (dispersão de fônons) de ambas as estruturas foram positivas, indicando que estes sistemas são dinamicamente estáveis. Verificou-se que a estrutura $\mathrm{AB}$ é energeticamente mais favorável em relação a estrutura $\mathrm{AB}^{\prime}$ na ordem de $0,01 \mathrm{eV}$. O próximo passo foi testar a estabilidade na adsorção de um átomo de Li entre as camadas de ambas estruturas. Embora a estrutura AB seja mais estável em comparação a estrutura $\mathrm{AB}^{\prime}$ sem o átomo de $\mathrm{Li}$, a $\mathrm{AB}$ não é capaz de adsorver um átomo $\mathrm{Li}$, enquanto que a $\mathrm{AB}^{\prime}$ consegue adsorver em uma posição intersticial acima do centro do hexágono. As distorções causadas pela introdução do átomo de Li na posição central da bicamada da AB'-SiC são pequenas indicando, assim, uma menor deterioração durante os ciclos de carga/descarga. Além disso, a energia de ligação para a adsorção de um átomo de Li é de aproximadamente -1,8 eV, a qual é similar a encontrada no estudo teórico da adsorção de um átomo de Li na grafite. Portanto, este material tem características importantes para compor o ânodo de baterias de íons de Li.

Um outro sistema bidimensional estudado foi o g-CN, que possui uma estrutura planar. O parâmetro de rede encontrado foi $a=2,40 \AA$ e distância de ligação C-N é 1, $38 \AA$. Com estes valores, foi obtida a estrutura de bandas, a PDOS e a dispersão de fônons. A partir da estrutura de bandas e da PDOS, notou-se que o material apresenta características de metal. O estudo da estabilidade dinâmica mostrou que a estrutura não é estável, pois apresentou frequências imaginárias para os ramos ZA e ZO. Um estudo realizado recentemente tentou resolver o problema da estabilidade com dopagem (retirada de elétrons do sistema) e aplicação de tensão na estrutura [79]. Aqui neste trabalho, tentou-se montar uma bicamada de CN 
no formato $\mathrm{AB}^{\prime}$, esta estrutura ainda apresentou frequências imaginárias, porém, diferentemente da folha g-CN, o ramo ZO ficou totalmente positivo. Os valores obtidos para a bicamada $\mathrm{AB}^{\prime}-\mathrm{CN}$ foram $a=2,39 \AA$, a distância de ligação C-N foi $1,39 \AA$, a distância C-C entre camadas foi de 3,30 $\AA$ e $\Delta z=0,15 \AA$ (esta estrutura é levemente buckled). Esta estrutura, assim como a g-CN, tem características de metal.

Uma solução encontrada para se estabilizar a estrutura foi hidrogenar o sistema. Esta estrutura, chamada neste trabalho de CNH, apresentou todas as frequências positivas na dispersão de fônons, indicando estabilidade dinâmica. O parâmetro de rede encontrado foi $a=2,38 \AA$, a distância de ligação C-N é $1,46 \AA$ e a distância de ligação C-H é $1,14 \AA$, esta estrutura é buckled com $\Delta z=0,48 \AA$. A partir da estrutura de bandas e da PDOS calculadas com os parâmetros teóricos obtidos, notou-se que o material apresenta características de isolante. Além disso, o cálculo da entalpia de formação resultou numa energia de $0,5 \mathrm{eV}$, implicando que o sistema CNH pode ser sintetizado em laboratório em ambiente rico em hidrogênio, solucionando assim a instabilidade do sistema g-CN para concentração de 1/2 (50\%). 



\section{Apêndice A}

\section{Energia de Formação}

\section{A.1 Energia de Formação}

\section{A.1.1 Potencial Químico}

A entropia total $S$ de um sistema homogêneo é função de sua energia interna $U$, do seu volume $V$ e do número total $N$ de partículas. Se o sistema contiver partículas de várias espécies, devemos especificar o número $n_{i}$ de cada espécie $i$ de partícula, sendo

$$
S=S\left(U, V, n_{1}, n_{2}, \ldots, n_{i}, n_{j}, \ldots, n_{n}\right) .
$$

Uma combinação da primeira lei da termodinâmica $(d Q=d U+p d V)$ com a segunda lei $(d S=đ Q / T)$, para sistemas reversíveis, permite escrever para a entropia do sistema a equação diferencial nas variáveis $U, V$ e no número de partículas $n_{i}$

$$
T d S=d U+p d V-\sum_{j} \mu_{j} d n_{j}
$$

As equações diferenciais para a entalpia $H=U+p V$, energia livre de Helmoltz $F=U-T S$ e energia de Gibbs $G=H-T S$, passarão a conter também a parcela $\sum_{j} \mu_{j} d n_{j}$, quando for permitida uma variação no número de partículas das diferentes espécies, de modo que 


$$
\begin{aligned}
& d H=T d S+V d p+\sum_{j} \mu_{j} d n_{j}, \\
& d F=-S d T-p d V+\sum_{j} \mu_{j} d n_{j}, \\
& d G=-S d T+V d p+\sum_{j} \mu_{j} d n_{j},
\end{aligned}
$$

e, com isso, a variável $\mu$ poderá ser expressa em termos destes potenciais termodinâmicos, dependendo da escolha das variáveis independentes mais convenientes para o problema a ser tratado. Assim,

$$
\begin{aligned}
& \left.\mu_{j}=\frac{\partial U}{\partial n_{i}}\right)_{S, V, n_{j}^{\prime}}, \\
& \left.\mu_{j}=\frac{\partial H}{\partial n_{i}}\right)_{S, p, n_{j}^{\prime}}, \\
& \left.\mu_{j}=\frac{\partial F}{\partial n_{i}}\right)_{T, V, n_{j}^{\prime}}, \\
& \left.\mu_{j}=\frac{\partial G}{\partial n_{i}}\right)_{T, p, n_{j}^{\prime}} .
\end{aligned}
$$

Quando utilizamos processos em que se mantêm a pressão e a temperatura constantes, a última relação, expressão (A.9), é a mais conveniente.

Para analisar mais detalhadamente a expressão (A.9), imaginemos que o sistema tenha variado por um valor fixo $\zeta$. Portanto, todas as quantidades extensivas, como volume $V$, entropia $S$ e o número de partículas $n_{i}$ serão também multiplicadas pelo fator $\zeta$, enquanto que as quantidades intensivas, como temperatura $T$, pressão $p$ e os potencias químicos $\mu_{i}$ permanecerão constantes. Vemos, portanto, através da equação A.9, que a energia de Gibbs $G$ passa a ser multiplicada por $\zeta$, mostrando que $G$ deve ser uma função homogênea de primeiro grau nos $n_{i}$ 's: 


$$
G\left(p, T, \zeta n_{i}\right)=\zeta G\left(p, T, n_{i}\right)
$$

Aplicando a regra de Euler para funções homogêneas, ou seja, diferenciando em relação a $\zeta$ e impondo $\zeta=1$, obtemos para a energia de Gibbs:

$$
\left.G=\sum_{i} n_{i} \frac{\partial G}{\partial n_{i}}\right)_{T, p, n_{j}^{\prime}} .
$$

Combinando as equações A.9 e A.11 temos que

$$
G=\sum_{i} n_{i} \mu_{i}
$$

As variáveis $\mu_{i}$ 's dependem de $p, T$, e dos $n_{i}$ 's. A partir da equação A.11 escrevemos, para a condição de equilíbrio $(\delta G=0)$, com a condição específica de que o número total de partículas deve ser conservado,

$$
\left.\delta G=\sum_{i} \delta n_{i} \frac{\partial G}{\partial n_{i}}\right)_{T, p, n_{j}^{\prime}}=\sum_{i} \mu_{i} \delta n_{i} ; \quad \delta p=0 ; \quad \delta T=0 .
$$

$\mu_{j}$ é o potencial químico, por átomo (molécula), da j'ésima espécie e possui dimensão de energia. Assim, adicionando-se $d n$ moles ao material, adiciona-se ao sistema uma energia igual a $\mu d n$. O valor da energia adicionada pode ser determinado através do calor gerado pela reação química.

O "potencial químico $\mu$ "é a medida de quanto varia a energia livre do sistema se adicionamos ou removemos um número $d n_{i}$ de partículas da espécie $i$, enquanto mantemos constantes o número das outras partículas, assim como a temperatura e o volume do sistema.

Em um sistema que possua partículas de diferentes espécies, existe um potencial químico diferente associado a cada espécie de partícula e definido como sendo a variação na energia total quando um número de partículas de uma dada espécie é aumentado ou diminuído de uma unidade.

Quando em equilíbrio, os potenciais químicos de partículas da mesma espécie devem ser iguais, porque qualquer aumento em um potencial químico irá permitir 
que as partículas se transportem de uma para outra região do sistema por meio de emissão de calor. Como o número de partículas é uma grandeza adimensional, a unidade para o potencial químico é a de energia, o que justifica o seu nome. Se o sistema de $n$ partícula tiver somente um tipo de partícula, então teremos

$$
G=n g(T, p) \Rightarrow g(T, p)=\frac{G}{n}=\mu .
$$

O potencial químico por átomo (molécula) é simplesmente a energia livre de Gibbs por átomo (molécula). Quando o sistema tiver vários tipos de partículas, teremos

$$
\left.G=G\left(T, p, n_{1}, n_{2}, \ldots, n_{i}, n_{j}, \ldots, n_{n}\right) \Rightarrow \mu_{i}=\frac{\partial G}{\partial n_{j}}\right)_{T, V, n_{j}^{\prime}} \neq \frac{G}{n} .
$$

O potencial químico é uma grandeza intensiva. A diferença no potencial químico de uma substância que se encontra em duas fases diferentes determina a direção para a qual substância vai difundir espontaneamente $\Rightarrow$ da fase de maior potencial químico para a de menor potencial químico. As partículas consideradas no contexto da termodinâmica não são, necessariamente, átomos ou moléculas, isto é, objetos da química, mas sim qualquer coisa que possa ser identificada e quantificada. Nos materiais semicondutores temos os férmions, elétrons e buracos. O potencial químico dos elétrons é, por exemplo, um parâmetro de grande importância do sistema e na física do estado sólido, onde é usualmente denominado energia de Fermi. Os elétrons também se deslocam da fase de maior potencial químico para a de menor potencial químico.

Definição: Potencial químico do estado de referência de um elemento é o seu estado mais estável na temperatura especificada, à pressão de 1 bar $\left(10^{5} \mathrm{~Pa}\right)$ e será sempre designado por $\mu^{*}$.

\section{A.1.2 Entalpia de Formação}

A entalpia de formação $\left(\Delta_{f} H\right)$ é definida como sendo a variação da entalpia na reação em que um mol da substância é formada a partir dos elementos em seus 
estados mais estáveis. Ela é negativa para compostos estáveis e é dada, para o g-CN, por:

$$
\Delta_{f} H^{\mathrm{g}-\mathrm{CN}}=\mu_{\mathrm{g}-\mathrm{CN}}^{*}-\mu_{\text {grafite }}^{*}-\mu_{\mathrm{N}_{2}}^{*}
$$

onde $\mu_{\mathrm{g} \text {-CN }}$ é a energia total da folha $\mathrm{CN}, \mu_{\text {grafite }}^{*}$ e $\mu_{\mathrm{N}_{2}}^{*}$ são os valores utilizados para o potencial químico da grafite e molécula de nitrogênio, respectivamente, os quais são obtidos através dos valores das energias totais dos sistemas, pois os cálculos foram realizados a tempetura nula. $\mathrm{O}$ valor utilizado do potencial químico do nitrogênio é a metade da energia total da molécula de $\mathrm{N}_{2}$, ou seja, $\mu_{\mathrm{N}}^{*}=E_{\mathrm{T}}\left(\mathrm{N}_{2}\right) / 2=$ $-383,753 \mathrm{eV}$, enquanto a da grafite é $\mu_{\text {grafite }}^{*}=E_{\mathrm{T}} / 4=-253,621 \mathrm{eV}$, pois a célula primitiva tem uma base de 4 átomos.

Na tabela A.1 mostramos os valores das energias totais $\left(\mathrm{E}_{\mathrm{T}}\right)$ e das entalpias de formação dos sistemas atômicos e moleculares, obtidos dentro do modelo do átomo ou da molécula na caixa, assim como dos sistemas cristalinos. Para o modelo na caixa supracitado utilizamos uma rede de Bravais cúbica simples, com parâmetro de rede $a=15,0 \AA$, contendo na base o átomo ou a molécula de interesse. Assim, evita-se que o átomo ou molécula interaja com a sua imagem.

Tabela A.1: Valores das energias totais $\left(\mathrm{E}_{\mathrm{T}}\right)$ e das entalpias de formação dos sistemas .

\begin{tabular}{|c|c|c|}
\hline Sistema & $\bar{E}_{\mathrm{T}}(\mathrm{eV})$ & Entalpia (eV) \\
\hline $\mathrm{Li}$ & $-204,042$ & - \\
\hline $\mathrm{H}_{2}$ & $-32,380$ & - \\
\hline $\mathrm{N}_{2}$ & $-773,863$ & - \\
\hline Grafeno & $-507,099$ & 0,071 \\
\hline Grafite & $-1014,483$ & - \\
\hline Silício & $-1285,673$ & - \\
\hline $\mathrm{AB}^{\prime}-\mathrm{SiC}$ & $-1791,679$ & 0,547 \\
\hline AB-SiC & $-1791,704$ & 0,534 \\
\hline $\mathrm{AB}^{\prime}-\mathrm{Si}_{18} \mathrm{C}_{18}$ & $-16125,111$ & - \\
\hline $\mathrm{AB}^{\prime}-\mathrm{LiSi}_{18} \mathrm{C}_{18}$ & $-16330,941$ & $-1,788$ \\
\hline $\mathrm{g}-\mathrm{CN}$ & $-633,000$ & 1,573 \\
\hline $\mathrm{AB}^{\prime}-\mathrm{CN}$ & $-1277,979$ & 1,491 \\
\hline $\mathrm{CNH}$ & $-656,245$ & 0,497 \\
\hline
\end{tabular}





\section{Referências Bibliográficas}

[1] B. Xu, D. Qian, Z. Wang, e Y. S. Meng, Materials Science and Engineering R: Reports 73, 51 (2012).

[2] Y. Hwang, K. H. Yun, e Y. C. Chung, Journal of Power Sources 275, 32 (2015).

[3] B. L. Ellis, K. Town, e L. F. Nazar, Electrochimica Acta 84, 145 (2012).

[4] G. A. N. e G. Pistoia, Lithium Batteries Science and Technology (Springer, New York, 2009).

[5] M. Armand, F. Endres, D. R. MacFarlane, H. Ohno, e B. Scrosati, Nature Materials 8, 621 (2009).

[6] S. B. Chikkannanavar, D. M. Bernardi, e L. Liu, Journal of Power Sources 248, 91 (2014).

[7] X. Y. et al, Lithium-Ion Batteries: Advanced Materials and Technologies (Taylor \& Francis Group, Boca Raton, 2012).

[8] S. Goriparti, E. Miele, F. De Angelis, E. Di Fabrizio, R. Proietti Zaccaria, e C. Capiglia, Journal of Power Sources 257, 421 (2014).

[9] K. S. Novoselov, A. K. Geim, S. V. Morozov, D. Jiang, Y. Zhang, S. V. Dubonos, I. V. Grigorieva, e A. A. Firsov, Science 306, 666 (2004).

[10] X. Li, L. Tao, Z. Chen, H. Fang, X. Li, X. Wang, J.-B. Xu, e H. Zhu, Applied Physics Reviews 4, 021306 (2017). 
[11] L. Ji, Z. Lin, M. Alcoutlabi, e X. Zhang, Energy \& Environmental Science 4, $2682(2011)$.

[12] A. Kara, H. Enriquez, A. P. Seitsonen, L. C. Lew Yan Voon, S. Vizzini, B. Aufray, e H. Oughaddou, Surface Science Reports 67, 1 (2012).

[13] S. M. Seyed-Talebi, I. Kazeminezhad, e J. Beheshtian, Physical Chemistry Chemical Physics : PCCP 17, 29689 (2015).

[14] B. Scrosati e J. Garche, Journal of Power Sources 195, 2419 (2010).

[15] P. Hohenberg e W. Kohn, Physical Review B 136, (1964).

[16] W. Kohn e L. J. Sham, Physical Review A 140, (1965).

[17] J. P. Perdew, K. Burke, e M. Ernzerhof, Physical Review Letters 77, 3865 (1996).

[18] D. M. Ceperley e B. J. Alder, Physical Review Lett. 45, 566 (1980).

[19] J. P. Perdew e A. Zunger, Physical Review B 23, 5048 (1981).

[20] L. Hedin, Physical Review 139, A796 (1965).

[21] A. D. Becke, Physical Review A 38, 3098 (1988).

[22] J. P. Perdew e K. Burke, International Journal of Quantum Chemistry 57, 309 (1996).

[23] G. L. Oliver e J. P. Perdew, Physical Review A 20, 397 (1979).

[24] E. H. Lieb e S. Oxford, International Journal of Quantum Chemistry 19, 427 (1981).

[25] J. Klimeš, D. R. Bowler, e A. Michaelides, Physical Review B 83, 195131 (2011). 
[26] K. Berland, V. R. Cooper, K. Lee, E. Schröder, T. Thonhauser, P. Hyldgaard, e B. I. Lundqvist, Reports on Progress in Physics 78, 066501 (2015).

[27] J. Klimeš e A. Michaelides, The Journal of Chemical Physics 137, 120901 (2012).

[28] S. Grimme, Journal of computational chemistry 27, 1787 (2006).

[29] S. Grimme, J. Antony, S. Ehrlich, e H. Krieg, The Journal of Chemical Physics 132, 154104 (2010).

[30] A. Tkatchenko, R. A. DiStasio Jr, R. Car, e M. Scheffler, Physical Review letters 108, 236402 (2012).

[31] M. Dion, H. Rydberg, E. Schröder, D. C. Langreth, e B. I. Lundqvist, Physical review letters 92, 246401 (2004).

[32] Y. Zhang e W. Yang, Physical Review Letters 80, 890 (1998).

[33] J. Klimeš, D. R. Bowler, e A. Michaelides, Journal of Physics: Condensed Matter 22, 022201 (2009).

[34] J. C. Slater, Physical Review 51, 846 (1937).

[35] C. Herring, Physical Review 57, 1169 (1940).

[36] P. E. Blöchl, Physical Review B 50, 17953 (1994).

[37] D. Vanderbilt, Physical Review B 41, 7892 (1990).

[38] N. L. Singh, David J., Planewaves, Pseudopotentials, and the LAPW Method (Springer, Springer, 2006).

[39] G. Kresse e D. Joubert, Physical Review B 59, 1758 (1999).

[40] P. E. Blöchl, C. J. Först, e J. Schimpl, Bulletin of Materials Science 26, 33 (2003). 
[41] G. P. Srivastava, The Physics of Phonons (Adam Hilger, Philadelphia and New York, 1990).

[42] E. A. Hylleraas, Zeitschrift für Physik A Hadrons and Nuclei 65, 209 (1930).

[43] J. G. Ángyán, Journal of Mathematical Chemistry 46, 1 (2009).

[44] E. Wigner, Math. Natur. Anz.(Budapest) 53, 477 (1935).

[45] P. Giannozzi et al., Journal of Physics: Condensed Matter 21, 395502 (2009).

[46] R. M. Wentzcovitch, J. L. Martins, e G. Price, Physical Review Letters 70, 3947 (1993).

[47] A. C. Ferrari, J. Meyer, V. Scardaci, C. Casiraghi, M. Lazzeri, F. Mauri, S. Piscanec, D. Jiang, K. Novoselov, S. Roth, et al., Physical Review letters 97, 187401 (2006).

[48] A. K. Geim e K. S. Novoselov, Nature Materials 6, 183 (2007).

[49] P. Trucano e R. Chen, Nature 258, 136 (1975).

[50] B. Xu, M. Wu, G. Liu, e C. Ouyang, Journal of Applied Physics 111, 124325 (2012).

[51] K. Toyoura, Y. Koyama, A. Kuwabara, e I. Tanaka, The Journal of Physical Chemistry C 114, 2375 (2010).

[52] J.-S. Filhol, C. Combelles, R. Yazami, e M.-L. Doublet, The Journal of Physical Chemistry C 112, 3982 (2008).

[53] K. Kganyago e P. Ngoepe, Physical Review B 68, 205111 (2003).

[54] W. Setyawan e S. Curtarolo, Computational Materials Science 49, 299 (2010).

[55] A. Marinopoulos, L. Reining, A. Rubio, e V. Olevano, Physical Review B 69, 245419 (2004). 
[56] N. Mounet e N. Marzari, Physical Review B 71, 205214 (2005).

[57] M. Mohr, J. Maultzsch, E. Dobardžić, S. Reich, I. Milošević, M. Damnjanović, A. Bosak, M. Krisch, e C. Thomsen, Physical Review B 76, 035439 (2007).

[58] A. C. Neto, F. Guinea, N. M. Peres, K. S. Novoselov, e A. K. Geim, Reviews of Modern Physics 81, 109 (2009).

[59] S. Reich, J. Maultzsch, C. Thomsen, e P. Ordejón, Physical Review B 66, 035412 (2002).

[60] M. N. Huda, Y. Yan, e M. M. Al-Jassim, Chemical Physics Letters 479, 255 (2009).

[61] E. Bekaroglu, M. Topsakal, S. Cahangirov, e S. Ciraci, Physical Review B 81, 075433 (2010).

[62] H. Nakano, T. Mitsuoka, M. Harada, K. Horibuchi, H. Nozaki, N. Takahashi, T. Nonaka, Y. Seno, e H. Nakamura, Angewandte Chemie International Edition 45, 6303 (2006).

[63] L. Lew Yan Voon, E. Sandberg, R. Aga, e A. Farajian, Applied Physics Letters 97, 163114 (2010).

[64] S. Cahangirov, M. Topsakal, E. Aktürk, H. Şahin, e S. Ciraci, Physical Review Letters 102, 236804 (2009).

[65] M. Houssa, G. Pourtois, V. Afanas Ev, e A. Stesmans, Applied Physics Letters 96, 082111 (2010).

[66] S. Tang e Z. Cao, Chemical Physics Letters 488, 67 (2010).

[67] M. Topsakal, E. Aktürk, e S. Ciraci, Physical Review B 79, 115442 (2009).

[68] Y. Zhang, S.-Q. Wu, Y.-H. Wen, e Z.-Z. Zhu, Applied Physics Letters 96, 223113 (2010). 
[69] J. Garcia, D. de Lima, L. Assali, e J. Justo, The Journal of Physical Chemistry C 13242 (2011).

[70] L. Pan, H. Liu, Y. Wen, X. Tan, H. Lv, J. Shi, e X. Tang, Physics Letters A 375, 614 (2011).

[71] L. Yuan, Z. Li, e J. Yang, Physical Chemistry Chemical Physics 15, 497 (2013).

[72] J.-A. Yan, W. Ruan, e M. Chou, Physical Review B 77, 125401 (2008).

[73] J. Zhu, A. Chroneos, e U. Schwingenschlögl, Nanoscale 8, 7272 (2016).

[74] H. Jiang, W. Shyy, M. Liu, L. Wei, M. Wu, e T. Zhao, Journal of Materials Chemistry A 5, 672 (2017).

[75] M. Yu, C. Jayanthi, e S. Wu, Physical Review B 82, 075407 (2010).

[76] J. Sforzini, P. Hapala, M. Franke, G. Van Straaten, A. Stöhr, S. Link, S. Soubatch, P. Jelínek, T.-L. Lee, U. Starke, et al., Physical Review Letters 116, 126805 (2016).

[77] S. Zhang, S. Tsuzuki, K. Ueno, K. Dokko, e M. Watanabe, Angewandte Chemie International Edition 54, 1302 (2015).

[78] Z. Shi, A. Kutana, e B. I. Yakobson, Journal of Physical Chemistry Letters 6, 106 (2015).

[79] J. Zhou, Q. Sun, Q. Wang, e P. Jena, Physical Review B 92, 064505 (2015).

[80] S. Mann, P. Rani, R. Kumar, G. S. Dubey, e V. Jindal, RSC Advances 6, 12158 (2016).

[81] L.-F. Huang, P.-L. Gong, e Z. Zeng, Physical Review B 91, 205433 (2015).

[82] H. Sahin, O. Leenaerts, S. Singh, e F. Peeters, Wiley Interdisciplinary Reviews: Computational Molecular Science 5, 255 (2015). 